Portland State University

PDXScholar

1981

\title{
The influence of halloysite content on the shear strength of kaolinite
}

Reka Katalin Gabor

Portland State University

Follow this and additional works at: https://pdxscholar.library.pdx.edu/open_access_etds

Part of the Geology Commons, and the Materials Science and Engineering Commons Let us know how access to this document benefits you.

\section{Recommended Citation}

Gabor, Reka Katalin, "The influence of halloysite content on the shear strength of kaolinite" (1981). Dissertations and Theses. Paper 3215.

https://doi.org/10.15760/etd.3206

This Thesis is brought to you for free and open access. It has been accepted for inclusion in Dissertations and Theses by an authorized administrator of PDXScholar. Please contact us if we can make this document more accessible: pdxscholar@pdx.edu. 
AN ABSTRACT OF THE THESIS OF Reka Katalin Gabor for the Master of Science in Geology presented October 6, 1981.

Title: The Influence of Halloysite Content on the Shear Strength of Kaolinite.

APPROVED BY MEMBERS OF THE THESIS COMMITTEE:

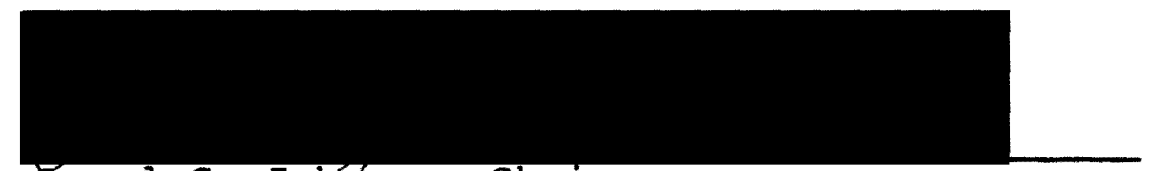

Ănsel G. Jokhnson, Chairman

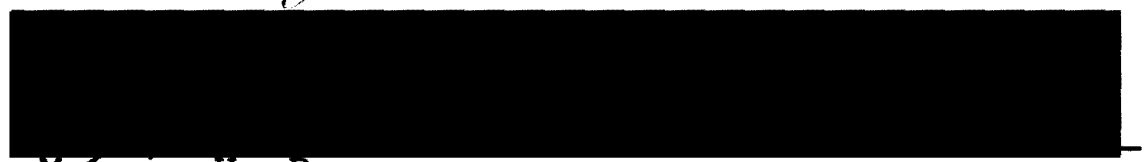

Mervin H. Beeson

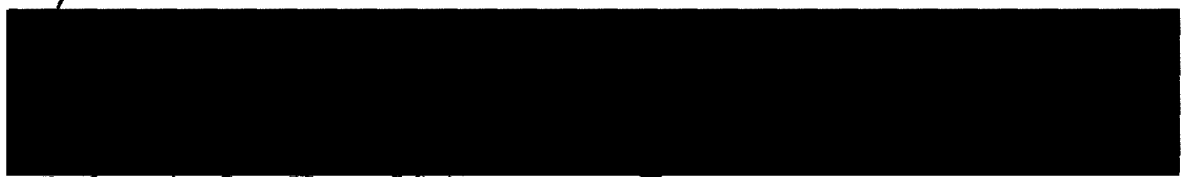

Robert 0. Van Atta

The objective of this thesis is to determine the relative shear strengths of halloysite, kaolinite, synthetic mixtures, and local soils, to investigate the influence of halloysite content on the shear strength of kaolinite, and to explore the possibility that the strength properties of soil clays might be controlled by the relative content of their component minerals.

Sets of samples of pure kaolinite and halloysite minerals and their mixtures in proportions of $1: 1,3: 1$, and 
1:3 were prepared in the Harvard Miniature Compaction device, each compacted in four separate layers with 35 tampings from the 30 pound spring compactor on each layer. The specimens were cured at 15 degrees Celsius for 48 days and then tested in a MST Computer controlled servohydraulic Closed Loop unconfined compression unit. Two local soils known to contain halloysite or mixtures of halloysite and kaolinite were also investigated in a similar manner and correlated with the pure minerals. Samples used for correlations were compacted at optimum moisture content and yielded optimum densities in the 838 to 988 saturation range. Within the testing range, the relative shear strength of halloysite \#13 from Eureka, Utah was higher at $1.88 \pm 0.17 \mathrm{~kg} / \mathrm{cm}^{2}$ than the $1.51 \pm 0.2 \mathrm{~kg} / \mathrm{cm}^{2}$ value of kaolinite from Twiggs Co., Macon, Georgia. The relative shear strengths of the synthetic mixtures at $1.58 \pm 0.36 \mathrm{~kg} / \mathrm{cm}^{2}$, $1.74 \pm 0.23 \mathrm{~kg} / \mathrm{cm}^{2}$, and $1.81 \pm 0.22 \mathrm{~kg} / \mathrm{cm}^{2}$, respectively, ranged between the limiting values of the mineralogically pure halloysite and kaolinite and were in direct proportion to the percentage of their component minerals. The shear strength of the soil halloysite at $1.78 \pm 0.11 \mathrm{~kg} / \mathrm{cm}^{2}$ and that of the soil kaolin mixture at $1.74 \pm 0.09 \mathrm{~kg} / \mathrm{cm}^{2}$ correlated with the shear strength of the pure halloysite mineral and of the 1:3 (kaolinite:halloysite) synthetic mixture, respectively. 
THE INFLUENCE OF HALLOYSITE CONTENT ON THE SHEAR STRENGTH OF KAOLINITE

\title{
by
}

REKA KATALIN GABOR

A thesis submitted in partial fulfillment of the requirements for the degree of

\author{
MASTER OF SCIENCE \\ in \\ GEOLOGY
}

Portland State University

1981 
TO THE OFFICE OF GRADUATE STUDIES AND RESEARCH:

The members of the Committee approve the thesis of Reka Katalin Gabor presented October 6, 1981.

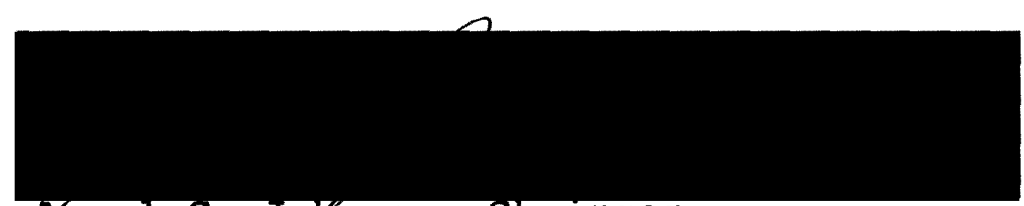

Ansel G. Joknson, Chairman

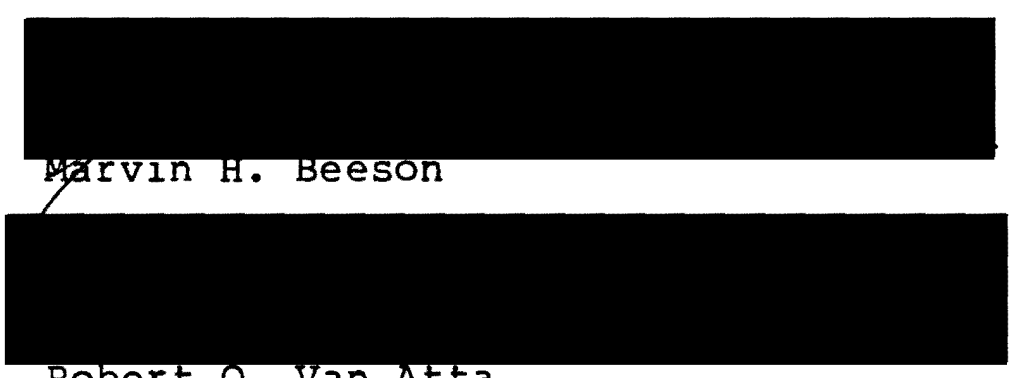

Robert 0. Van Atta

APPROVED :

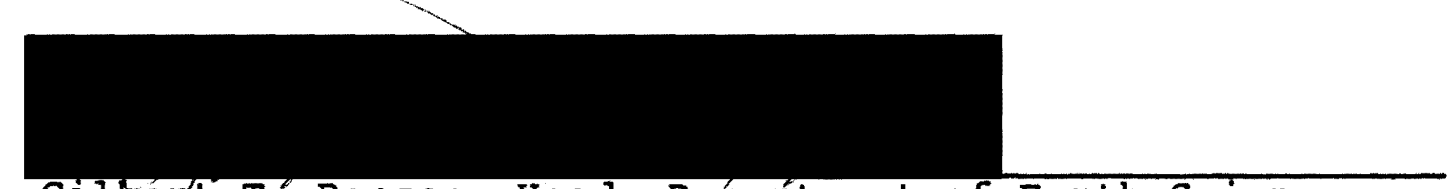

Gilbedt T. Benson, Head, Department of Earth Sciences

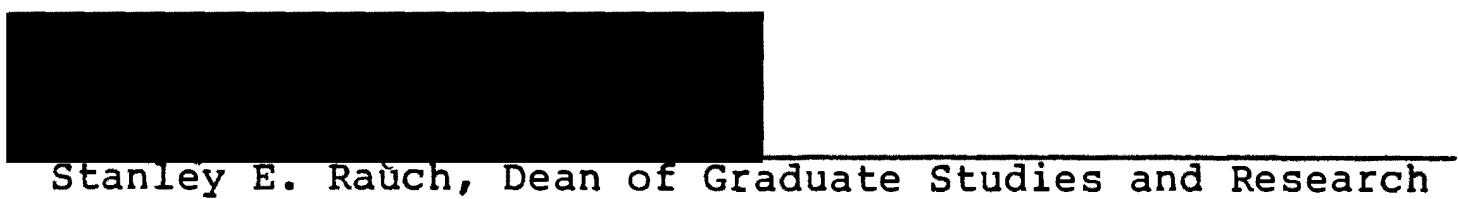




\section{ACKNOWLEDGEMENTS}

The writer of this thesis is very grateful to the Department of Earth Sciences and to the Division of Engineering and Applied Science at Portland State University for the use of their facilities. She is also grateful to Rittenhouse-Zeman and Associates, to Messrs. R. Williamson, G. Edmonstone, and D. Reay of the USDA Forest Service, and to Mr. W. Roberts of the US Army, Department of Corps of Engineers for the use of their Testing Laboratories and equipment. The writer is thankful to Dr. A. G. Johnson for his guidance and encouragement during the entire project, to Drs. M. H. Beeson and R. O. Van Atta for reviewing the manuscript, to Drs. M. L. Cummings and T. Neff for their suggestions, and to Dr. L. A. Palmer who provided the soil halloysite for the study. 
TABLE OF CONTENTS

PAGE

ACKNOWLEDGEMENTS

ii i

LIST OF TABLES . . . . . . . . . . . . . •

vi

LIST OF FIGURES

CHAPTER

I INTRODUCTION • • . • . • . • • • •

Scope of study . . . . . . . .

II BACKGROUND INFORMATION AND REVIEW OF LITERATURE $\cdot$. • . • • • • • • • • •

Chemistry and Structure ...... . 3

Morphology . . . . . . . . 5

Electrical Forces ........ . 6

Permanent and $\mathrm{pH}$ Dependent Charges . . 7

Clay-Water System . . . . . . 7

Particle Arrangement . . . . . . 9

Compaction ........... 10

Mineral Identification by

$\mathrm{X}$-ray Diffraction Analysis . . .

Origin of Kaolins . . . . . . . 14

III SHEAR STRENGTH . . . . . . . . . 17

Theory . . . . . . . . .

Atterberg Limits as Strength

Indicators ............ 
IV LABORATORY INVESTIGATION • • • • • • • • •

Materials . . . . . . . . • •

Preparation of Clay Minerals and Soil Clays. • . . . . . • •

Compaction and Test Specimen

Preparation . . . . . . . .

Unconfined Compression Analysis . •

Atterberg Limits and Indices . . . •

X-ray Diffraction Analysis • • • • •

V DATA PRESENTATION AND INTERPRETATION • •

Data Presentation . . . - . • • •

Data Interpretation . $\cdot$ - $\cdot$ - $\cdot$.

$\mathrm{x}$-ray Identification

Compaction

Unconfined Compression Analysis

Atterberg Limits

VI DISCUSSION AND CONCLUSION $\bullet \cdot \cdot \cdot \cdot \cdot \cdot \cdot \cdot$

Discussion • • • • • • • • • • • •

Conclusion - • • • • • - • • • • 


\section{LIST OF TABLES}

TABLE

PAGE

I Identification of One Hundred and Six

Compacted Specimens . . . . . . .

II Results of the X-ray Diffraction Analysis of

Halloysite, Kaolinite, synthetic

Mixtures, and Soil Clays . . . . . .

91

II Optimum Moisture Content and Dry Density of

Halloysite, Kaolinite, Synthetic

Mixtures, and Soil Clays . . . . .

IV Results of the Unconfined Compression

Analysis on 106 Compacted Halloysite,

Kaolinite, Synthetic Mixtures, and Soil

Clay Samples . • . • . • . • • • •

$\mathrm{V}$ Iist of Halloysite, Kaolinite, Synthetic

Mixtures, and Soil Clay samples and Their

Properties Used for Correlations . . . 100

VI Precision Calculation for Unconfined

Compression Testing of Halloysite,

Kaolinite, Synthetic Mixtures, and Soil

Clay Samples Used in Correlation . . . 
vii

TABLE

PAGE

VII Atterberg I.imits and Index Properties of Halloysite, Kaolinite, Synthetic Mixtures, and Soil clays . . . . . 106

VIII Comparison of Mean shear strength of Halloysite, Kaolinite, synthetic Mixtures, and Soil Clays by Using Statistical Paired "t" Tests . . . . 107 


\section{LIST OF FIGURES}

F IGURE

PAGE

1. Ion Distribution and Double-Layer Formation .

2. Scil Siructures of Clay Minerals in Soils..

3. Mohr's Circle for Unconfined Compression

Test . . . . . . . . . . .

4. Location of Soil Clays OMSI-2 and OMSI-4 .

5. Soil Clay WP-2 . . . . . . . . . •

6. Grain Size Distribution of Halloysite and Kaolinite . . . . . . . . . .

7. Grain Size Distribution of Synthetic Mixtures : . . . . . . . . . .

8. Grain Size Distribution of Soil Clays . . •

9. Harvard Miniature Compactor and Balance

Used for Density Determination . . . .

10. Dehydration Curves of Halloysite, Kaolinite, and Synthetic Mixtures . . . . . .

11. Dehydration Curves of Soil Clays . . . .

12. MST Computer Controlled Servohydraulic Closed Loop Testing Machine Used for Unconfined Compression Analysis . . . . . •

13. X-ray Diffractograms of Halloysite (a) and 
14. X-ray Diffractograms of Synthetic Mixture TWK-B $(k: h=3: 1)$. . . . . . . .

15. X-ray Diffractograms of Synthetic Mixtures:

$$
\text { TWK-C }(k: h=1: 1) \text { (a), TWK-D }(k: h=1: 3) \text { (b) . } 57
$$

16. X-ray Diffractograms of Soil Clays . . . . . 58

17. Compaction Curves of Halloysite, Kaolinite,

Synthetic Mixtures, and Soil Clays . . . 62

18. Failure Pattern of Halloysite and Kaolinite • 64

19. Failure Pattern of Synthetic Mixtures . . . . 65

20. Failure Pattern of Soil Clays . . . . . . 66

21. Relation Between Shear Strength and Strain of

Halloysite, Kaolinite, Synthetic Mixtures, and Soil clays . . . . . . . . . 70

22. Relation Between Void Ratio and Shear Strength

of Halloysite, Kaolinite, Synthetic

Mixtures, and Soil clays . . . . . . 71

23. Relation Between Shear Strength and Mineral

Content at Optimum Moisture Content . . . 73

24. Relation Between Atterberg Limits and Mineral

Content . . . . . . . . . 76

25. Plasticity Chart . . . . . . . . . 79

1A. Compaction Curves of Halloysite H-13-A . . . 109

2A. Compaction Curves of Kaolinite TWK-A . . . . 110

3A. Compaction Curves of $3: 1(k: h)$ Synthetic 
FIGURE

PAGE

4A. Compaction Curves of $1: 1 \quad(k: h)$ synthetic Mixture TWK-C . • . . . . . . . . .

5A. Compaction Curves of $1: 3$ (k:h) Synthetic

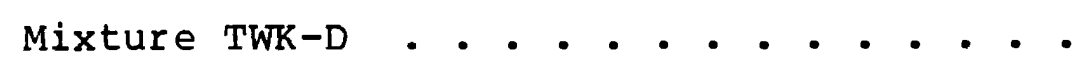

6A. Compaction Curves of Soil Clay WP-2 . • • . • 114

7A. Compaction Curves of Soil Clay OMSI-2 • • • • 115

8A. Compaction Curves of Soil Clay OMSI-4 • • • • 116

9A. Compaction Curves of Coarse Grained Halloysite and Kaolinite . . . . . . . . . . 117

10A. Sample Chart of Load-Strain Relationship Using the 500 Pound Load Cell During Testing . .

11A. Sample Chart of Load-Strain Relationship Using the 2000 Pound Load Cell During Testing •

12A. Stress-strain Relationship of Halloysite

H-13-A Specimens . . . . . . . . . 120

13A. Stress-Strain Relationship of Kaolinite TWK-A Specimens • • • • . • • • • • 121 
CHAPTER I

\section{INTRODUCTION}

Two kandite group minerals, kaolinite and halloysite, occur widely in soils (Grim, 1953), yet little is known about their resistance to deformation and their strength characteristics. Kenney (1967) tested the influence of mineral composition on the residual strength of soils. He did not investigate the kaolin family minerals in detail, but suggested the possible existence of minerals within the group which differ in their residual strength properties. Keller and Haenni (1978) implied that many kaolinites are not aneralogically pure but are mixtures of kaolin polymorphs. Polymorph members kaolinite and halloysite have divergent mineralogical properties which should be reflected in the behavior of their mixtures.

ihis study was lindertaken to investigate the strength properties of halloysite and kaolinite and to test the influence of halloysite content on the shear strength of kaolinite. 


\section{SCOPE OF STUDY}

The purpose of the thesis is:

1) to determine the relative shear strength of halloysite, kaolinite, synthetic mixtures, and local soils

2) to investigate the influence of halloysite content on the shear strength of kaolinite

3) to investigate the possibility that the strength properties of natural clay soils might be controlled by the relative content of their component minerals. 
CHAPTER II

BACKGROUND INFORMATION AND REVIEW OF LITERATURE

\section{CHEMISTRY AND STRUCTURE}

Kaolinite and halloysite are the most prominent members of the kandite group clay minerals. Chemically, they both are hydrated aluminium silicates with the chemical composition of $\mathrm{Al}_{2} \mathrm{O}_{3}: \mathrm{SiO}_{2}: \mathrm{H}_{2} \mathrm{O}$. This ratio in kaolinite is $1: 2: 2$ and in halloysite is $1: 2: 4$. This indicates that halloysite contains twice as much water per molecule as does kaolinite.

The structure of kaolin minerals has been described by Pauling (1930), Gruner (1932), and Brindley and Robison (1946). Structurally, they are both phyllosilicates; each layer is made up of one sheet of silica tetrahedra and one sheet of aluminium octahedra. There are three available octahedral voids in the octahedral sheet but only two sites are occupied by the aluminium ions. Therefore, the kaolins are called dioctahedral minerals. If the vacant site is the same in each layer then well crystallized kaolin forms, but when the vacant site is randomly selected in each layer, poorly crystallized kaolin develops. Kaolins crystallize in the triclinic system (Brindley and Robison, 1946), 
but they rnight also belong to the monoclinic system (Gruner, 1932). According to Chukrov and zvyagin (1966), halloysites have monoclinic structures.

The water in kaolinite is in the form of hydroxyl. The hydroxyl ions of the octahedral sheet are in contact with the basal oxygens of the next structural unit. The thickness of each kaolinite layer is $7.15 \AA$ and the layers are stacked together in the "c" crystallographic direction. The layers are not placed directly on top of one another but are displaced along the "a" axis. Newnham (1961) thinks kaolinites develop this shifting mechanism to avoid superposition of $\mathrm{Si}$ and Al cations.

In halloysite, the successive kaolinite layers are displaced randomly in both the "a" and "b" directions (Brindley, 1951). As stated earlier, halloysite contains twice as much water as kaolinite does, but only one half of it is tied up as hydroxyl ions. The remaining water occupies a $2.9 \%$ spacing between two kaolinite layers and increases the basal spacing of a fully hydrated halloysite from $7.15 \AA$ to $10.1 \AA$. Halloysite, however, loses the interlayer water readily around 16 degrees Celsius and reverts back to the $7.2 \AA$ spacing of kaolinite. Brindley and Goodyear (1948) point out that not all of the interlayer water is removed by air-drying and it is estimated that every fourth layer will have a layer of water. The interlayer 
water loss is an irreversible process; dehydrated halloysite will not rehydrate in the presence of water.

\section{MORPHOLOGY}

Electron microscopic studies indicate that kaolinite crystallizes in well shaped, hexagonal plates or sometimes as elongated flakes. However, the degree of crystallinity influences the formation of kaolinite, and in a poorly crystallized mineral, less distinct flakes will form. Halloysite, on the other hand, has tubular morphology. According to Bates and others (1950), strain develops within the kaolinite structure because the "b" dimension of the unit cell is $8.93 \AA$ instead of the required $8.62 \AA$. While kaolinite is able to accomodate this strain, the presence of interlayer water prevents the halloysite from doing so (Hope and Kittrick, 1964), and the edges of the flakes will roll up and form the tubular morphology which is characteristic of halloysites. The tubes, however, may collapse, unroll, or split when halloysite dehydrates (Grim, 1953). Halloysite does not always have tubular morphology; platy and spheroidal forms have been reported by sudo and Takahashi (1956), Kunze and Bradley (1964), de Souza Santos and others (1966), Askenasy and others (1973), and Tazaki (1978). 


\section{ELECTRICAL FORCES}

Kaolin minerals behave as colloids because their particle size is less than two microns. Electrical forces dominate in these minerals over the gravitational forces since their specific surface (surface area/mass) is large (Kruyt, 1952; Evans, 1964; Pauling, 1967). The electrical forces can be primary and secondary valence forces in addition to the hydrogen bonds. Hydrogen bonds develop when a hydrogen atom bonded to an electronegative atom attracts another electronegative atom such as oxygen, nitrogen, or fluorine and forms a weak bond with it. Such bonds exist between the molecules of water and also between the basic units of kaolinites (Wieckowski and Wiewiora, 1976).

The primary valence forces such as ionic, covalent, and heteropolar bonds are responsible for holding the atoms of the mineral unit together. Ionic and heteropolar bonds connect electrically unsymmetrical atoms, and the units will act as dipoles, attracting or repelling other dipoles. Another type of primary valence force is the electrostatic attraction or repulsion between charged particles.

Secondary valence forces are weaker but act over larger distances than do primary valence forces or hydrogen bonds. They are produced by electrical moments that exist within units of the mineral. Like the primary forces, the 
secondary forces also attract or repel other dipoles, but the net effect is always attraction.

\section{PERMANENT AND PH DEPENDENT CHARGES}

The charges within the kaolin unit cell are balanced, but negative surface charges arise from isomorphous substitution within the silica tetrahedron unit. The substitution is one aluminium ion for every four-hundredth silicon ion (Lambe and Whitman, 1979). Available cations will neutralize the surface charge by gathering around the surface of the mineral particle. Besides the permanent negative charge on the kaolin surface, there exist pH dependent charges at the broken ends of the mineral. When the $\mathrm{pH}$ is higher than $8, \mathrm{Si}(\mathrm{OH})$ at the edges of the tetrahedral layers will dissociate and a negative end charge will result. In a neutral or acidic solution, the clay platelets become bipolar by developing positive end charges because of absorption of protons at the edges of octahedral layers (Schofield and Samson, 1953).

\section{CLAY-WATER SYSTEM}

Water in a clay-water system can exist as adsorbed water, as double-layer water, and as capillary water in the soil pores. In the soil-water system, the neutralizing cations are removed from the surface of the kaolin by a layer of adsorbed water. The cations will diffuse around 
the mineral particle and together with the negative surface charge of the plate, will form the electrical double-layer (Figure 1).

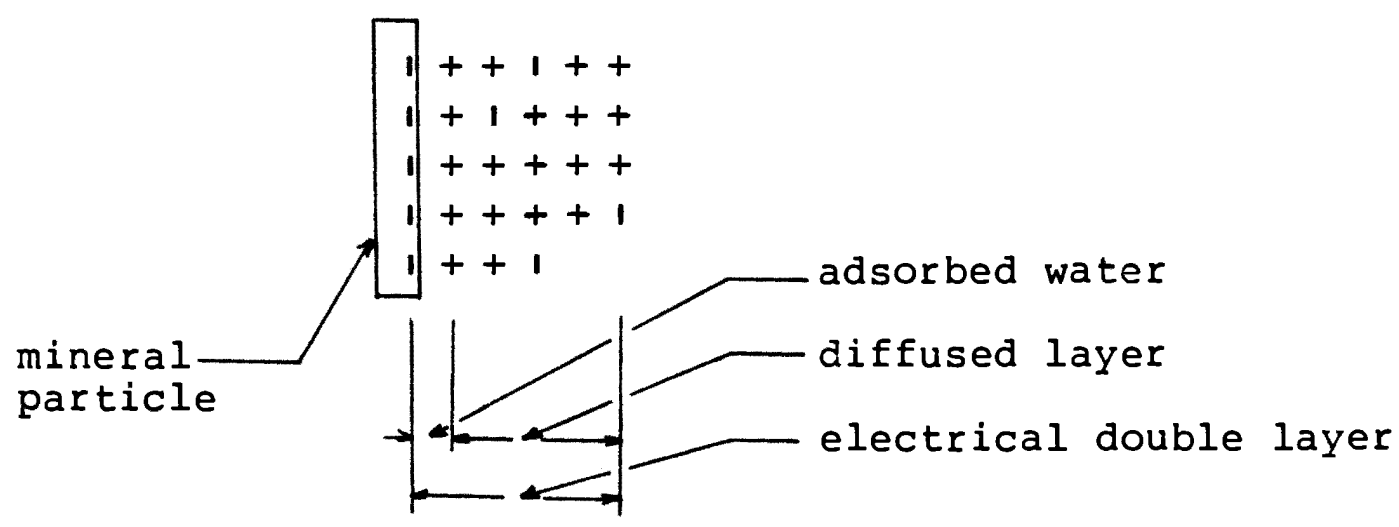

Figure 1. Ion distribution and double layer formation.

Water molecules are bipolar, are attracted to the negatively charged clay surfaces and will be adsorbed. The molecules of the adsorbed water are arranged in a hexagonal network around the mineral grain and act as "crystalline" water. Only some of the hydrogen atoms of the water molecules take part in the bonding within the hexagonal network; the rest tie the water to the surface of kaolinite (Hendricks and Jefferson, 1938). The negative surface charge of kaolin strongly holds the water to its surface, but farther away, the linkage is weaker.

The thickness of the double-layer is a function of the size of hydrated ion, ion valency, electrolyte concentration, and pH of the soil-water system. A thin double- 
layer forms if the size of the hydrated ion is small. Divalent cations are more attracted to negative surfaces than monovalent cations (Taylor, 1959) and will form a thin double-layer. Increased electrolyte concentration also results in a thin double-layer formation. Since the net charge on kaolins decreases with decreasing $\mathrm{pH}$, the acidic environment, too, favors the formation of a thin doublelayer.

The electrical potential of the double-layer has been expressed by Gouy and Chapman and has been modified by Stern (1924). When kaolin particles approach each other and their potential energy is reduced, the particles aggregate and will flocculate, according to Bolt (1955). If, however, the double-layers of the approaching kaolins overlap, repulsive forces will dominate and the clay will be dispersed. Since low pH environment and increased electrolyte concentration favor the formation of relatively thin double layers, acidic condition and salt concentration helps to initiate flocculation.

\section{PARTICLE ARRANGEMENT}

Natural soil deposits are arranged either in flocculated or in dispersed structures. Dispersed soils develop when the net electrical forces between particles are repulsive at the time of formation, while flocculated soils 
form when the same forces are attractive. Flocculated structures can be either non-salt or salt flocculated. Non-salt type flocculation developes when electrostatic forces act between the negatively charged surfaces and the positive ends of the particles. Loose, open type structure results where the particles are perpendicular to each other (Figure 2a). Salt type flocculation maintains the surfaceto-edge connection of the mineral flakes, but the perpendicular orientation will change to random orientation with individual particles forming parallel domains (Figure 2b). In a dispersed network, the kaolin flakes are oriented in a face-to-face structure (Figure $2 c$ ).
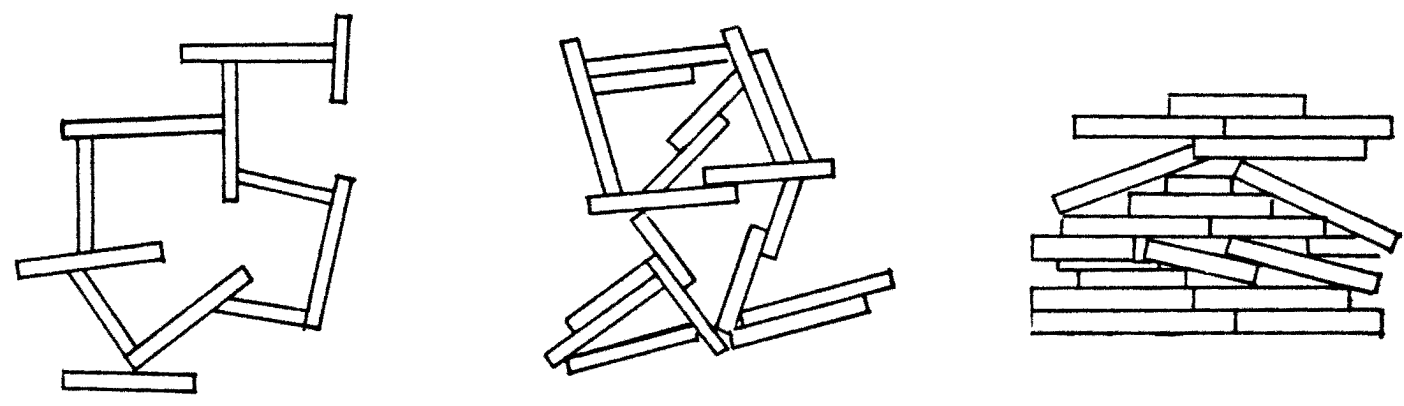

a. Non-Salt Flocculation

b. Salt Flocculation

c. Dispersion

Figure 2. Soil structures of clay minerals in soils. COMPACTION

Compaction establishes a relationship between the density and the water content of a soil. This relationship 
is expressed as a bell-shaped curve (see Figure 17 for examples) where the water content is the abscissa and the density is the ordinate. During compaction, energy is put into the soil to increase its density and shear strength and to decrease its shrinkage, permeability, and compressibility. The input of energy to the soil depends on the compaction method used; higher compactive effort results in higher density at a lower water content.

Lambe (1958a) used the physico-chemical approach to explain compaction of clay soils. At a low water content, the electrolyte concentration of the soil is high, which results in reduced double-layer formation and increased interparticle attraction. As a result, flocculated soil structure aevelops with disoriented particle array, high void ratio, and low density. The shear strength of this clay is high, but only at low strains, and can undergo only small deformation without failure. As the water content increases, the electrolyte concentration decreases and the double-layer expands. This results in the increase of interparticle repulsion, more oriented particle arrangement, and increased density. The water which has been added to the clay serves as a lubricant to aid particle orientation and replaces air from the voids of the soil mass. This procedure continues until the optimum moisture content is reached where the soil exists in its densest condition. 
The addition of more water to the system further enhances particle orientation and a dispersed structure developes. However, the density will have no further increase, but will be reduced, instead, because a high degree of saturation has been reached, and water occupies space that could be filled with soil. The shear strength of soils compacted on the wet side of the optimum moisture content is lower, but can undergo large deformation without failure.

Olson (1963) does not think that water added to clay acts as a lubricant. He feels that during compaction, the effective stress, $\vec{\sigma}$,

$$
\bar{\sigma}=\sigma-u_{w}(x)-u_{a}(1-x)
$$

where $\quad \sigma=$ normal stress

$$
\begin{aligned}
u_{w} & =\text { pore water pressure } \\
u_{a} & =\text { pore air pressure } \\
x & =\text { empirical coefficient (Bishop, 1961)) }
\end{aligned}
$$

is reduced by the development of pore pressures which reduce the shearing strength of the interparticle contacts. This allows the particles to slide over one another. However, McRae and Turnbull (1963) could not establish a trend of effective stress reduction with increasing water content.

MINERAL IDENTIFICATION BY X-RAY DIFFRACTION ANALYSIS

A close relationship exists beiween the atomic struc- 
ture and the chemical composition of minerals which enables a mineral to be identified by measurement of its atomic structure. The spacing of atomic planes of an unknown crystal can be determined by $x$-ray diffraction analysis. This method employs an $\mathrm{X}-\mathrm{ray}$ beam of known wavelength which is diffracted by the atoms of the unknown crystal. The angle of diffraction is measured by the diffractometer and the Bragg equation allows the computation of the unknown spacing:

$$
n \lambda=2 d \sin
$$

where $n=$ order of diffraction

$\lambda=$ known wavelength of diffracted $x-r a y$

$\mathrm{d}=$ spacing of atomic planes

$\theta=$ diffraction angle.

Each mineral has its own characteristic intensity pattern when subjected to $\mathrm{x}-\mathrm{ray}$ diffraction analysis. However, many of the clay minerals may have similarities which complicate their identification. Therefore, the clay samples are subjected to special treatments such as heat and/or organic liquid applications to further their identification.

Kaolinite has characteristic first basal $\left(\mathrm{d}_{001}\right)$ anō second basal $\left(d_{002}\right)$ reflections at $7.15 \AA$ and $3.56 \AA$ respectively (Brindley, 1961). In well crystallized kaolinite, the reflections are strong and distinct but when the miner- 
al is poorly crystallized, the reflections will be broad and weak. The first basal spacing of a fully hydrated halloysite is at $10.1 \AA$ and the third one $\left(\mathrm{d}_{003}\right)$ is at $3.75 \AA$. It also has a $d_{002}$ reflection at $5 \AA$, but it is seldom strong enough to be observed. As mentioned earlier, hydrated halloysite loses the interlayer water readily at temperatures as low as 15 degrees Celsius and collapses from its $10.1 \AA$ first basal spacing to the $7.15 \AA$ reflection of kaolinite. Since dehydrated halloysite still contains a small portion of interlayer water in its air-dried state (approximately every fourti layer contains one mclecular layer of water), the collapsed $d_{001}$ reflection will be broad, weak, and indistinguishable from the basal spacing of the poorly crystallized kaolinite. When treated with organic liquids, kaolinite remains unaffected unless it has been subjected to very specific intercalation reactions (Wada, 1961; Alietti, 1966; Wiewiora and Brindley, 1969; Lee and others, 1975; Jackson and Abdel-Kader, 1978), while halloysite readily replaces the interlayer water with organic liquids (Grim, 1953). Even dehydrated halloysite may rehydrate in the presence of selected organic molecules.

\section{ORIGIN OF KAOLINS}

Clay minerals are the product of weathering and their formation is environmentally controlled. Different clay minerals can form from the same parent rock under differing 
weathering conditions. When a feldspar rich rock weathers under poor drainage conditions, the released magnesium, potassium, or calcium will stay within the system and montmorillonite or illite will form (Grim, 1953). From the same parent material, kaolinite develops if adequate water is available and good drainage has been provided for the removal of the dissolved alkali metals. The same soil clays might develop from rocks of a different composition. Time is a significant factor in these processes which will influence the mineral composition of the weathered material. If, for example, the removal of alkalis from a rock is slow, first montmorillonite develops and kaolinite will form only at a later weathering stage.

The alteration of rocks may be due to the actions of descending surface waters or ascending hot waters. The $\mathrm{pH}$ of these waters is important in the formation of weathering products. The $\mathrm{pH}$ itself of the percolating water is influenced by the climate and the vegetation. In warm, humid conditions with altering wet and dry seasons, the organic material will be oxidized and the downward moving waters will be alkaline. The silica is removed from the soil, aluminium and iron are left behind, and kaolins or lateric soils will form. In colder and more temperate climates, the organic materials are not fully oxidized and the downward seeping waters contain organic acids which will dis- 
solve and carry away iron and aluminium to a lower soil horizon, and only silica will be left behind.

In the Pacific Northwest, kaolin minerals might form from basalt under conditions of a wet climate, good drainage, and acidic conditions (Trimble, 1963). The progressive stages of weathering can be represented first by an amorphous phase which, in time, will alter to halloysite. The halloysite, in turn, might change to kaolinite, which, with continued weathering, could alter to laterite. As a result, the weathering product within one geologic deposit might not be uniform, but could be the mixture of different clay minerals as has been suggested by Keller and Haenni (1978).

Kaolins can be authigenic and remain at the site where the weathering took place, or they could be transported by water, wind, or ice and redeposited in a new environment. Kaolins also occur as hydrothermal alteration products in the argillaceous alteration zone around sulfide veins. 


\section{CHAPTER III}

\section{SHEAR STRENGTH}

\section{THEORY}

One of the main concerns of soil scientists is the understanding of the shear strength of clays in order to predict or prevent landslides, creep, or construction failures.

Shear strength of a clay is the force which causes movement between adjacent soil particles. It can be expressed by the Coulomb equation:

$$
\tau=c+\bar{\sigma} \tan \phi
$$

where $\tau=$ shear strength

$$
\begin{aligned}
& c=\text { cohesion } \\
& \bar{\sigma}=\text { effective normal stress } \\
& \phi=\text { friction angle. }
\end{aligned}
$$

Terzaghi (1936) expressed the value of the effective normal stress for saturated soils as:

$$
\bar{\sigma}=\sigma-u_{w} \ldots
$$

where $\bar{\sigma}=$ effective normal stress

$$
\begin{aligned}
\sigma & =\text { total normal stress } \\
u_{w} & =\text { pore pressure. }
\end{aligned}
$$

According to Bishop (1961), for unsaturated soils: 


$$
\bar{\sigma}=\sigma-u_{w}(x)-u_{a}(1-x)
$$

where $\bar{\sigma}=$ effective normal stress

$$
\begin{aligned}
\sigma= & \text { total normal stress } \\
u_{w}= & \text { pore water pressure } \\
u_{a}= & \text { pore air pressure } \\
x & =\text { coefficient: } \quad x(\text { saturated soil })=1 \\
& x(\text { dry soil soil })=0
\end{aligned}
$$

Different laboratory testing methods are available for shear strength measurements (Lambe, 1951; Bowles, 1970). In this study, the unconfined compression technique, which measures the compressive strength of a laterally unsupported $\left(\sigma_{3}=0\right)$ cylinder of soil, has been used. The test is a "quick" or "undrained" method which does not measure the pore water pressure. Calculation of the shear strength is based on the assumption that the angle of internal friction, $\phi$, is equal to zero for cohesive soils (Bowles, 1970). When $\phi=0$, equation (3) will change to

$$
\tau=\mathbf{c}
$$

and the shear strength is equal to the cohesion. From the Mohr's circle construction (see Figure 3), the cohesion, c, is equal to one half of the maximum compressive strength.

$$
\tau=c=\frac{q u}{2}
$$

where the maximum compressive strength, qu, is equal to

$$
q u=\frac{\text { Maximum Normal Load }}{\text { Cross Sectional Area of Soil Sample }}
$$




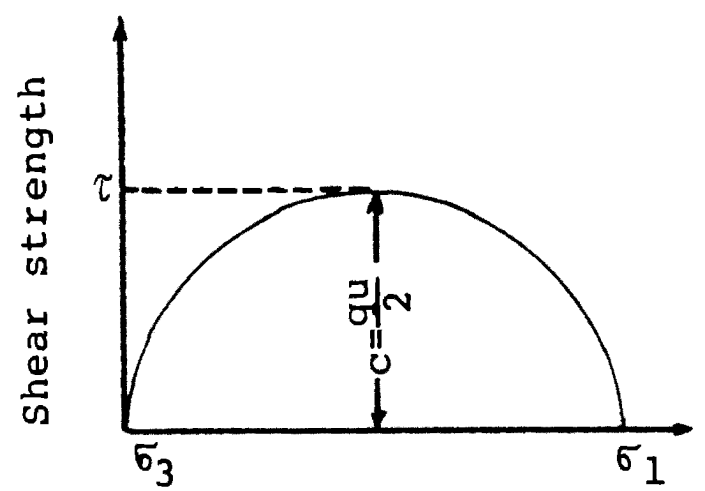

Normal stress

$$
\begin{aligned}
\tau= & \text { shear strength } \\
c= & \text { cohesion } \\
q u= & \text { maximum compressive } \\
& \text { strength }=\sigma_{1} \\
\sigma_{1}= & \text { major principle stress } \\
\sigma_{3}= & \text { minor principle stress } \\
= & 0
\end{aligned}
$$

Figure 3. Mohr's circle for unconfined compression test.

The development of the shear strength of a cohesive soil is influenced by the acting electrical forces within the clay, the particle spacing and orientation, the nature of the soil-water system, the applied external forces, and the geologic history of material (Lambe, 1958b; Ingles, 1968).

The electrical forces between particles are attractive (van der Waals, electrostatic) and repulsive (electrostatic) forces. Another electrical repulsive stress is the contact pressure which might be caused by forces acting either within or without the soil system (Lambe, 1958b). Increased attraction, increased contact pressure, and reduced repulsive force will increase the shear strength of soils.

The effect of particle spacing reduction on the shear strength depends on whether or not the electrical forces will be attractive or repulsive. In the case of compacted 
clays, reduction in spacing causes the increase of contact pressure resulting in the increase of shear strength.

The effect of particle orientation on the shear strength of soil is such that less force is required to slide one particle over another when the clay flakes are oriented in a parallel array instead of a random arrangement. Therefore, the flocculated structure with its random edge-to-face orientation has a higher strength (Warkentin and Yong, 1962) than the dispersed structure does; also, the electrostatic attraction of the edge-to-face connection of the flocculated clays contributes to the higher shear strength of these soils.

The nature of the soil-water system will influence the electrical forces that exist within the system. Any condition - such as increased electrolyte concentration and ion valency or low $\mathrm{pH}$ value of the pore fluid and small size of the hydrated ion - which favors the depression of the double-layer formation will decrease particle repulsion, which, in turn, increases shear strength. The quantity of water available to the soil-water system also influences the shear strength of the mineral. If not enough water has been provided to the system, and the particles cannot satisfy their double-layer requirement, then tension will develop in the pore water which increases intergranular pressure and increases the undrained shear strength of 
the clay. On the other hand, the soil decreases its strength when more water is added to the system than required by the clay-water equilibrium.

External forces alter the orientation and spacing of particles which will influence the electrical forces and the shear strength. In dispersed soils there is no mineral-to-mineral contact and stresses are transmitted through long range electrical forces, while in flocculated soils, particle-to-particle contact forces take part in the stress transmission. External forces also can cause volumetric changes in the soil. Volume reduction increases the pore water pressure which lowers the shear strength. Expansion, on the other hand, can put tension in the pore water (Lambe, 1951), thus increasing intergranular pressure and the shear strength.

\section{ATTERBERG LIMITS AS STRENGTH INDICATORS}

The behavior of soil is related to the amount of water the soil-water system contains. Atterberg (1911) defined three stages in terms of "limits." They represent water contents at which the soil changes from one state into another.

The first stage, the liquid limit, has been defined as the boundary between the liquid and plastic states; it is the water content at which a pat of soil in a brass cup 
will close a $1 \mathrm{~cm}$ deep groove when dropped from a height of $1 \mathrm{~cm} 25$ times. There is a linear relationship between the water content and the logarithm of the number of blows (drops). Therefore, if three or four points are determined at different water contents, together with the corresponding blow counts, they will define a straight line on the "flow curve." The flow curve is a graph which is produced when the water content is plotted as the ordinate and the logarithm of the number of blows as the abscissa. The line on the graph will indicate the liquid limit as the water content that corresponds to the blow count of 25 .

The second stage, the plastic limit, has been defined as the boundary between the plastic and semi-solid states; it is the water content at which a thread of clay $3 \mathrm{~mm}$ in diameter starts to crumble.

The third stage, the shrinkage limit, is the boundary between the semi-solid and solid states. It is defined as the water content below which no volume change takes place with change in water content. The shrinkage limit, $w_{s}$, is calculated from the equation

$$
w_{S}=\frac{\gamma w V}{w_{S}}-\frac{G_{t}}{G_{S}} .
$$

where $\gamma_{w}=$ unit weight of water

$$
\begin{aligned}
\mathrm{V} & =\text { volume of a dry soil pat } \\
\mathrm{W}_{\mathbf{S}} & =\text { weight of a dry soil pat }
\end{aligned}
$$


$G_{t}=$ specific gravity of water

$\mathrm{G}_{\mathbf{S}}=$ specific gravity of soil.

The liquid and plastic limits can be used as indicators of the shear strength of soils. These limits will not yield a numerical value for shear strength which could be used in engineering calculations, but they allow soils to be compared at their limits and inferences might be made concerning their general behavior. For example: when soils at equal plasticity index - which is equal to the liquid limit minus the plastic limit - are compared, the soil with increasing liquid limit will have the lower dry strength and toughness (resistance to molding at plastic limit). When soils at equal liquid limits are compared, the one with increasing plasticity index will have the higher dry strength and toughness. When comparing soils at equal plasticity index but with different flow indices (slope of flow curve), the soil with the largest flow index will have the lowest shear strength.

At the liquid limit, the soil has a low shear strength and the $1 \mathrm{~cm}$ deep groove in a soil pat will be closed by 25 blows. Casagrande (1932) found that each blow that causes the closure of the standard groove corresponds to a shear strength of $1 \mathrm{gm} / \mathrm{cm}^{2}$. Therefore, at the liquid limit, soils have a shear strength of approximately $25 \mathrm{gm} / \mathrm{cm}^{2}$. 


\section{CHAPTER IV}

\section{LABORATORY INVESTIGATION}

\section{MATERIALS}

Both halloysite and kaolinite were obtained from Ward's Natural Science Establishment Incorporated, Rochester, New York. The halloysite is from Dragon Iron Mine, Eureka, Utah, and is hydrothermal in origin. The mine is located along the contact between the Tertiary monzonite intrusive and Ordovician Ajax limestone. The halloysite itself is within the argillic alteration zone and has been identified as \#13 in Reference Clay Minerals, American Petroleum Institute Research Project 49 (Kerr and Kulp, 1949). The halloysite shipment consisted of a lustrous, well cemented, porcelain-like material and a loosely cemented, stained, porous type that could be pulverized easily.

The kaolinite is from Twiggs County, Georgia, but the exact geographical position where the mineral was taken from is not known. The mineral is white, massive, porous, medium hard, and contains some mica. The Cretaceous kaolins of Georgia are sedimentary in origin. They are the alteration product of the feldspathic crystalline 
rocks of the Piedmont Plateau which underwent considerable chemical weathering in pre-Cretaceous time. After the Cretaceous uplift of the plateau, the authigenic kaolins were transported and redeposited on the coastal plains of Georgia and South Carolina (Kerr and Kulp, 1949).

The soil clays for this study were collected within the Washington Park area of Porland, Oregon. Detailed geological setting of Portland is given by Trimble (1963) and several consulting firms (e.g. Shannon and wilson Incorporated, 1969; Dames and Moore, 1975) provide subsurface information about the area. The bedrock is the columbia River basalt, which, in places, has been weathered to a hard, bright-red, oolithic or pisolithic laterite, or to a softer, earthy laterite which may contain hard nodules or rock fragments. At some locations, weathered basalt is overlain by stiff, reddish-brown, silty clay and red clay with occasional pebbles. This unit was tentatively identified as the Helvetia formation by Shannon and Wilson Incorporated (1969). The Portland Hills Silt overlies the Helvetia formation or the weathered Columbia River basalt.

The sampling sites are located in TlS, RlE, Sec. 5. Excavation in 1980 for the foundation of the Harold A. Miller Hall of the Western Forestry Center exposed several soil horozons. At the northwest corner of the excavation 
site, the gray-brown Portland Hills Silt is approximately one meter thick and is underlain by a stiff, brick-red, silty clay of undetermined thickness. The red clay contains soft, black, rounded or rectangular impressions of carbonatized material. Grayish inclusions a few centimeters in diameter also exist within this clay and display fabric of the weathered basalt.

A pocket-like inclusion two to three meters long and approximately two meters thick, consisting of reddish-brown weathered basalt with soft, yellow mineraloids exist between the Portland Hills silt and the brick-red silty clay. The clay soil, OMSI-2, was collected from this pocket-like inclusion, while OMSI-4 was taken from the brick-red weathered basalt from the lower section of the excavation pit, one half meter below the pocket-like inclusion (Figure 4).

The soil clay, wP-2 - tentatively identified as a member of the Helvetia formation - was collected 22 years ago, approximately 250 meters to the southeast of the above described excavation site. The soil was part of the failure plane of the Washington Park-Zoo-OMSI landslide (January 14, 1959). The soil is a cream colored, mottled, fine grained, silty clay with hard, dark-red concretions of nonuniform size (Figure 5). 


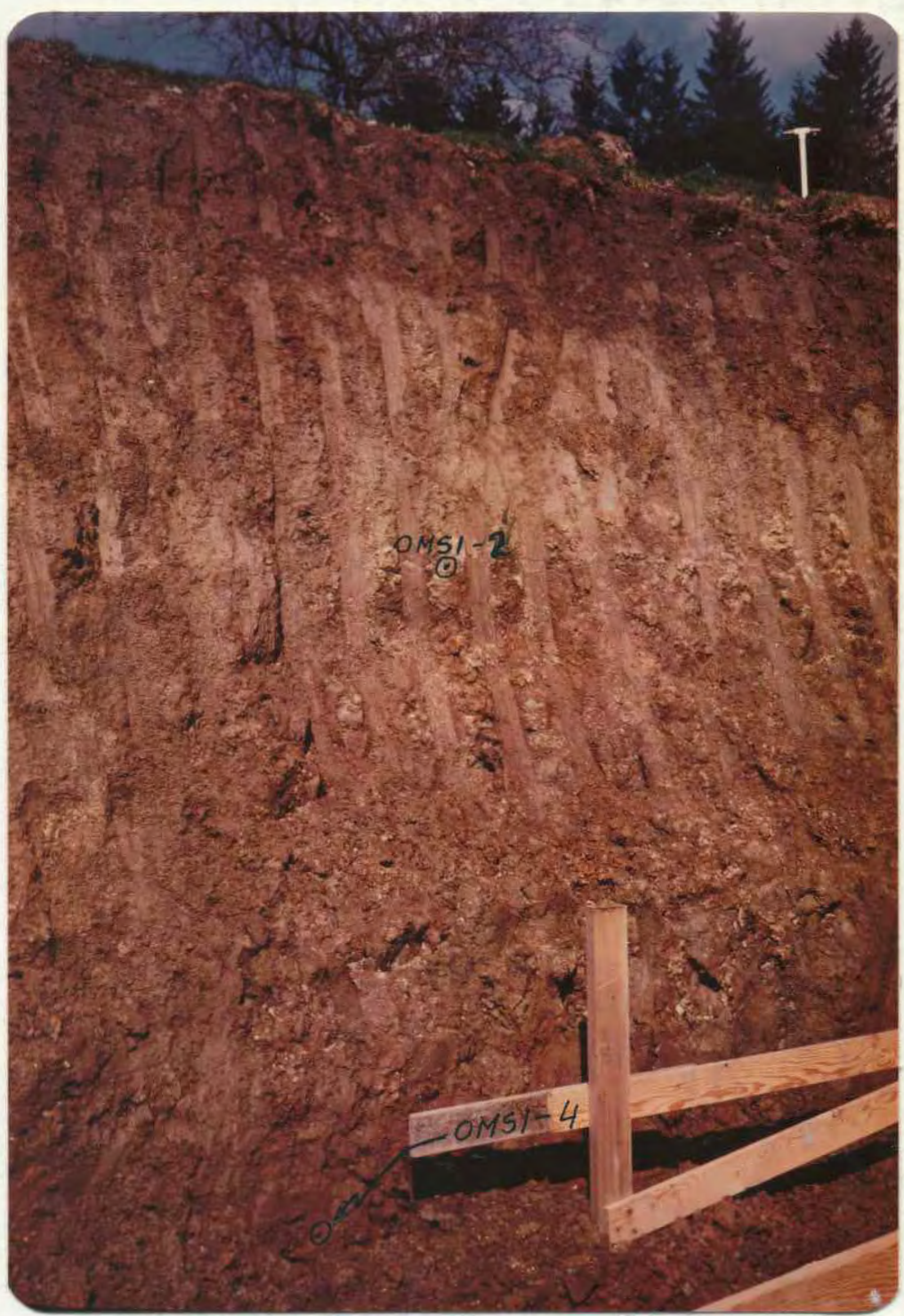

Figure 4. Location of soil clays OMSI-2 and OMSI-4. 


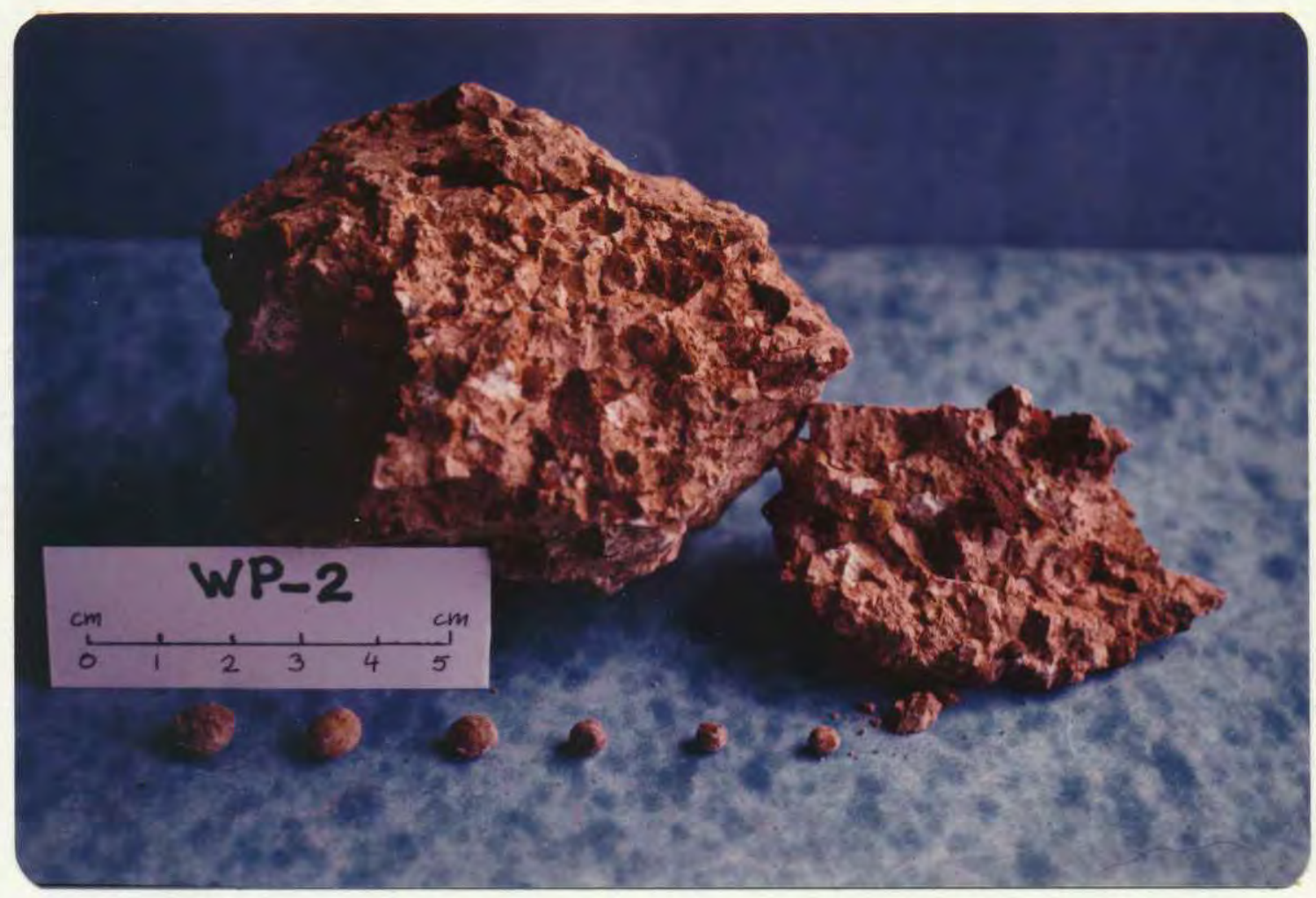

Figure 5. Soil clay WP-2.

\section{PREPARATION OF CLAY MINERALS AND SOIL CLAYS}

Both minerals and soil clays were air-dried, then hand pulverized in an iron mortar and passed through a set of ASTM sieves. The portion that passed through the 80 mesh size was used for the experimentations, although some testing was also performed on that portion which was retained on the 80 mesh sieve. Kaolinite had a tendency to cake up during sieving, and the 42 mesh sieve was the finest the kaolinite passed through. However, hydrometer analysis on the clays indicated (Figure 6 through 8 ) that the size fraction of the kaolinite that passed through the 


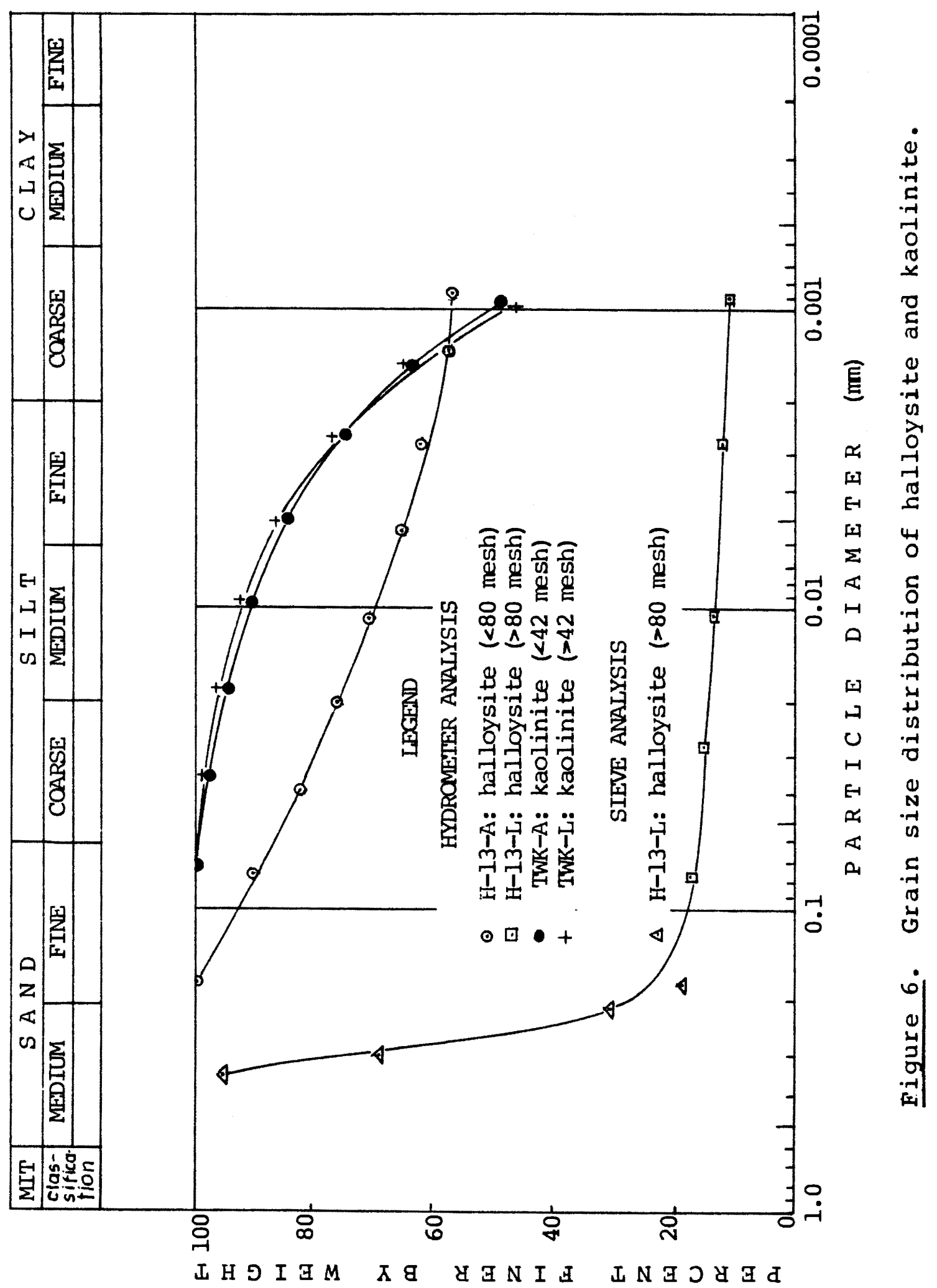




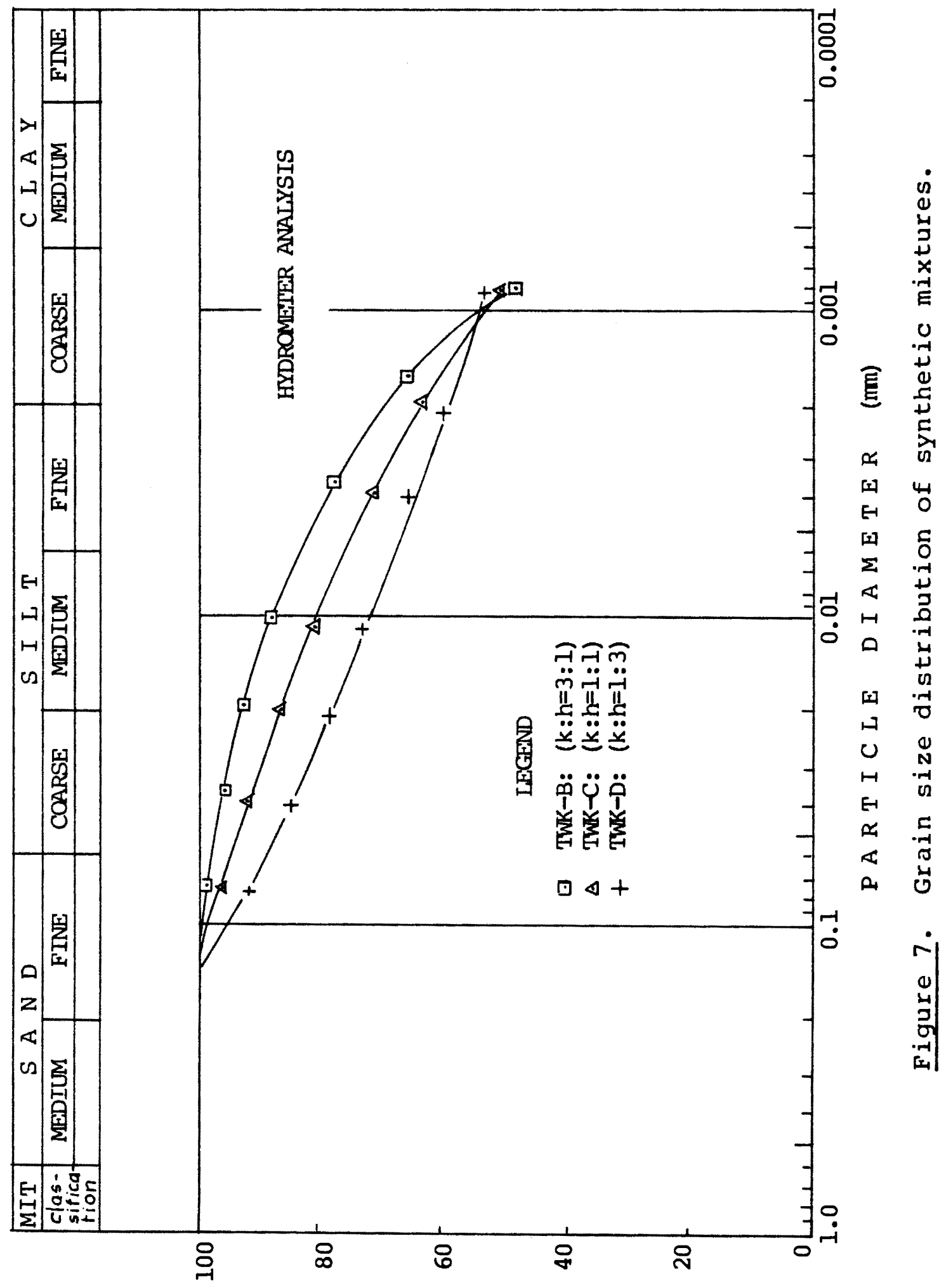

山H כ I 


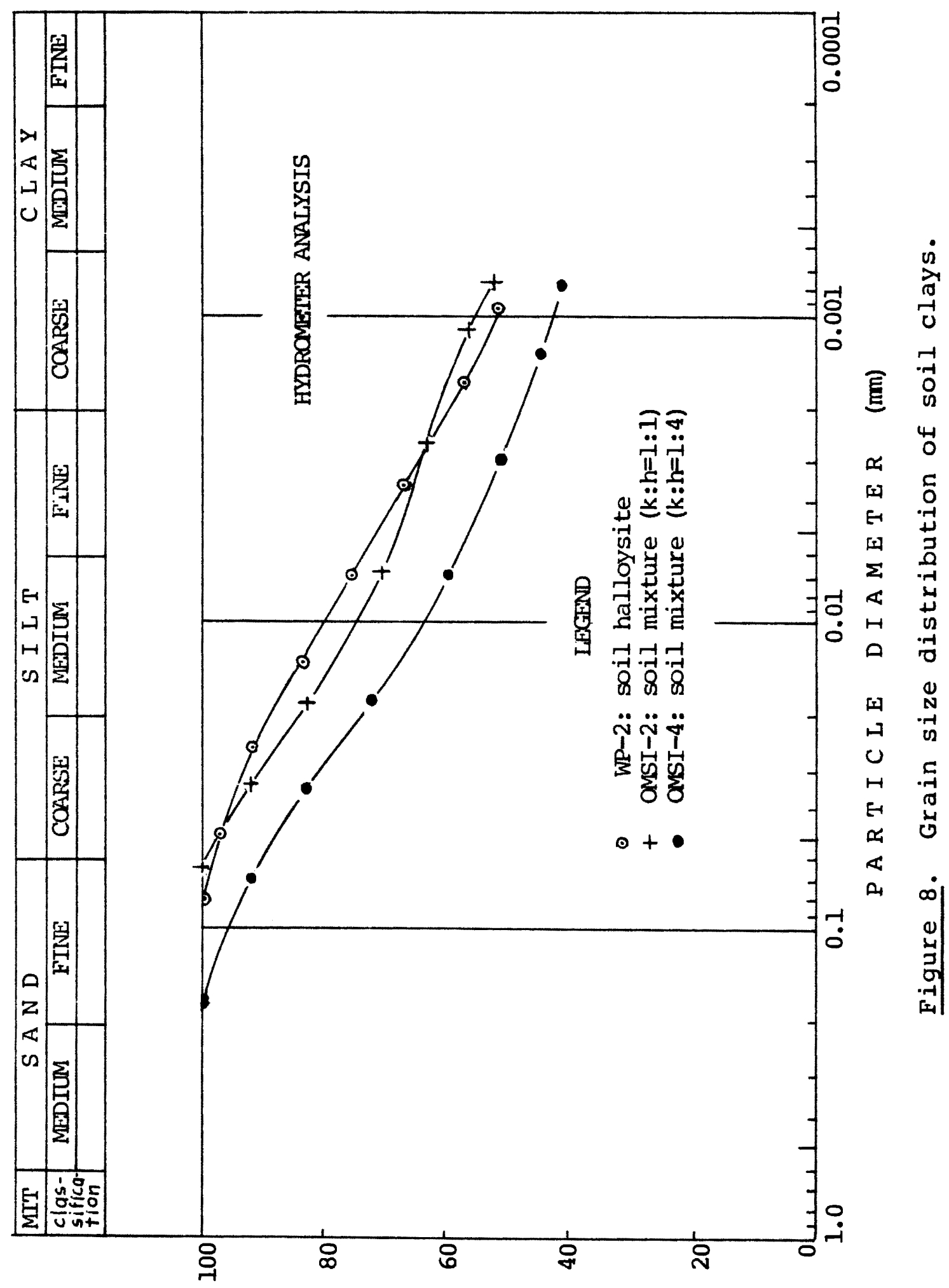

山 
42 mesh sieve was actually finer than the portion of halloysite or soil clays which was finer than the 80 mesh size. Thus it is assumed that the size fractions of minerals and soils are comparable.

Samples are labeled in the following manner: H-13-A: 1008 halloysite (finer than 80 mesh sieve) H-13-L: 1008 halloysite (retained on 80 mesh sieve) TWK-A : 1008 kaolinite (finer than 42 mesh sieve) TWK-L : 1008 kaolinite (retained on 42 mesh sieve) TWK-B : 758 kaolinite and $25 \%$ halloysite TWK-C : 508 kaolinite and 508 halloysite TWK-D : 258 kaolinite and 758 halloysite WP-2 : soil clay: halloysite OMSI-2: soil clay: approximately $50 \%$ halloysite and $50 \%$ kaolinite

OMSI-4: soil clay: approximately 808 halloysite and $20 \%$ kaolinite.

Synthetic mixtures TWK-B, TWK-C, and TWK-D were prepared using finer than 80 mesh halloysite and finer than 42 mesh kaolinite size fractions.

Unless otherwise specified, all data will refer to clays whose size fraction is finer than 80 mesh or 42 mesh. 


\section{COMPACTION AND TEST SPECIMEN PREPARATION}

Samples for the unconfined compression analysis were prepared in the Soil Testing Laboratory of RittenhouseZeman and Associate by using Soiltest's Harvard Miniature Compactor (Figure 9). The mold of the device is $7.15 \mathrm{~cm}$ long and its inside diameter is $3.33 \mathrm{~cm}$. The length to diameter ratio is 2.15 which satisfies the size requirement of $2<l / d<3$ of the unconfined compression test specimen.

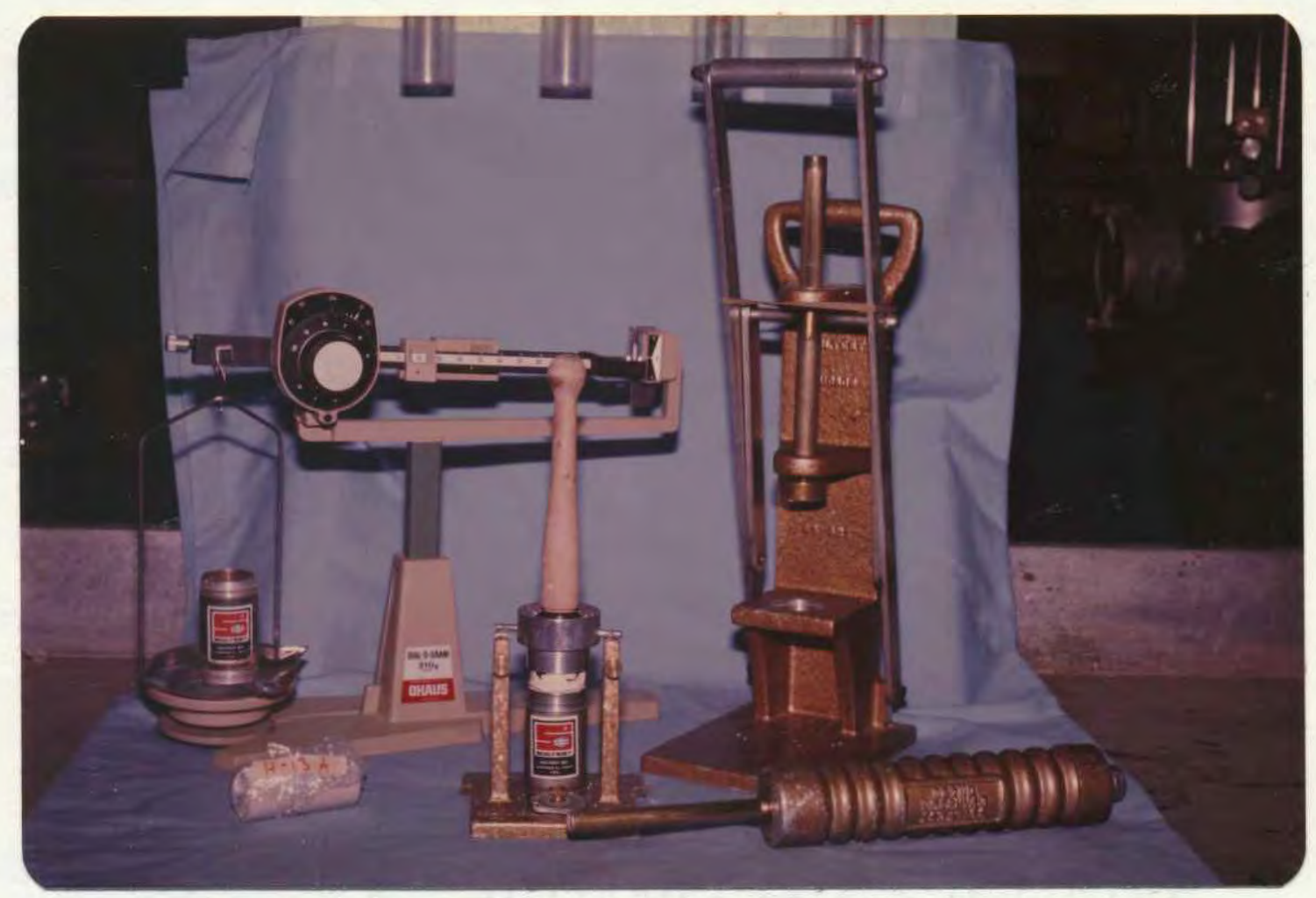

Figure 9. Harvard Miniature Compactor and balance used for density determination.

The first set of five to six samples of the minerals 
and clays were used to establish moisture-density relationships and to determine the optimum dry densities and water contents. Each sample was made from the mixture of $110 \mathrm{gm}$ of dry, pulverized, sieved clay and various amounts of water. The clay-water mixture was allowed to stand for 24 hours in a glass jar and then compacted in the Miniature Compactor in four layers with 25 tampings from the 30 pound spring compactor on each layer. The weight of the compacted sample was recorded. The leftover clay-water mixture was transfered into a small container and weighed.

The compacted sample was extruded from the mold, tightly sealed in a plastic wrap, then sealed in aluminium foil and in a ziplock sandwich bag. The sample was placed in a cardboard box and cured for 48 days in an unheated room where the temperature ranged between 13 and 16 degrees Celsius.

The container with the leftover clay-water mixture was placed in the oven for 24 hours at 120 degrees Celsius. Upon removal from the oven, the container and clay were cooled in a dessicator, after which the dry weight of the clay was measured.

The water content of a soil mass is defined as the ratio of the weight of water to the weight of dry soil grains in the mass: 


$$
w_{z}=\left(\frac{w_{\text {wet }}-w_{\text {dry }}}{w_{d r y}}\right)
$$

where $w^{q}=$ percentage water content

$\mathrm{W}_{\text {wet }}=$ wet weight of soil

$\mathrm{w}_{\mathrm{dry}}=\mathrm{dry}$ weight of soil

The density of a soil mass is the weight of soil grains per unit volume of soil mass:

$$
\gamma_{\mathrm{d}}=\frac{\mathrm{w}}{\mathrm{v}(1+\mathrm{w})} \ldots \ldots \ldots \ldots \ldots \ldots \ldots \ldots \ldots
$$

where $\gamma_{d}=$ compacted dry density of soil

$$
\begin{aligned}
& \mathrm{W}=\text { total weight of compacted soil } \\
& \mathrm{V}=\text { volume of compacted soil } \\
& \mathrm{w}=\text { water content }
\end{aligned}
$$

Other calculations included the computation of the void ratio and the degree of saturation of the clays. The void ratio, e, is the ratio of the volume of voids to the volume of solid grains of a soil mass. It is calculated from the equation

$$
e=\frac{G \gamma_{W V}}{W_{S}}-1 \ldots \ldots \ldots \ldots \ldots \ldots
$$

where $\quad G=$ specific gravity of soil grains

$$
\begin{aligned}
\gamma_{w} & =\text { unit weight of water } \\
v & =\text { volume of soil mass } \\
w_{S} & =\text { dry weight of soil gains }
\end{aligned}
$$

The degree of saturation, $S$, is the ratio of the volume of water in the soil voids to the total volume of the voids. 
It is calculated either from the equation

$$
s=\frac{w_{w}}{\gamma w V_{V}}
$$

or

$$
\mathrm{s}=\frac{\mathrm{GW}}{\mathrm{e}}
$$

where $W_{W}=$ weight of water in soil

$$
\begin{aligned}
\gamma_{W} & =\text { unit weight of water } \\
v_{V} & =\text { volume of voids } \\
G & =\text { specific gravity of soil grains } \\
w & =\text { water content of soil. }
\end{aligned}
$$

In this thesis, equation (14) was used to compute the value of the percentage saturation of the clays.

Compaction curves for the minerals, synthetic mixtures, and soil clays were established by plotting water contents as abscissas against densities as ordinates. The optimum water content was obtained for the clays from these graphs as the amount of water which produced the maximum weight of soil per volume or optimum density.

To provide an adequate number of samples (at least three or four) for shear strength correlation, additional samples were prepared to yield the optimum conditions indicated above. When the air-dried halloysite, synthetic mixtures, and soil clays were mixed with water of predetermined weight to yield optimum density, it resulted in compacted samples of a higher than optimum water content and a 
lower than optimum density. Since this problem was not experienced with the pure kaolinite mineral, the "residual" interlayer water in the halloysites was suspected to cause the deviation between the expected and actual optimum values. To determine the amount of "residual" interlayer water, the clays were subjected to dehydration analysis. The result of the analysis is plotted in Figures 10 and 11; they indicate the water content of the clays in terms of weight loss (ordinate) at increasing temperatures (abscissa). Since the water content determination requires oven drying ( 120 degrees Celsius in this study) of the clay samples, the amount of water necessary to achieve optimum water content was reduced by the percentage weight loss at 120 degrees Celsius indicated by the dehydration curves. This procedure yielded compacted samples which approached optimum moisture content and density. A total of $106 \mathrm{com}-$ pacted specimens were prepared for unconfined compression analysis (Table 1).

UNCONFINED COMPRESSION ANALYSIS

The unconfined compression analysis was carried out in the Testing Laboratory of the USDA Forest Service, Region 6 , on a MST Computer Controlled Servohydraulic closed Loop Testing Machine (Figure 12). The device, when used in compression analysis, measures the change in length of the test specimen. The strain, which is expressed as the 


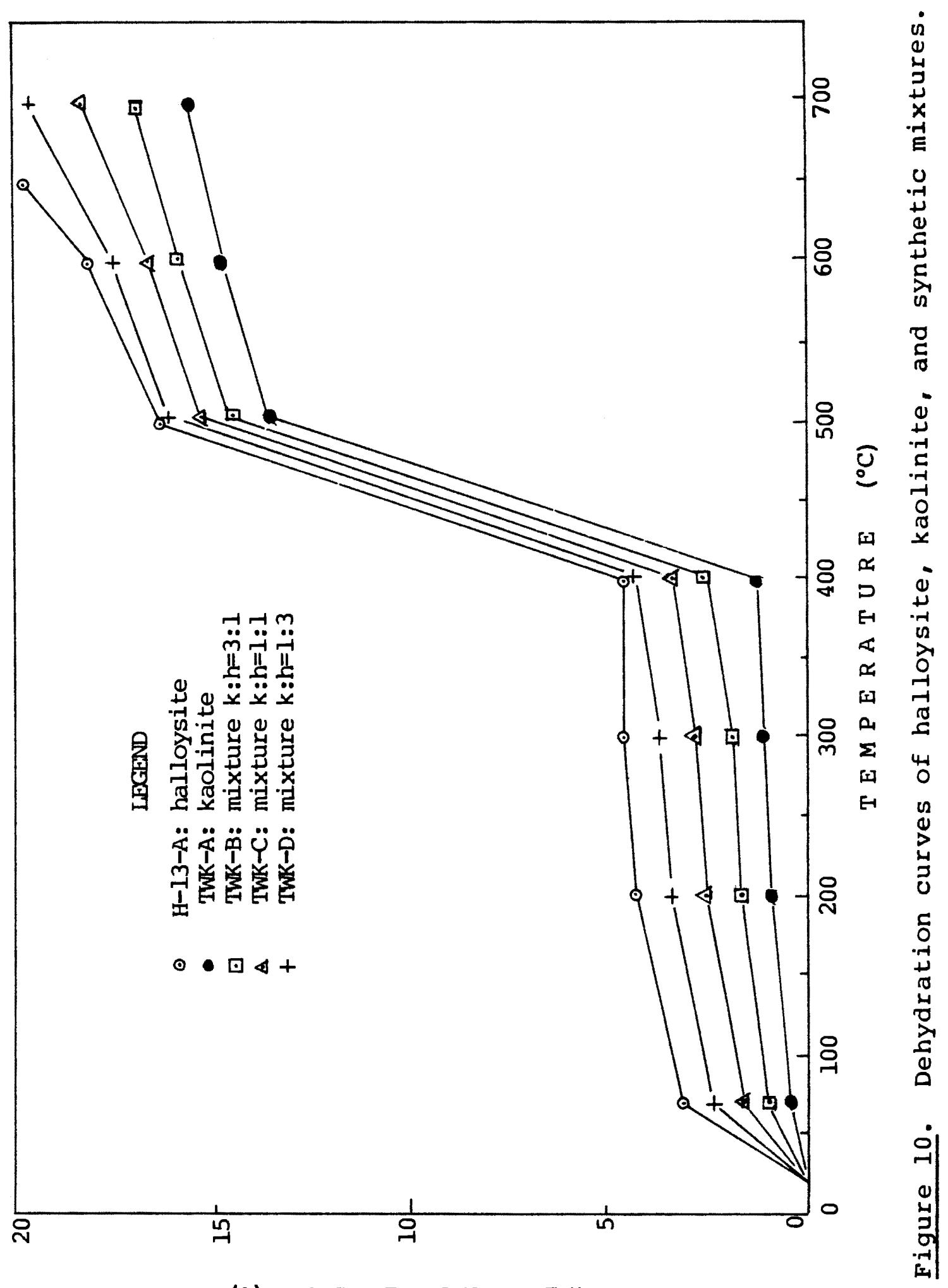

(8) S SOI Ч H I I G 


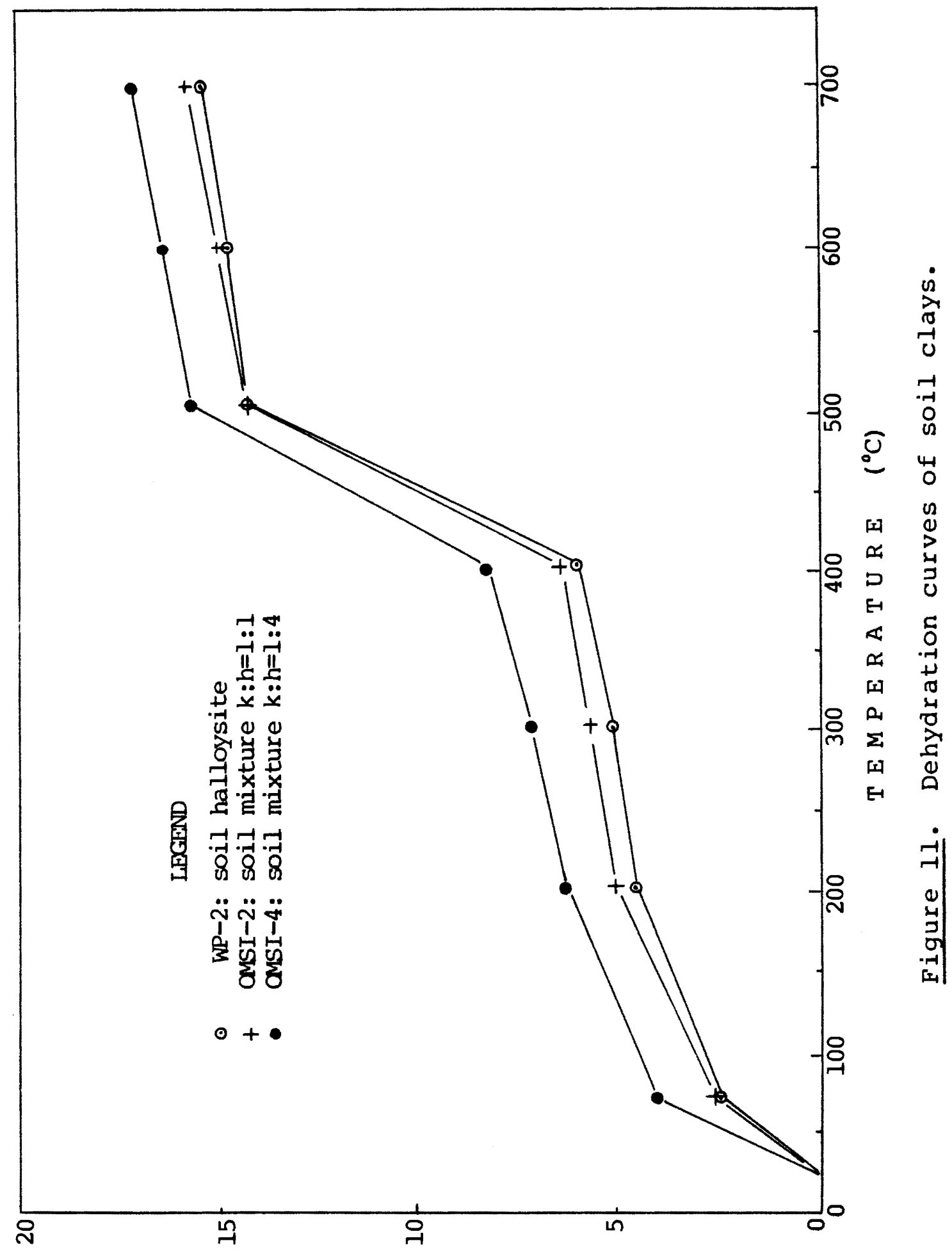

(8) S SOT IH OI I M 
length of change per original length of the sample, is due to the compression applied vertically to the specimen. The compression was applied in a manner as to produce axial strain at a rate of one half to two percent per minute. The rate of strain was regulated so that the failure time of the specimen did not exceed 10 minutes. This meant that the clay which was compacted on the wet side of the optimum water content and which underwent large deformation needed to be tested at a higher rate of strain than the one compacted on the dry side of the compaction curve which underwent smaller deformation.

TABLE 1

IDENTIFICATION OF ONE HUNDRED AND SIX COMPACTED SPECIMENS

\begin{tabular}{|c|c|c|c|}
\hline Sample & No of & Samples & Sample description \\
\hline $\begin{array}{r}\mathrm{H}-13-\mathrm{A} \\
\mathrm{TWK}-\mathrm{A}\end{array}$ & & $\begin{array}{l}12 \\
14\end{array}$ & $\begin{array}{lll}\text { halloysite } & (<80 \text { mesh }) \\
\text { kaolinite } & (<42 \text { mesh })\end{array}$ \\
\hline $\begin{array}{l}\text { TWK -B } \\
\text { TWK-C } \\
\text { TWK-D }\end{array}$ & & $\begin{array}{r}10 \\
15 \\
9\end{array}$ & $\begin{array}{ll}\text { mixture: } & k: h=3: 1 \\
\text { mixture: } & k: h=1: 1 \\
\text { mixture: } & k: h=1: 3\end{array}$ \\
\hline $\begin{array}{r}\text { WP }-2 \\
\text { OMSI }-2 \\
\text { OMSI }-4\end{array}$ & & $\begin{array}{r}16 \\
4 \\
12\end{array}$ & $\begin{array}{l}\text { soil halloysite } \\
\text { soil mixture: } k: h=1: 1 \\
\text { soil mixture: } k: h=1: 4\end{array}$ \\
\hline $\begin{array}{l}\mathrm{H}-13-\mathrm{L} \\
\mathrm{TWK}-\mathrm{L}\end{array}$ & & $\begin{array}{l}7 \\
7\end{array}$ & $\begin{array}{lll}\text { halloysite } & (>80 \text { mesh }) \\
\text { kaolinite } & (>42 \text { mesh })\end{array}$ \\
\hline
\end{tabular}

The testing device was connected to a chart recorder which plotted the change in length (inches) of the sample 


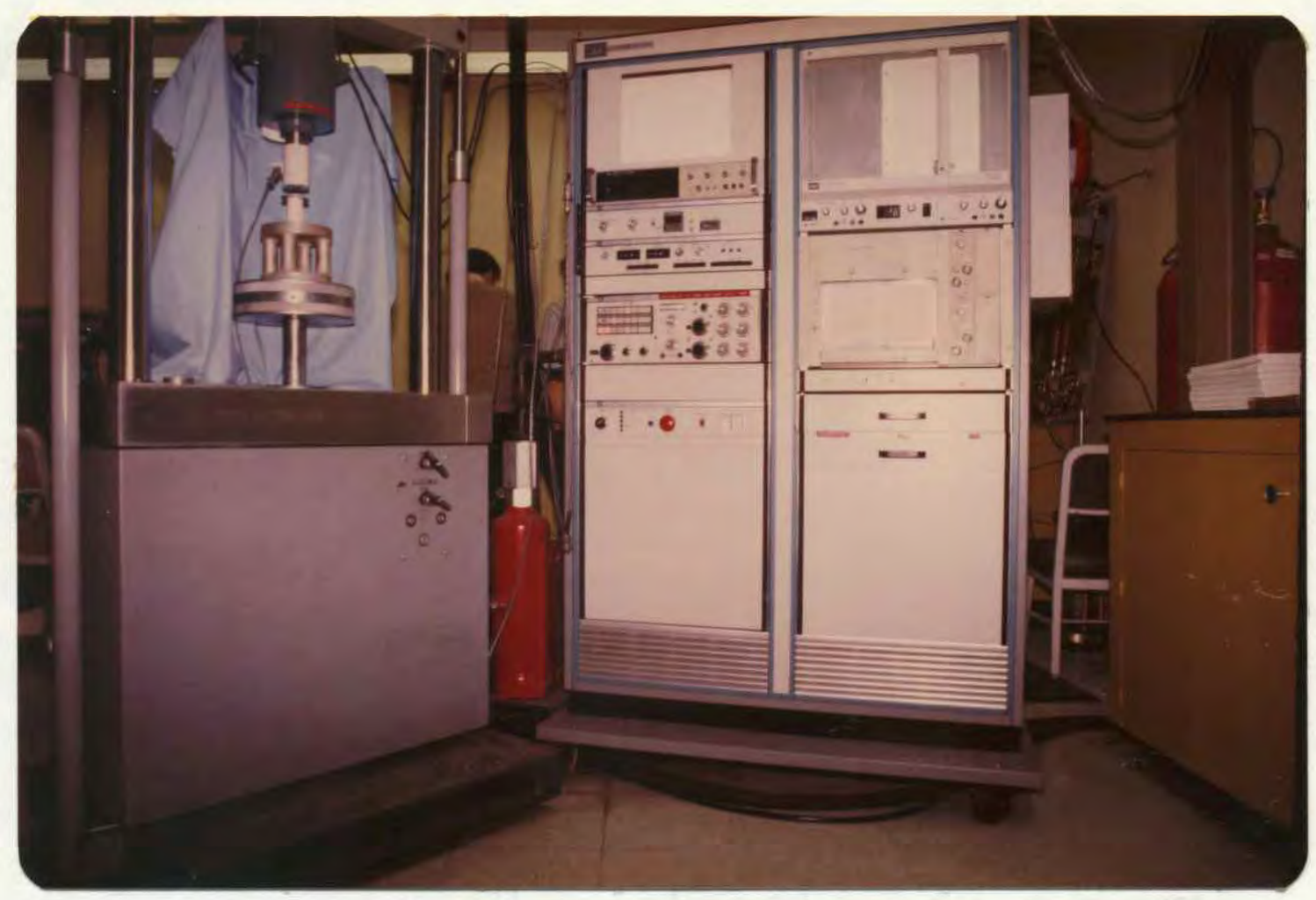

Figure 12. MST Computer Controlled Servohydraulic Closed Loop Testing Machine used for unconfined compression analysis.

on the horizontal scale and the applied force (pounds) on the vertical scale. The load cell of the machine regulates the applied compression. During the early part of testing, the specimens were sheared under a 500 pound load cell which was used at $20 \%$ of its capacity allowing the test samples to be compressed to 100 pounds. The chart recorder scale was set to give $1 "=10$ pounds for the vertical and $1 "=0.1$ inch for the horizontal scale. However, when this 500 pound cell became damaged, it was replaced with a 2000 pound load cell, which, at a $10 \%$ machine setting, gave a 
maximum loading capacity of 200 pounds. For the 2000 pound load cell, the chart recorder scale was $1 "=20$ pounds.

Prior to testing, the external dimensions of the sample were measured and the weight of the sample recorded. The sample was placed on the loading platform of the testing apparatus, and the endplate inserted between the sample and the loading cell. The loading platform was carefully raised until the endplate touched the loading cell. The required rate of strain was programmed into the machine, the chart recorder pen set at the zero position, and the starting time of testing recorded. A digital readout indicated the amount of applied load at any instant while the chart recorder plotted on a graph paper the strain vs. load curve. While the sample was being sheared, details of the failure pattern were studied and correlated to the strain vs. load curve. The time of failure was recorded, but the loading was continued well beyond failure. Afterwards, the loading platform was returned to its original position. The sheared specimen was removed from the platform and its weight recorded. The sample was dried in the oven for 24 hours at 120 degrees Celsius, cooled in a dessicator and weighed on the scale. The water content, w, was calculated as

$$
w=\frac{W_{w}}{W_{S}}
$$

the axial strain, $f$, as 


$$
\epsilon=\frac{\Delta L}{L_{0}}
$$

the average cross-sectional area, A, as

$$
A=\frac{A_{0}}{1-\epsilon}
$$

and the shear stress, $\tau$, as

$$
\tau=\frac{P}{2 A}
$$

where $w_{w}=$ weight of water

$W_{S}=$ weight of dry soil grains

$\Delta L=$ change in length of the sample

$L_{0}=$ original sample length

$A_{0}=$ cross sectional area at the begining of test $P$ = compressive force.

The results of the computations are plotted on graph paper with shear stress $\left(\mathrm{kg} / \mathrm{cm}^{2}\right)$ as ordinate and strain ( $(8)$ as abscissa. The shear strength of the clay is taken as the point of maxima on the stress-strain curve. Where no peak stress was observed, the shear stress at 158 strain was taken as the shear strength of the sample.

Because only a limited amount of raw clay materials was available, not every test sample was dried in the oven in an undisturbed state. Only parts of some samples were used for water content determination so that the remaining parts could be used for further experimentation and testings. 


\section{ATTERBERG IIMITS AND INDICES}

Liquid and plastic limit determinations of the clays were carried out in the Sedimentary Petrology Laboratory of Portland State University. Approximately 100 grams of air dried, sieved clay was mixed with distilled water and allowed to cure for 24 hours. After the curing period, a small portion (approximately $15 \mathrm{grams}$ ) of the mixture was used for the plastic limit determination by rolling it out on a glass plate to a thread of three millimeters in diameter. The rolling procedure was repeated several times until the three millimeter thread started to crumble. The thread was then placed into an evaporating dish and its water content - which is the plastic limit - was determined by the previously described method.

The remaining portion of the clay-water mixture was used for the liquid limit determination. Enough distilled water was added to the mixture to form a smooth uniform paste. The paste was transfered into the brass cup of the liquid limit device and a $1 \mathrm{~cm}$-deep groove was made in the clay with the ASTM standard grooving tool. The brass cup is so attached to the device that it is allowed to be dropped from a height of $1 \mathrm{~cm}$ by the turning of a handle. The handle is rotated with a speed of two revolutions per second until the repeated blows close the groove. The number of blows needed to close the groove for a distance of 
$1 \mathrm{~cm}$ was noted and a representative sample for water content was taken from the closed part of the groove. The remaining paste was removed from the brass cup, re-mixed with additional distilled water, and the procedure repeated until four sets of blow-count and water content data were obtained. The water contents plotted as ordinates and the blow-counts as abscissas on a semi-logarithem paper defined the blow line and the water content at a blow count of 25 , which is the liquid limit.

The Atterberg indices are calculated as follows: Plasticity index, $I_{p}$,

$$
I_{p}=w_{1}-w_{p}
$$

Flow index, $I_{f}$,

$$
I_{f}=\text { slope of flow curve. }
$$

Toughness index, $I_{t}$,

$$
I_{t}=\frac{I_{p}}{I_{f}}
$$

where $\quad w_{1}=$ liquid limit

$$
w_{p}=\text { plastic limit. }
$$

The activity, A, which is the ratio of the plasticity index to the percentage of the clay in the soil (Skempton, 1953) is computed from the equation

$$
A=\frac{I_{p}}{\text { percentage of clay in soil } \ldots . . . ~}
$$

where $I_{p}=$ plasticity index. 
The clays were received in their dried state and their natural water content - with the exception of soil clays OMSI-2 and OMSI-4 - are unknown. Therefore, the water plasticity ratio, $B$, has not been determined.

$$
B=\frac{w-w_{p}}{I_{p}}
$$

where $\quad w=$ water content

$$
\begin{aligned}
& \mathrm{w}_{\mathrm{p}}=\text { plastic limit } \\
& \mathrm{I}_{\mathrm{p}}=\text { plasticity index }
\end{aligned}
$$

\section{$X-R A Y$ DIFFRACTION ANALYSIS}

Sample preparation for $\mathrm{X}$-ray diffraction analysis (outlined by Enlows, 1970) has been carried out at Portland State University. Approximately $10 \mathrm{gm}$ of the air-dried, powdered clay was soaked in water to free it from the soluble salts. The clay was then washed through a 325 mesh sieve to seperate the finer sized fractions from the coarser ones. The coarse fractions were discarded and the remaining suspension was filtered to retain the finer sized fraction of the clay.

Since the soil clays reacted vigorously with acetic acid and hydrogen peroxide, the clays were treated to purge the carbonates and organic matter from them. The calcium carbonate was removed from the clay by soaking it in $0.1 \mathrm{~N}$ acetic acid until all effervescence ceased. The leachates were decanted and the clay was washed through with dis- 
tilled water. The organic matter removal from the soil called for soaking the clay for 16 hours in $30 \% \mathrm{H}_{2} \mathrm{O}_{2}$, then boiling it for 15 minutes to remove the peroxide. The leachates were decanted, and the soil was rinsed with distilled water.

To obtain better $\mathrm{x}$-ray diffractograms, the soil clays were also cleansed of iron. Sodium citrate and sodium bicarbonate were added to the soil and the mixture was heated up to 80 degrees Celsius. Then, $\mathrm{Na}_{2} \mathrm{~S}_{2} \mathrm{O}_{4}$ was added to the clay and the mixture was subjected to a steam bath for 15 minutes. Later, the suspension was centrifuged at high speed, and the supernatants were discarded.

In the next step, the silt size fraction was separated from the clay size fraction first by dispersing the material with sodium carbonate, then by centrifuging the suspension at 750 revolutions per minute for 5 minutes. The procedure enabled the silt to settle out and left the finer than two micron size fraction in the suspension. The silt was discarded and the suspension was centrifuged at 6000 revolutions per minute for 7 minutes to further divide the clay into a 2 to 0.2 micron and into a less than 0.2 micron size group.

The clays were solvated with calcium chloride before mounting the clay slurry by suction on porous tiles. For 
each of the clay minerals and soil clays, three such tiles were prepared; one was treated with ethylene glycol, another with dimethyl sulfoxide (DMSO) to detect swelling of the clay minerals, and the third was used as a calcium solvated mount. Both DMSO and ethylene glycol were applied directly on the wet surface of the mounted clay as a thin layer coating, while the vacuum pump was still engaged to provide suction. The ceramic tiles were dried under the heat of a desk lamp for 16 hours.

The $\mathrm{X}$-ray diffractogram analysis was carried out at the Troutdale office of the U.S. Army, Department of Corps of Engineers using a Philips-Norelco diffractometer with nickel filtered $\mathrm{CuK}_{\alpha}$ radiation at $40 \mathrm{kV}$. and $20 \mathrm{~mA}$. The scanning speed was two degrees $2 \theta$ per minute from two degrees to 30 degrees $2 \theta$. The wavelength, $\lambda$, of the Cuk $\mathrm{C}_{\alpha}$ adiation is $1.54050 \AA$. The unknown latice spacing, $d$, was obtained from a prepared table which was made up by calculating the "d" spacings for varying diffraction angles by using Bragg's equation (equation (2)). 


\section{CHAPTER V}

\section{DATA PRESENTATION AND INTERPRETATION}

\section{DATA PRESENTATION}

The results of the $\mathrm{x}-\mathrm{ray}$ diffraction analysis, sompaction analysis, unconfined compression testing, Atterberg limit determination, and statistical calculations are listed in Tables II through VIII in Appendix A. The data is presented graphically in Figures 13 through 25 and also in Appendix $B$ in Figures IA through 15A. Table II shows the results of the $\mathrm{X}-\mathrm{ray}$ diffraction analysis of halloysite, kaolinite, synthetic mixtures, and soil clays; it lists the basal spacings of the primary and secondary refractions of the calcium solvated, ethylene glycolated, DMSO and heat treated specimens and indicates the clay mineral contents of the samples. The estimation of the clay mineral content was based on the ratios (kaolinite:halloysite) of the peak areas of the primary reflections of the DMSO treated samples (see X-ray diffractograms of Figures 13 through 16). Table III enumerates the optimum moisture content and the optimum compacted dry density of the pure minerals, their synthetic mixtures, and soil clays. The optimum conditions were obtained from the compaction curves of the clays (see 
Figures IA through 9A in Appendix B). To provide visual comparison of the optimum conditions of the pure minerals, synthetic mixtures, and soil clays, the compaction curves were assembled into a single graph in Figure 17.

The results of the unconfined compression analysis are tabulated in Table IV. One hundred and six (106) compacted specimens and their properties are enumerated in this table. These properties include water content, compacted dry density (before and after the 48 day curing period), saturation, void ratio, strain deformation, and shear strength. Calculation of the stress-strain values of every specimen was based on the load-strain charts which were produced by the chart recorder of the unconfined compression testing unit. Typical examples of these charts are shown in Appendix $B$ in Figures $10 \mathrm{~A}$ and $11 \mathrm{~A}$. Figure 10A shows a chart which was generated when a 500 pound load cell was used during the testing; Figure IlA displays the load-strain relationship using a 2000 pound load cell. The stress-strain values are graphically presented as the stress-strain curves. The stress is plotted as the ordinate and the strain as the abscissa. The shear strength is taken as the maximum shear stress of the sample. To show representative samples of these graphs, stress-strain curves of the halloysite and kaolinite minerals are included in Appendix B in Figures $12 \mathrm{~A}$ and $13 \mathrm{~A}$. Numbers along the 
curves indicate water contents and identification numbers for the specimens. Figures 18 through 20 are photographs of the sheared clay samples. The photographs show typical failure patterns and the development of the failure plane during the unconfined compression test. Numbers at the base of the specimens indicate their water contents and the identification numbers of the specimens are shown on the upper portion of the samples. Selected halloysite and kaolinite samples are illustrated in Figure 18, synthetic mixtures in Figure 19, and soil clays in Figure 20.

From the 106 specimens, 34 were selected and used for shear strength correlation. These 34 samples were compacted at optimum water content and yielded optimum densities in the 838 to 988 saturation range. Table V shows the distribution of the 34 samples, lists their properties (i.e. water content, dry density, saturation, void ratio, strain deformation, and shear strength), and indicates the average strain and shear strength of halloysite, kaolintie, synthetic mixtures, and soil clays. Table VI is the extension of Table $V ;$ it lists the percentage of strain deformation and the shear strength of the 34 specimens. It also indicates the mean shear strength and strain deformation of the clays and the precision of instrumentation of the unconfined compression testing unit. In order to correlate the clays, the mean shear strength and strain deformation val- 
ues of halloysite, kaolinite, synthetic mixtures, and soil clays were plotted in Figure 21. The strain deformation represents the abscissa and the shear strength identifies the ordinate on the graph. The precision of instrumentation is indicated by the length of the horizontal lines drawn across the mean strain values of the clays. Figure 22 shows the relation between the void ratio and shear strength of the pure minerals, synthetic mixtures, and soil clays. The shear strength is plotted as the abscissa and the void ratio as the ordinate. The relationship is represented by a straight line on the graph. Figure 23 shows a linear relationship between the shear strength and clay mineral content at optimum moisture content. The shear strength represents the ordinate and the percentage mineral concentration the abscissa in this graph. The precision of the instrumentation is shown by the lengths of the vertical lines through the mean values of the shear strengths. Numbers displayed next to the plotted "mean" shear strengths indicate the number of samples used for calculating the mean values. The hatched lines on the graph represent the "error region". Both soil clays WP-2 and OMSI-4 plot within this error region.

Table VII is a list of the Atterberg limits and index properties of the pure minerals, synthetic mixtures, and soil clays. Beside the liquid and plastic limits, 
plasticity index, flow index and toughness index, Table VII also lists specific gravity, percentage clay content, and activity values. Figure 24 shows a non-linear relation between the liquid or plastic limits of halloysite, kaolinite, synthetic mixtures, and soil clays and their mineral contents. On this graph the liquid or plastic limit is plotted as the ordinate against the mineral concentration as the abscissa. Figure 25 is the plasticity chart on which the liquid limit is the abscissa and the plasticity index is the ordinate. The Casagrande (1932) "A" line, which is used in the Unified Soil Classification System (Casagrande, 1948) to subdivide fine grained soils is shown in Figure 25 as the line which intersects the abscissa at $20 \%$ liquid limit and has a slope of 0.73 . The "A" line divides the chart into an upper and a lower region. All of the tested clays are represented in the lower region.

\section{DATA INTERPRETATION}

\section{$\underline{X-r a y}$ Identification}

The diffractograms of the calcium solvated samples indicate that the tested clays have a first basal reflection between $7.2 \AA$ and $7.4 \AA$ and a second basal reflection in the vicinity of $3.6 \AA$. The reflections of halloysite $\mathrm{H}-13-\mathrm{A}$ (Figure 13a) are weak and broad in character and could be mistakenly identified as poorly crystallized kaolinite 


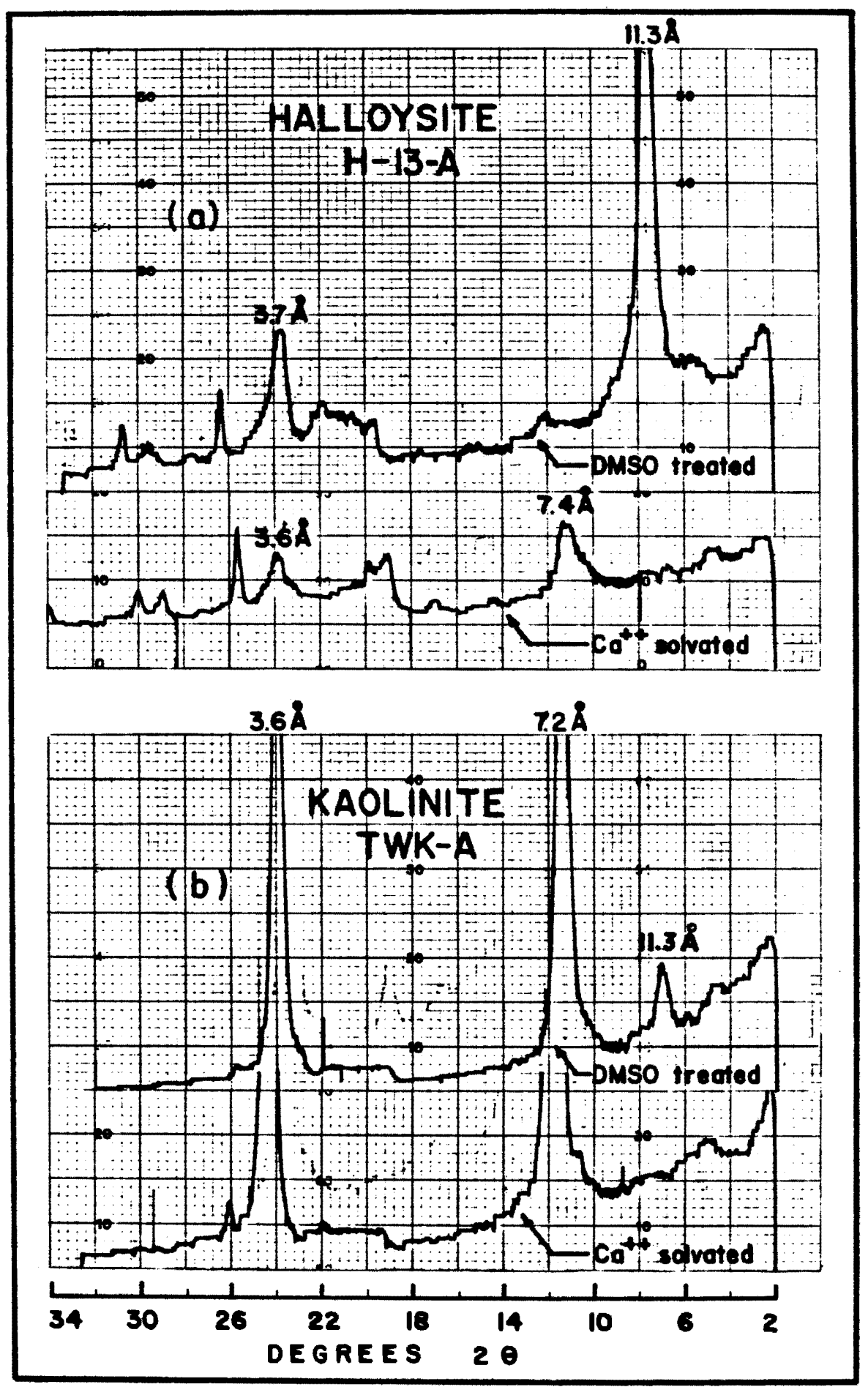

Figure 13. X-ray diffractograms of halloysite (a) and kaolinite (b). 
while the reflections of the pure kaolinite (Figure 13b) are strong and distinct, indicating a well crystallized mineral. Diffractograms of the calcium solvated synthetic mixtures are deceiving. A mixture in proportion of $k: h=3: 1$ (Figure 14) yields a diffractogram almost indistinguishable from that of the pure kaolinite. Even the 1:l mixture (Figure 15a) gives no indication of the presence of halloysite.

Ethylene glycol treatment of the clays did not result in a significant change of the diffractograms, indicating that glycolation is not a successful treatment for delineating kaolin minerals.

The DMSO treatment resulted in the replacement of the $\mathrm{d}_{001}$ and $\mathrm{d}_{002}$ reflections of halloysite $\mathrm{H}-13-\mathrm{A}$ from $7.4 \AA$ to $11.3 \AA$ and from $3.6 \AA$ to $3.7 \AA$, respectively (Figure $13 a$ ). The DMSO treatment, however, had no effect on the diffractogram of the pure kaolinite other than adding the relatively small deflection at $11.3 \AA$ (Figure $13 b$ ). The diffractograms of the synthetic mixtures (Figures 14 and 15) indicated the presence of a portion of the original $7.2 \AA$ and $3.6 \AA$ peaks besides the expanded $11.3 \AA$ and $3.7 \AA$ deflections. In a similar manner, soil clay OMSI-4, too, yielded a diffractogram (Figure 16a) with only partially expanded basal reflections while soil clay WP-2 (see Figure 16b) showed an almost identical diffractogram as that of 


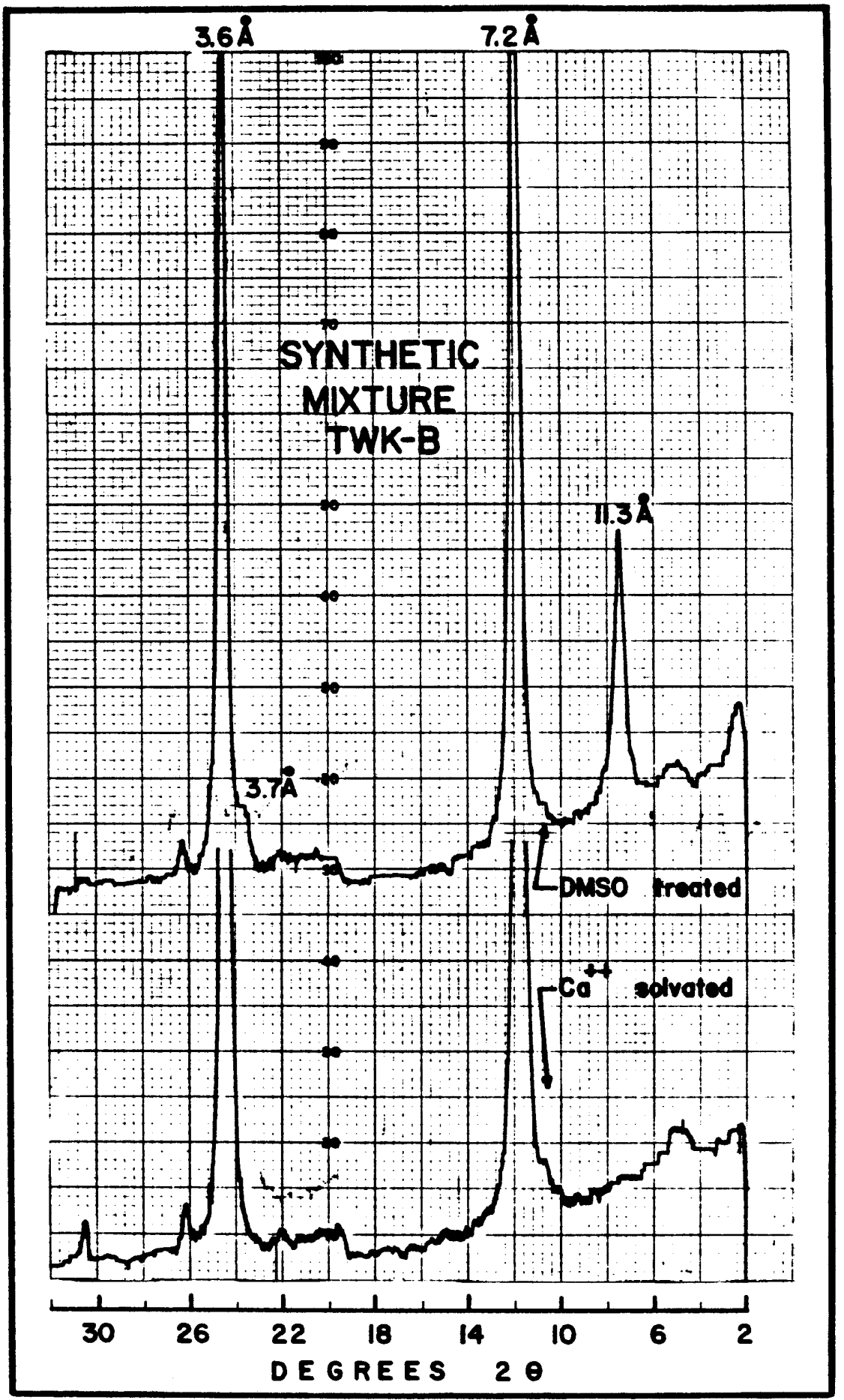

Figure 14. X-ray diffractograms of synthetic mixture TWK-B $(k: h=3: 1)$. 


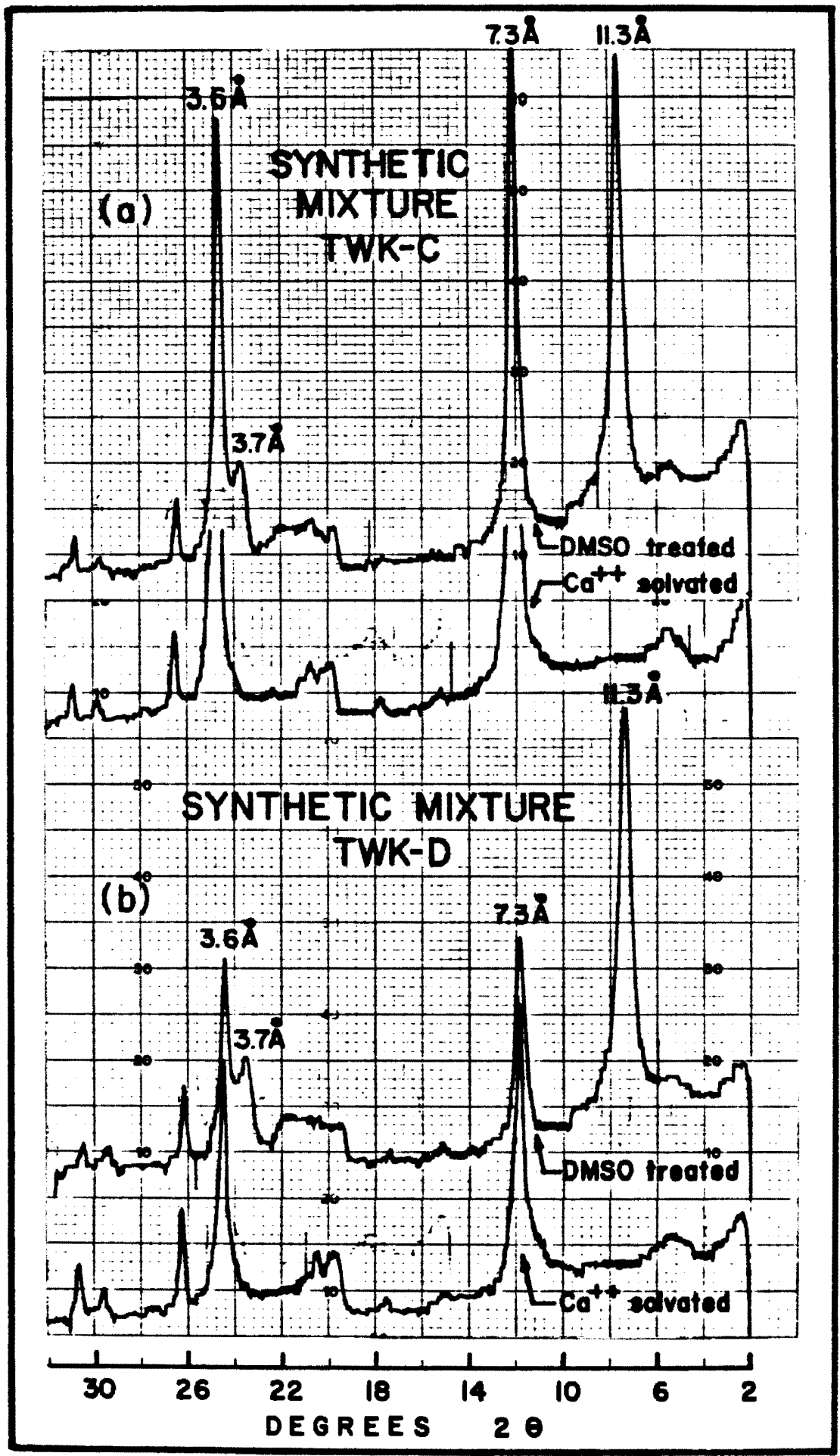

Figure 15. X-ray diffractograms of synthetic mixtures: TWK-C $(k: h=1: 1)(a), T W K-D(k: h=1: 3)(b)$. 


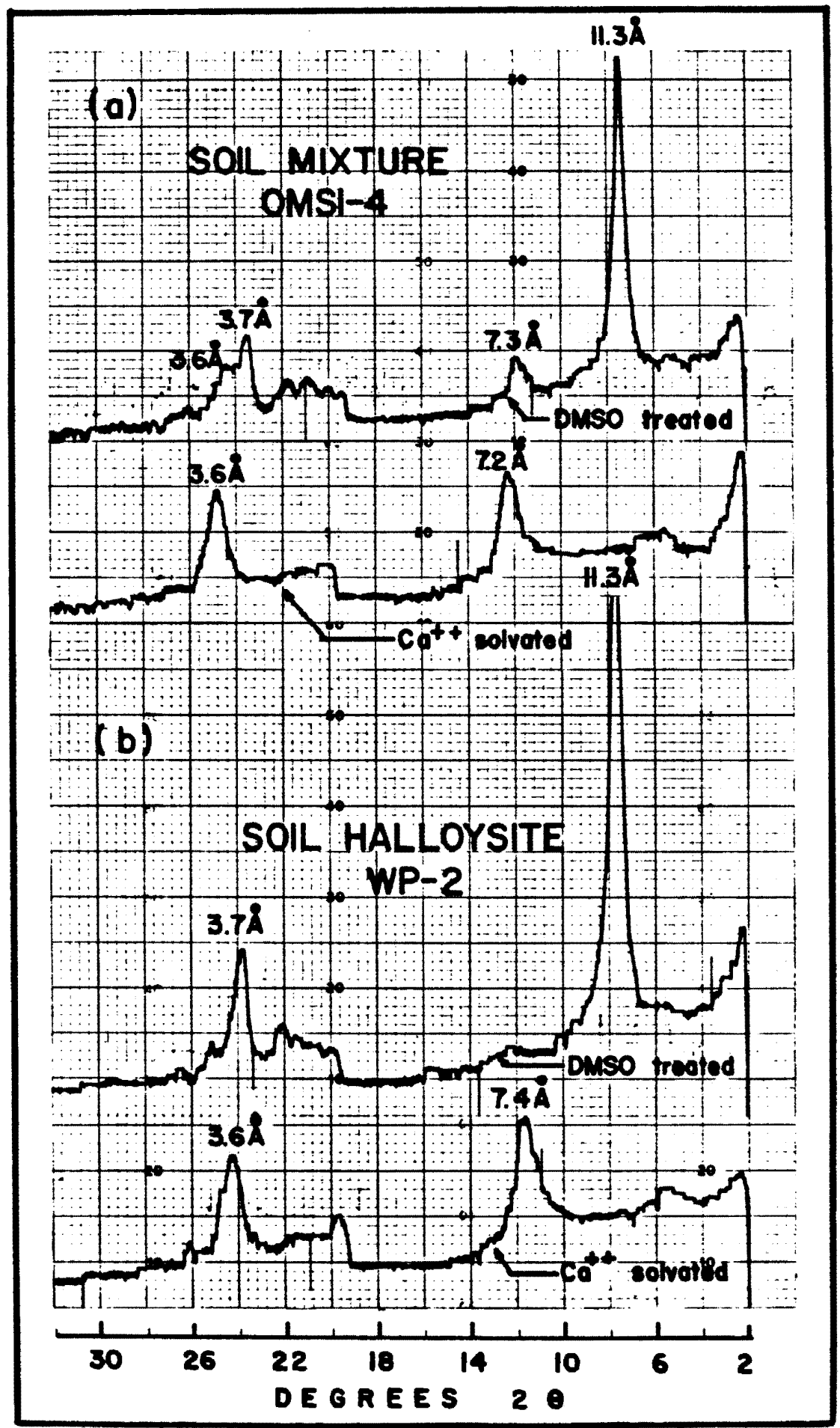

Figure 16. X-ray diffractograms of soil clays: soil mixture (a), soil halloysite WP-2 (b). 
halloysite $\mathrm{H}-13-\mathrm{A}$.

Mineral identification was based on the diffractograms of the DMSO treated samples, of which the results are listed in Table II. It is believed that the kaolinite surfaces will not readily take part in reactions since their internal surfaces have a tendency not to separate unless specific intercalation reactions are provided (Gast, 1977). Some reactions, however, might occur along the broken edges of the mineral. On the other hand, halloysite willingly takes up selected organic molecules into its structure and even dehydrated halloysite will expand in the presence of DMSO. Since kaolinite is not affected by the DMSO treatmeat, its basal peaks will not show any changes in their original positions, while the basal spacings of the halloysite will be replaced by deflections at $11.3 \AA$ and $3.7 \AA$. Accordingly, the diffractogram of a non-homogenous kaolin sample will show the unchanged basal spacings of the kaolinite at $7.2 \AA$ and $3.6 \AA$ and the expanded deflections of halloysite at $11.3 \AA$ and $3.7 \AA$. The formation of the doublet peak at $d_{002}$ reflection is typical of the non-homogenous kaolin minerals. However, when one of the component minerals is present in the mixture in a very large percentage, the stronger reflection at $\mathrm{d}_{002}$ of the well crystallized mineral will oppress the development of the typical doublet peak. In this case, the minor peak is represented by a 
notch-like extension of the major peak either at the $3.6 \AA$ or at the $3.7 \AA$ position (Figures 15 and $16 a$ ) and by the broadening of the reflection at the base of the major peak.

The diffractograms of the DMSO treated samples indicate that the soil clay WP-2 is a monomineralic kaolin containing halloysite (with considerable iron impurity) while OMSI-4 is a mixture of kaolinite and halloysite in the proportion of approximately $k: h=1: 4$.

The small deflection at $11.32 \AA$ of the kaolinite diffractogram (Figure 13b) might represent reactions along the broken edges or it might indicate the presence of a very small amount of halloysite. Since the $\mathrm{d}_{002}$ reflection of halloysite at $3.7 \AA$ did not develop at all, surface reactions along the broken edges are suspected. However, the presence of halloysite in a very small percentage has not been ruled out since the lower limit of detection of the $\mathrm{d}_{002}$ doublet peak has not been established yet. In this study, the TWK-A kaolinite is considered to be monomineralic.

Compaction

The compaction curves of Figures $1 \mathrm{~A}$ through $9 \mathrm{~A}$ indicate the relationship between the moisture contents and the dry densities of the clays before and after the curing. Numbers along the curves identify the specimens. Figure IA 
shows that halloysite samples compacted to the dry side of the optimum condition underwent a slight volume increase during the 48 day curing period. Kaolinite and the soil clays, on the other hand, sustained volume reductions (Figures $2 \mathrm{~A}, 6 \mathrm{~A}$, and $8 \mathrm{~A})$. Synthetic mixtures TWK-B and TWK-C (Figures $3 A$ and $4 A$ ) also suffered volume reduction but TWK-D (Figure 5A) showed no substantial volume change. All of the specimens compacted on the wet side of the density curves underwent compression during sample extraction from the mold.

Table III and Figure 17 are used to compare and contrast the optimum compacted dry densities and water contents of the clays. The $1.405 \mathrm{gm} / \mathrm{cm}^{3}$ optimum density of halloysite is lower and its optimum moisture content at 308 is slightly higher than the kaolinite density of 1.436 $\mathrm{gm} / \mathrm{cm}^{3}$ and water content of 298 . The distribution of the optimum values of the artificial mixtures does not follow a predictable pattern: mixture TWK-D ( $k: h=1: 3)$ occupies an intermediate position between the optimum values of its component members, while samples TWK-B $(k: h=3: 1)$ and TWK-C $(k: h=1: 1)$ have equivalent optimum conditions with higher dry density and lower water content values than either of their component minerals. Increasing the grain size of kaolinite and halloysite (samples H-13-L and TWK-L) resulted in the shifting of the compaction curves to the left 


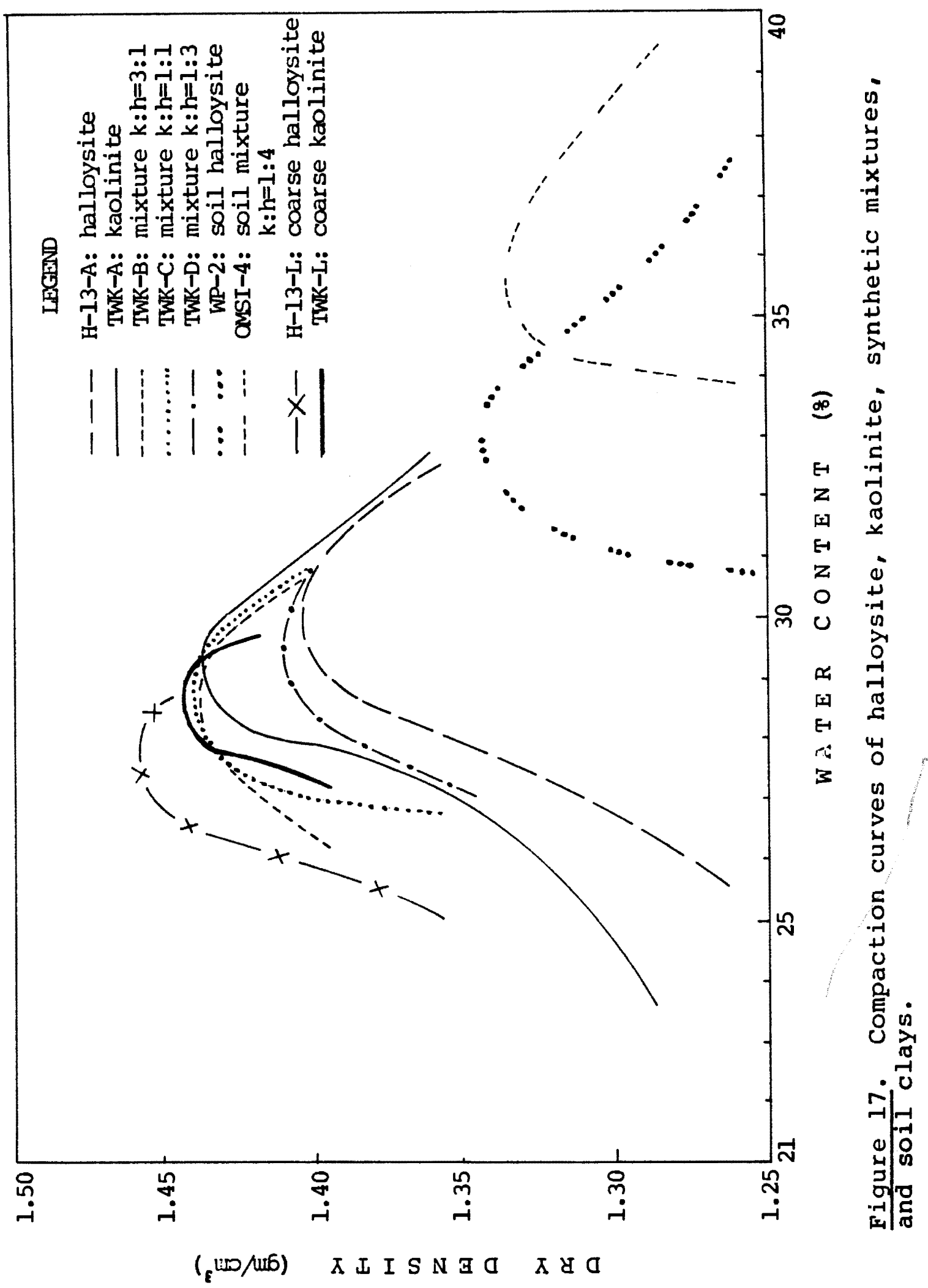


and upward (Figure 17). However, only in the case of halloysite might this change be called "substantial." This could be explained by the grain size distribution of the minerals. In general, increasing the coarse size fraction of a clay results in a higher dry density and lower water content value for the optimum condition (Lambe, 1951). Figure 5 indicates the increase of the coarser fractions from 408 in sample $\mathrm{H}-13-\mathrm{A}$ to $88 \%$ in halloysite $\mathrm{H}-13-\mathrm{L}$. On the other hand, the size distribution of the coarser kaolinite is almost the same as that of the finer one (Figure 5) which accounts for their comparable optimum values.

The soil clays have very low optimum densities and high optimum water contents (Figure 17). The true densitymoisture relationship for soil OMSI-2 could not be determined due to lack of sufficient data points but Figure 7A indicates that this soil might have the lowest optimum dry density and highest optimum water content of the tested clays.

\section{Unconfined Compression Analysis}

The photographs of the failed specimens (Figures 18 through 20) indicate that the water content of the samples define the nature of the failure that takes place during the unconfined compression test. At a very low water content, the clays behaved as brittle materials and failed under very small strain deformations. The failures took 


\section{FAILURE PATTERN OF HALLOYSITE}

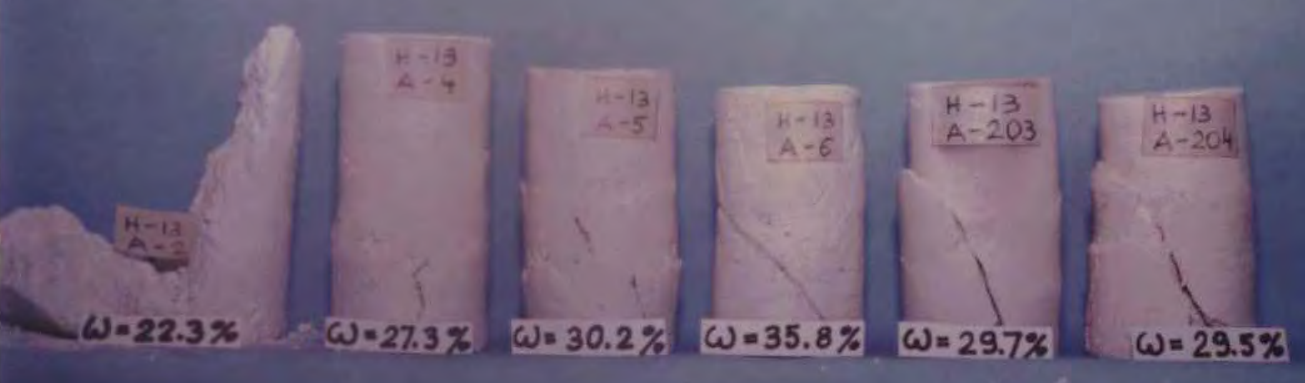

\section{FAILURE PATTERN OF KAOLINITE}

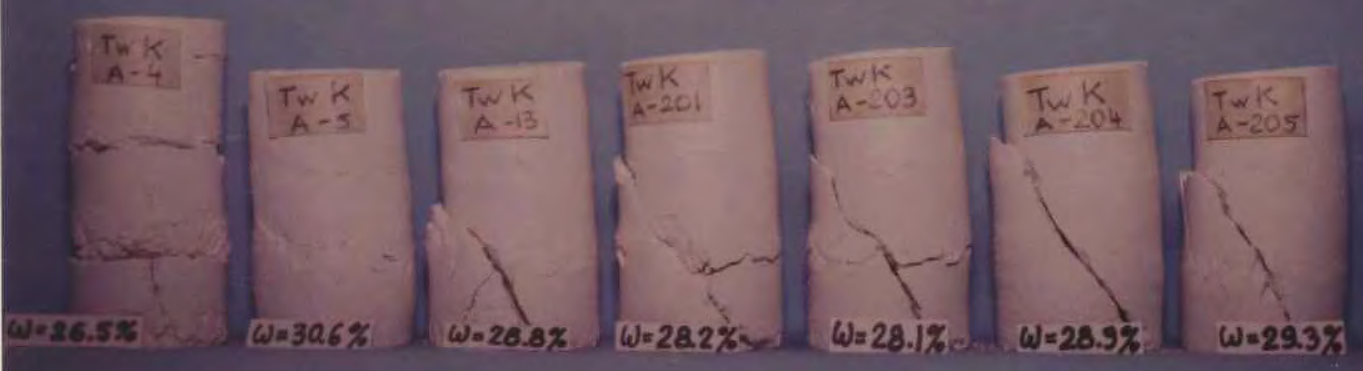

Figure 18. Failure pattern of halloysite and kaolinite $(\omega$ is the percentage water content). 

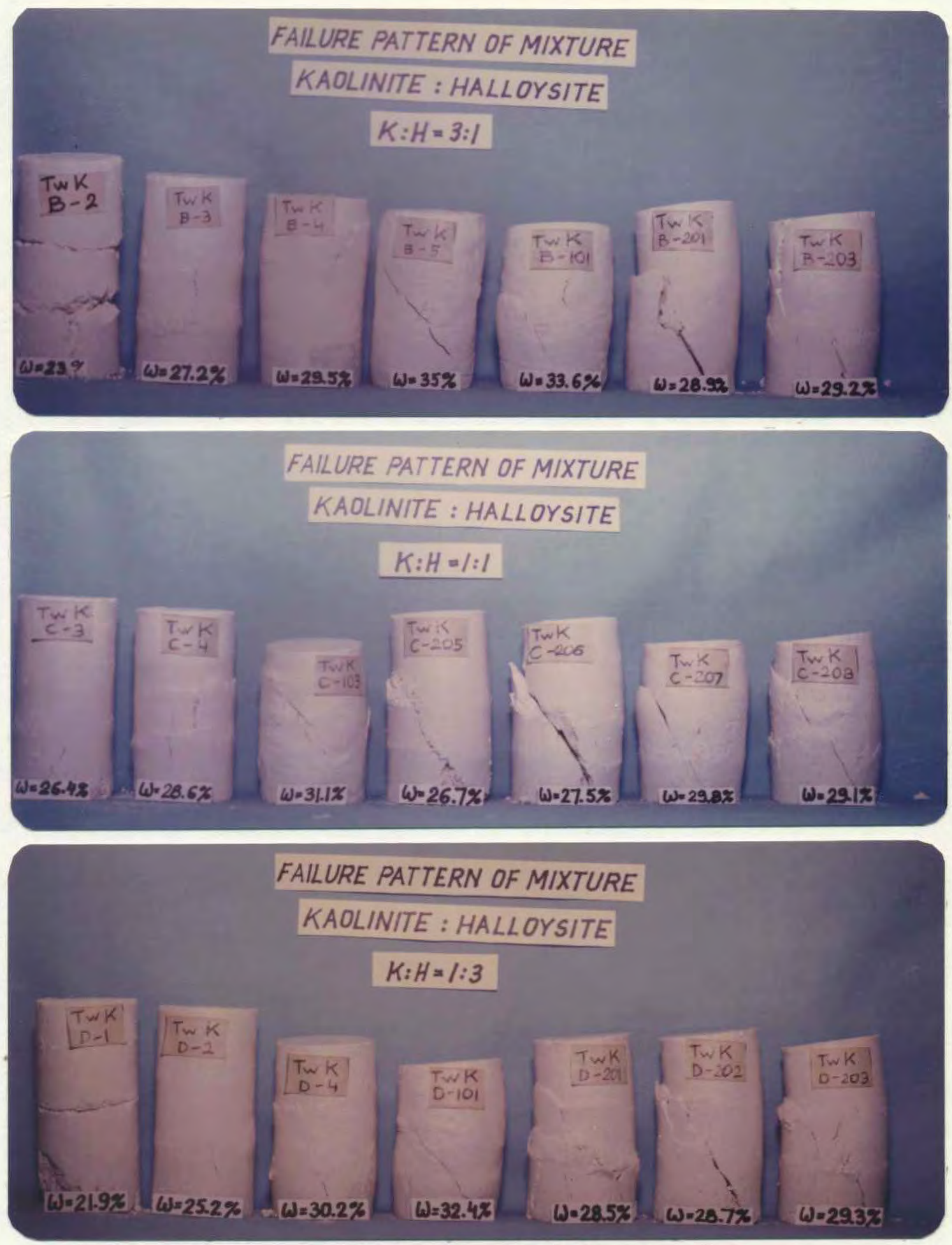

Figure 19. Failure pattern of synthetic mixtures TWK-B $(k: h=3: 1)$, TWK-C $(k: h=1: 1)$, and TWK-D $(k: h=1: 3)(\omega$ is the percentage water content). 


\section{FAILURE PATTERN OF SOIL CLAY}

$$
\text { W.P. }-2
$$

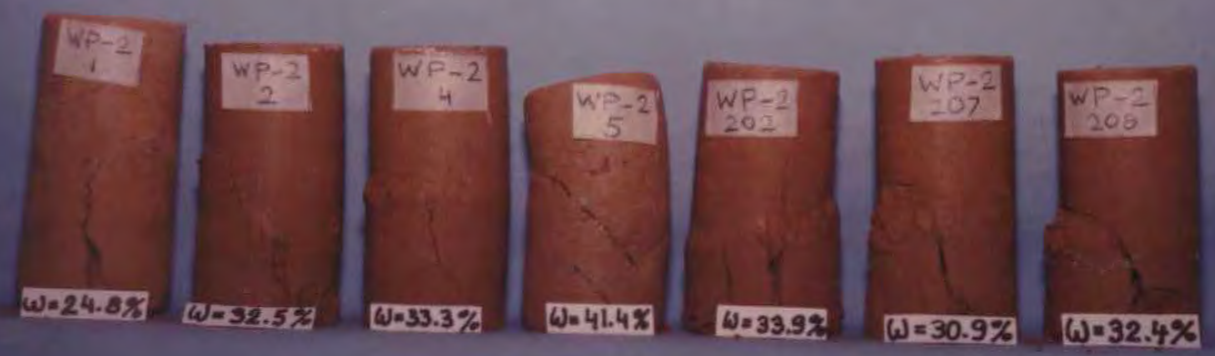

\section{FAILURE PATTERN OF SOIL CLAY}

$$
\text { OMSI-4 }
$$

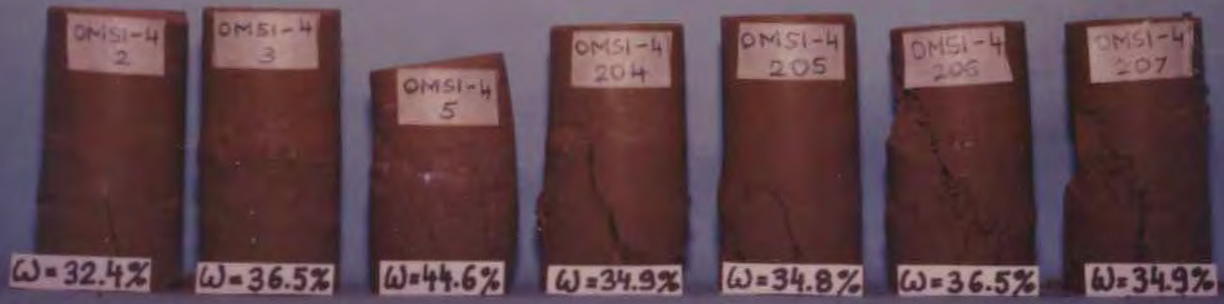

Figure 20. Failure pattern of soil clays: soil halloysite (WP-2) and soil mixture $k: h=1: 4$ $($ OMSI-4) ( $\omega$ is the percentage water content). 
place along the contact of the compacted layers by horizontal separation. The development of near-vertical fissures in the lowest of the compacted layers is also typical for this stage as shown by the kaolinite sample TWK A-4 in Figure 18. As the water content increases, bulging along the contacts of the compacted layers will take the place of the layer separation as in halloysite $\mathrm{H}-13 \mathrm{~A}-4$ in Figure 18. The development of fissures may extend into the other compacted layers (see Figure 19, TWK B-3 and Figure 20, WP-2, 1). These samples show near vertical, step-like, rugged failure surfaces along the fissures (Figure 18, H-13 A-2). Samples with near optimum moisture contents developed approximately 45 degree failure planes as in kaolinite samples TWK A-13, 204, and 205 in Figure 18. The failure planes are smooth and slickensided, and in some specimens, the alignment of mica flakes along the slip surfaces indicates the reorientation of particles parallel to the failure plane. Another indication for particle reorientation might be the development of the slashed or wavy lines seen on the charts of Figures $10 \mathrm{~A}$ and $11 \mathrm{~A}$. The same charts also suggest that "mini-failures" take place when hair-line cracks or fissures develop in the samples during the course of the testing.

Specimens with water content higher than their optimum values underwent considerable strain deformation with- 
out failure, developing barrel-like bulging along their sides. "V"-shaped "wrinkles" in these samples (Figure 19, TWK (-103) evolve into failure surfaces only after the 208 strain deformation has been attained. Sometimes multiple failure planes develop as in TWK-B 101 of Figure 19.

The representative stress-strain curves (Figures 12A and 13A) also indicate that clays compacted on the dry side of the optimum density behaved as brittle materials, displaying high strength with little strain deformations (Figures $12 \mathrm{~A}$ and $13 \mathrm{~A}$, samples $1,2,3,4)$ while samples compacted to the wet side of the optimum water content had a lower shear strength but underwent larger strain deformations before failure (Figure 12A, samples 6 and 101). This means that samples of a clay mineral such as 5 and 202 of Figure $2 \mathrm{~A}$ compacted to the same dry density but at a different water content will have different shear characteristics (Figure 13A, samples 5 and 202). Therefore, samples used for correlation were selected to represent optimum water content values within $\pm 1.5 \%$. These samples and their properties are listed in Table $V$. The average values of shear strengths and strain deformations with their margins of error are also listed in this table.

Correlations of the shear strengths of the clays were drawn in terms of strain, void ratio, and mineral content. The shear strength-strain relationship of halloysite, kao- 
linite, and synthetic mixtures might be represented best by a straight line (Figure 21) although all three of the synthetic mixtures indicate higher strain deformation at faillire than the strains of halloysite or kaolinite. Soil clay WP-2 has a slightly higher shear strength and is able to undergo larger strain deformation than soil clay OMSI-4, but neither of the soils could sustain deformations as great in magnitude as did kaolinite and halloysite minerals.

The relationship between the shear strength and void ratio of the clays is illustrated in Figure 22. Kaolinite has a denser structure and therefore a lower void ratio than halloysite. If a linear relationship exists between the pure minerals as drawn in Figure 22, only TWK-D ( $k: h=$ 1:3) of the synthetic mixtures would plot along this presumed line. The other mixtures, TWK-B, TWK-C, and the coarse kaolinite TWK-L are positioned below the line near the location of kaolinite TWK-A. The arrangement of the synthetic mixtures TWK-B $(k: h=3: l)$ and TWK-C $(k: h=l: l)$ and the coarse kaolinite below the hypothetical line was expected since they were all compacted to comparable optimum densities (Figure 17). The soil clays yield high void ratios implying that they have loose, flocculated type structures.

The effect of the halloysite content on the shear 


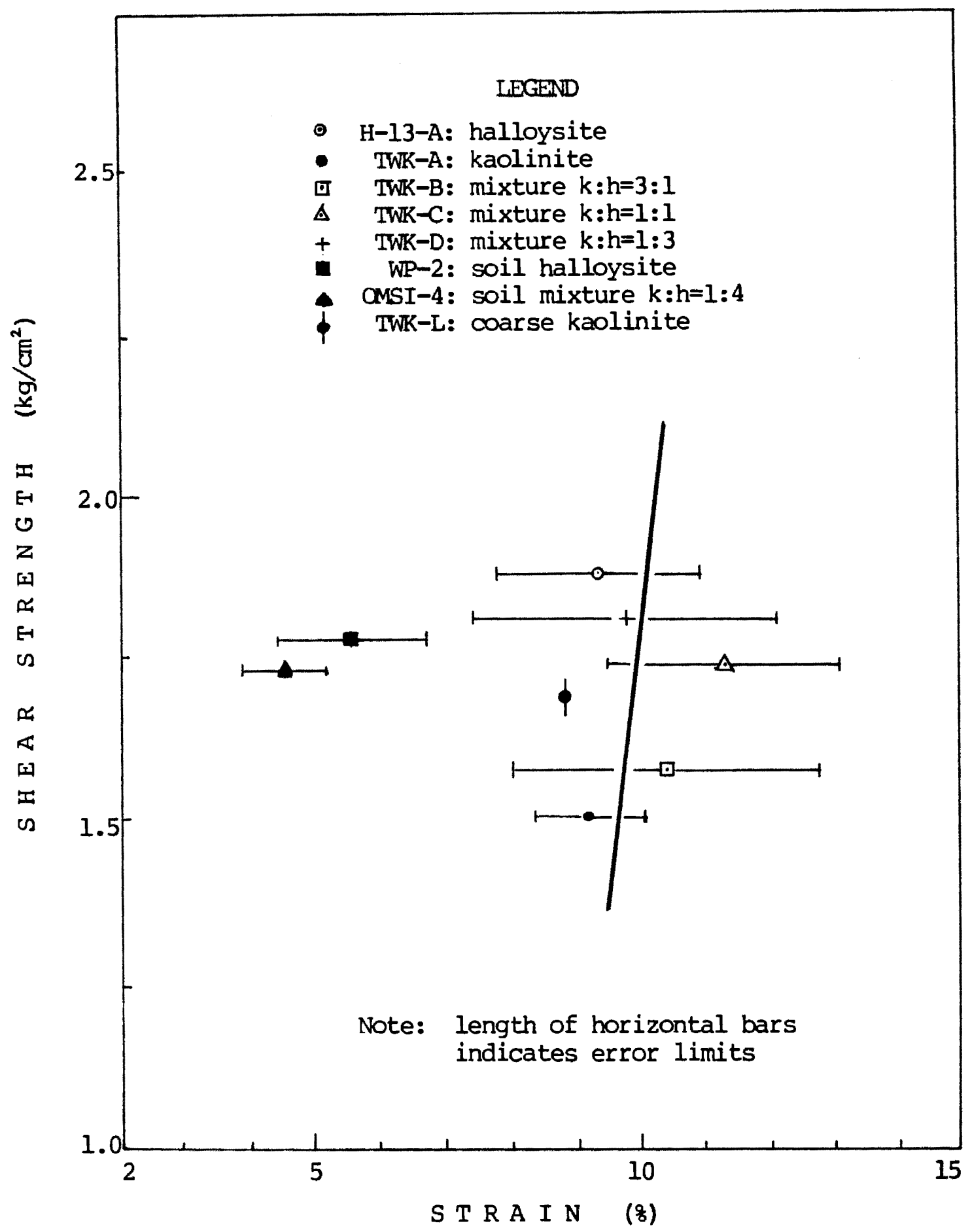

Figure 21. Relation between shear strength and strain of halloysite, kaolinite, synthetic mixtures, and soil clays. 


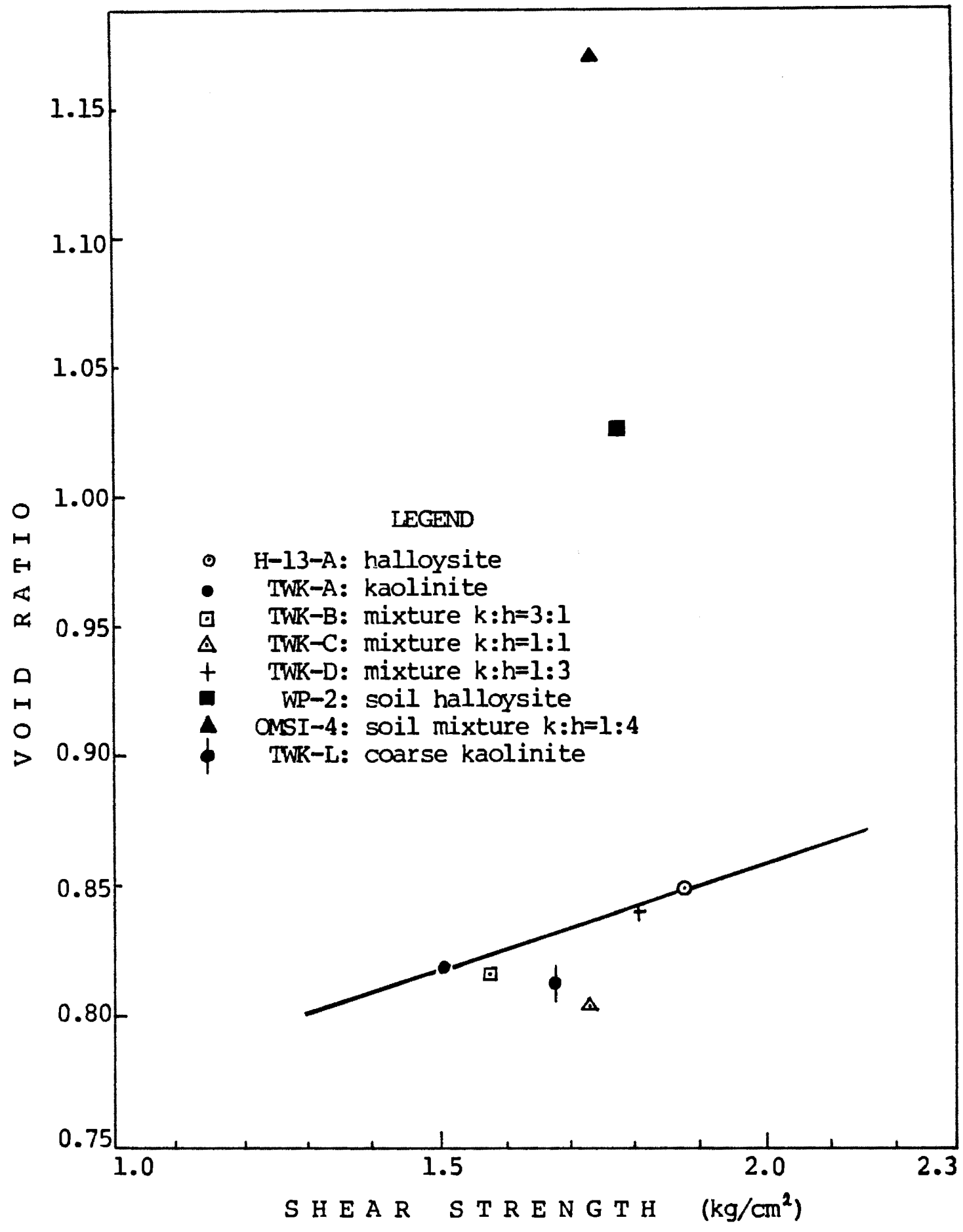

Figure 22. Relation between void ratio and shear strength of halloysite, kaolinite, synthetic mixtures, and soil clays. 
strength of kaolinite has been evaluated in Figure 23 . Shear strengths are plotted as ordinates and mineral contents as abscissae. The shear strengths represent the mean value of several failed specimens. The number of samples used for calculating the mean values are indicated by numbers next to the plotted points. The vertical lines with bars represent the margins of error while the error region is illustrated by the hatching on the graph. There is a direct relationship between the shear strength and mineral content of clays. Kaolinite has a low shear strength of $1.51 \mathrm{~kg} / \mathrm{cm}^{2}$. As the halloysite concentrations in the samples increase, the shear strengths will also increase, until the highest value of $1.88 \mathrm{~kg} / \mathrm{cm}^{2}$, which is the shear strength of the pure halloysite mineral, is reached. Soil halloysite, with its $1.78 \mathrm{~kg} / \mathrm{cm}^{2}$ shear strength, plots well within the error limit of halloysite H-13-A. Soil clay OMSI-4, the natural mixture of halloysite and kaolinite, also locates within the error region as shown in figure 23, and indicates a slightly reduced shear strength when compared to soil WP-2. The coarse grained kaolinite, TWK-L, has a higher strength than the finer TWK-A. This, however, was expected since those samples which were used for correlation (TWK L-2, 6, and 7) have been compacted on the dry side of the optimum water content (Figure 9A). Nevertheless, the shear strength of the coarse grained kaolinite still exists within the error limit of the fine grained ka- 


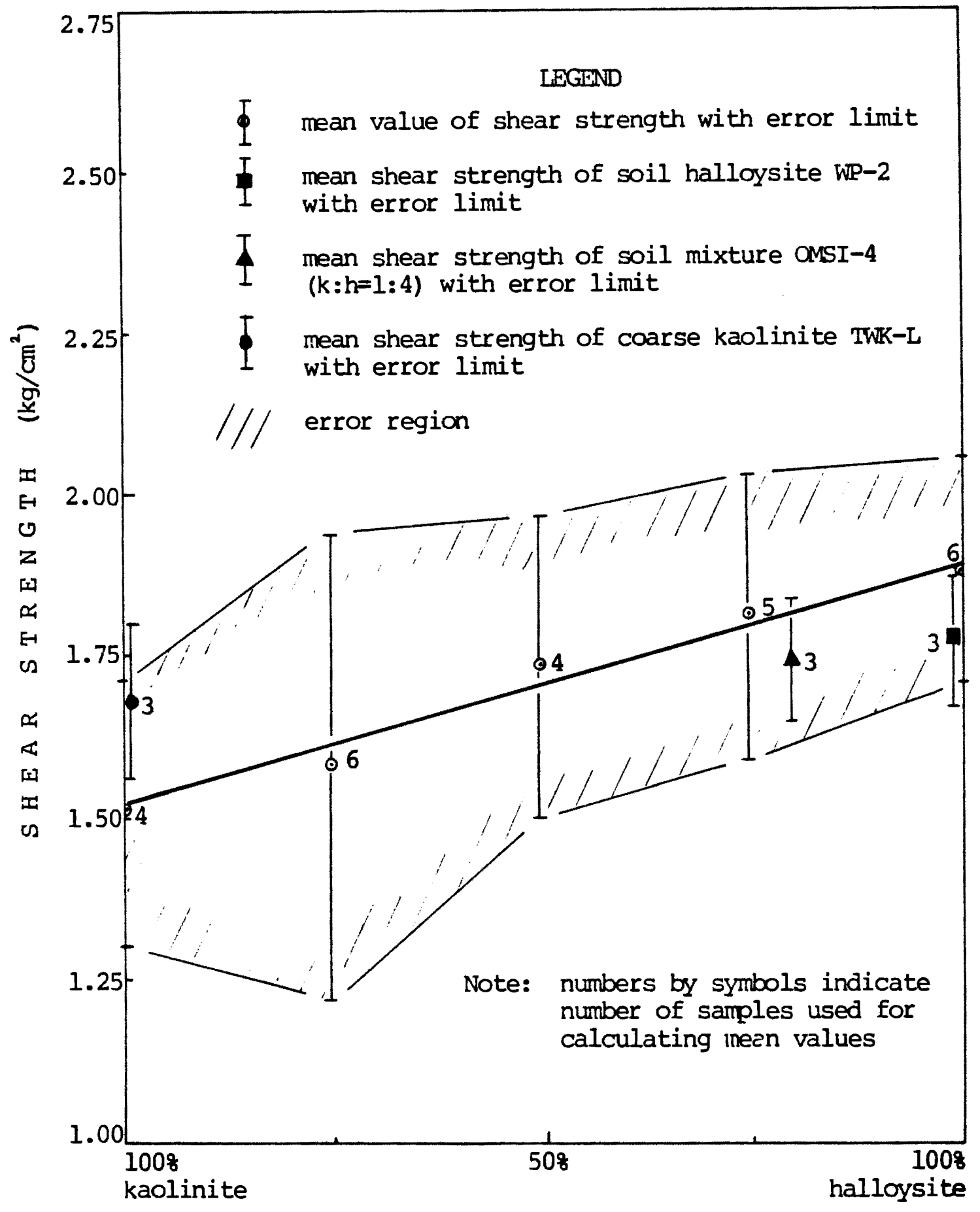

Figure 23. Relation between shear strength and mineral content at optimum moisture content. 
olinite. The insufficient data for the coarse grained halloysite and soil OMSI-2 does not warrant the use of these clays for correlation.

The possibility of using mineral composition as a strength indicator has been explored by applying statistical methods for data evaluation. The analysis of variance (Davis, 1973) indicates that, with the large variability within the same type of clays, the shear strength variation at the 58 level of significance is the same in the parent population of kaolinite, halloysite, synthetic mixtures, and soil minerals. The clays were compared by paired "t" tests to detect significant differences in their mean shear strength. The examination (see Table VIII in Appendix A) suggests that halloysite, synthetic mixture TWK-D ( $k: h=$ 1:3), and the soil clays differ significantly from kaolinite at the 908 level while the soil clays have the same mean shear strength as do the synthetic mixtures and halloysite.

The precision of instrumentation (the ability to repeat analyses with the same result) is listed in Table VI. The average precision of the shear strength is $\pm 11 \%$ while that for strain deformation is $\pm 16 \%$. Accuracy was not stressed in this study since the shear strengths of the clays relative to each other needed to be compared for correlation, not the absolute value of the strengths. 


\section{Atterberg Limits}

Table IV lists the specific gravities, clay contents of minerals and soils, and their Atterberg limits and index properties. The specific gravities had been determined prior to the limit testing. The specific gravity of kaolinite is 2.62 and that of halloysite is 2.58 . The specific gravity of the synthetic mixtures ranges between these end values. The specific gravity of the soil clays is higher than the specific gravity of either of the pure minerals. The high value of 2.91 for OMSI-4 probably reflects the high iron content of this soil.

The clay contents of the samples (Table IV) were obtained from the grain-size analysis curves of Figures 5 through 7 as the finer than 0.002 millimeter size fraction. The clay contents were used to compute the activities of the minerals and soils. Table IV indicates that the clays are inactive with activity less than 0.5 . The higher activity value of 0.9 for halloysite $\mathrm{H}-13-\mathrm{L}$ is due to the low clay size content of this mineral.

Table IV also indicates that the plastic and liquid limits of kaolinite are higher than those of halloysite. However, as can be seen in Figure 24, the synthetic mixtures did not attain an intermediate liquid limit value between the limits of their component minerals. TWK-C, the 1:1 mixture, has comparable limit values, as do the limits 


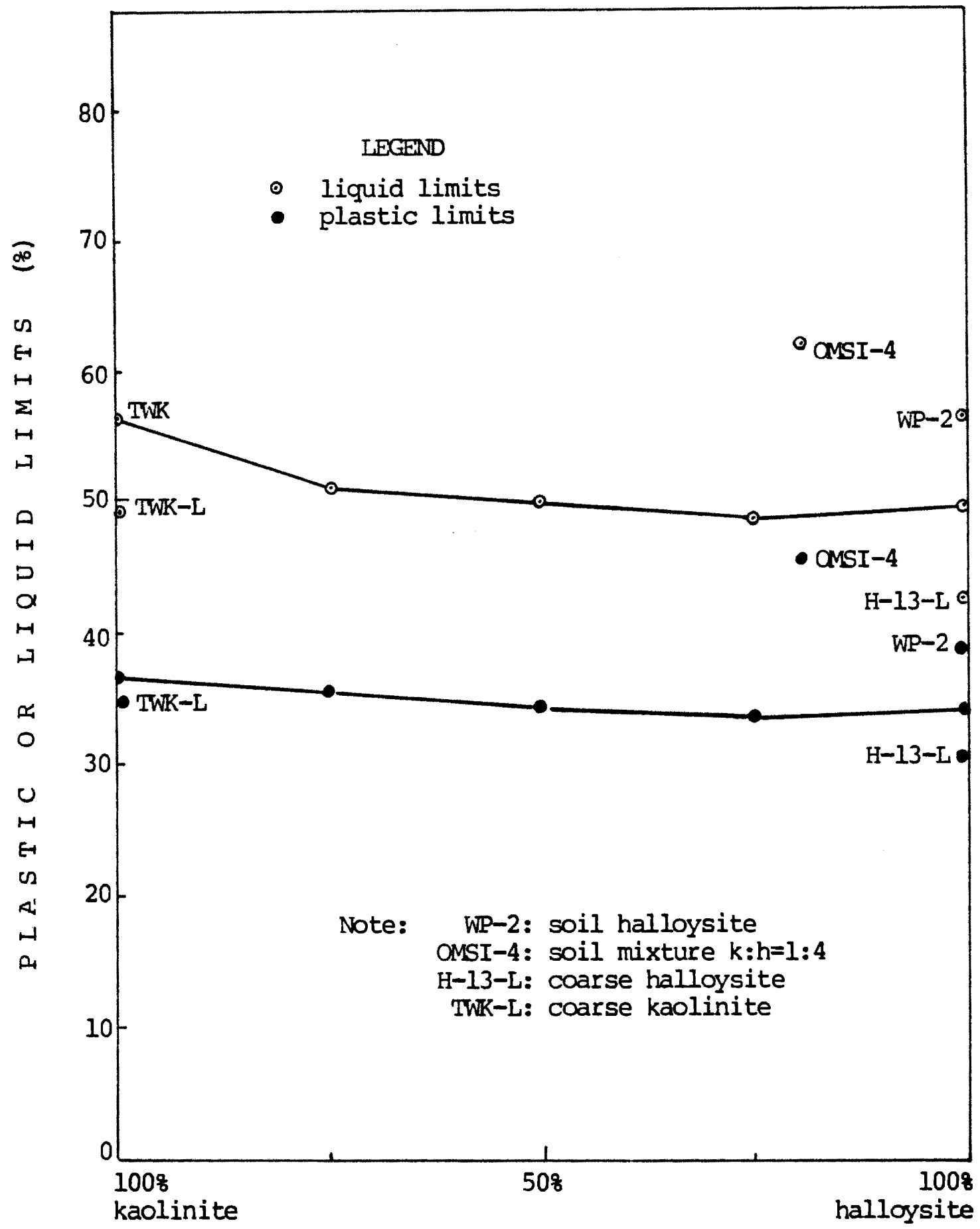

Fiqure 24. Relation between Atterberg limits and mineral content. 
of halloysite $\mathrm{H}-13-\mathrm{A}$, but the limits of TWK-B are slightly higher while those of TWK-D are slightly lower. According to Grim (1962), crystallinity and particle size control the liquid limit of the kaolin minerals. Poorly crystallized and finer kaolinites have higher liquid limits than their well-crystallized, coarser counter parts. Kaolinite TWK-A is well crystallized, but its particle size is finer than that of halloysite $\mathrm{H}-13-\mathrm{A}$. Therefore, the higher liquid limit of $56 \%$ is reasonable for kaolinite compared to the 49.58 limit value of halloysite. The behavior of the synthetic mixtures, in regard to their liquid limits, could not be explained. Nevertheless, it is possible that a similar event takes place within the mixture as suggested by Schofield and Samson (1954). Accordingly, the mutual edge-to-face attraction of a mineral can be superseded in a mixture of several minerals. The result is that the finer grains, with their negative surface charges, will coat the positive edges of larger crystals. It is conceivable that the adhering of the smaller particles to the larger ones will change the size of the fabric units or domain aggregations which might account for the liquid limit values of the synthetic mixtures (Table IV).

The limits of soil clay WP-2 are comparable to the limit values of kaolinite. OMSI-4 has the highest limit of the studied materials, and bears no relation to either the 
pure minerals or their synthetic mixtures (Figure 24). The high limit values of the soils are attributed to the presence of organic materials in these clays.

The relation between the plasticity index and liquid limit is illustrated in the plasticity chart (Figure 25). The minerals on this chart are related to the Casagrande "A" line. Generally, kaolinites locate close to the "A" line, while halloysites plot below it. Dumbleton and West (1966) report that kaolinite plots below the "A" line when it contains muscovite. It is possible, therefore, that kaolinite TWK-A owes its position on the plasticity chart to its mica impurity.

Based on the "Unified Soil Classification System" one of the more widely used classification methods - the plasticity chart indicates that the pure kaolinite in this study would be micaceous, silty soil. Soils WP-2 and OMSI-4 would be labelled as organic clays of medium to high plasticity. Halloysite H-13-A, synthetic mixtures and coarse-grained kaolinite TWK-L would be clayey silts with slight plasticity. Coarse-grained halloysite H-13-L would be classified as inorganic silt and fine sand. Based on grain size distribution, the MIT classification (Glossop and Skempton, 1945) classifies kaolinites TWK-A and TWK-L, halloysite $\mathrm{H}-13-\mathrm{A}$, synthetic mixtures, and soil WP-2 as silty clay, soil OMSI-4 as clayey silt, and halloysite 


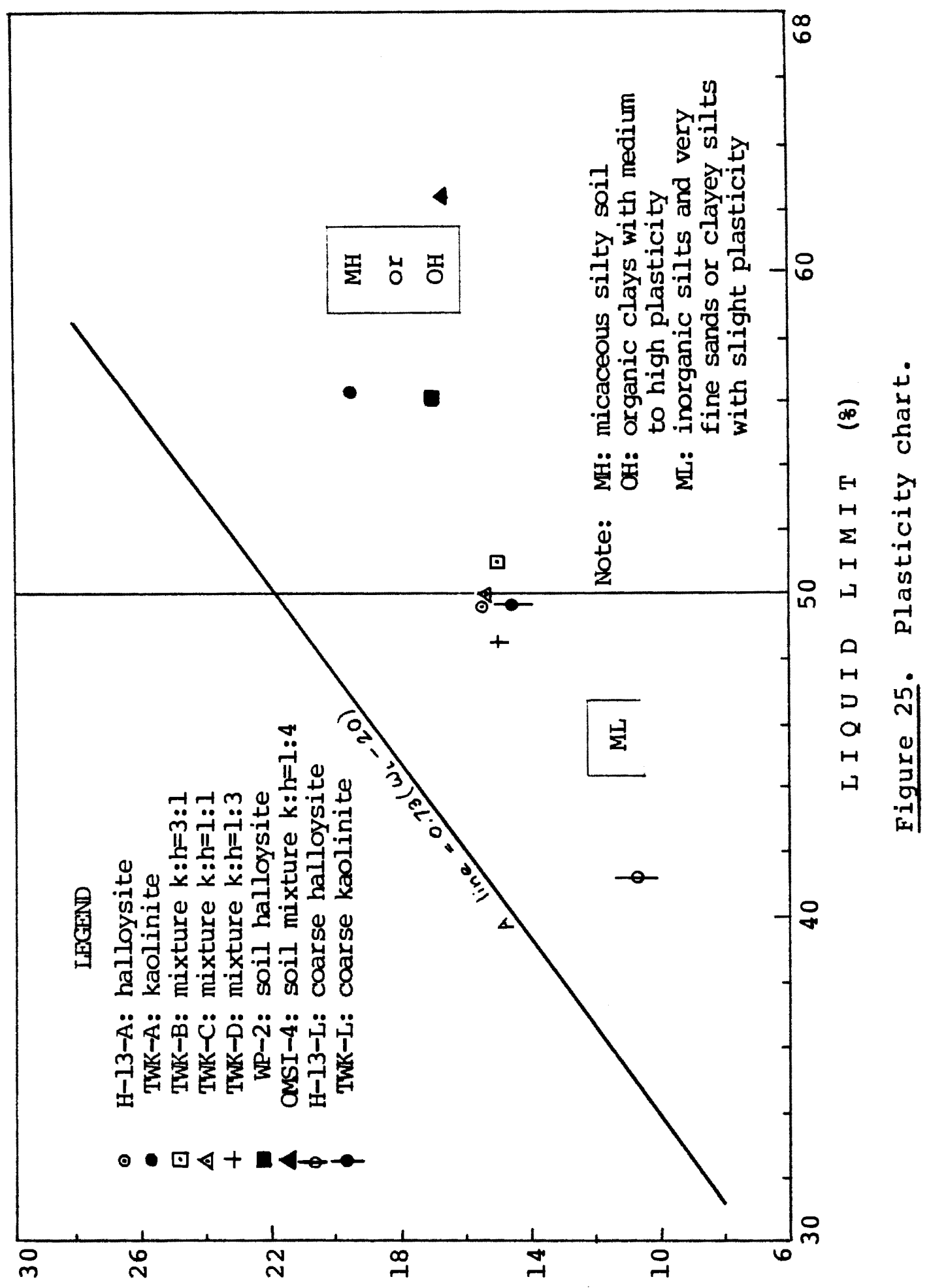

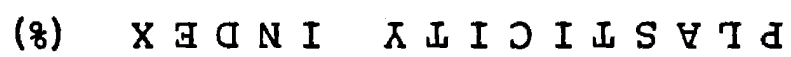


H-13-L as silty sand (see Figures 5 through 7 ). Since plasticity is a typical fine-grained soil property, the Unified Soil Classification System is prefered to the MIT classification for the fine-grained clays of this study.

The Atterberg limits and indices are used as indicators of engineering properties of clays. When the soils are compared at equal liquid limits, the one with higher plasticity index should have a higher dry strength. TWK-A and WP-2 are compared at liquid limits of $56 \%$ (Table VII). Kaolinite should have higher dry strength than the soil clay, but the dry strength of kaolinite is much lower. When soils at equal plasticity indices are compared, the one with the lowest flow index should have the highest shear strength; the synthetic mixtures, halloysite, and the coarse kaolinite, at a plasticity index of 15 , should have, in order of decreasing shear strengths: TWK-D, TWK-B, TWK-C, H-13-A, TWK-L. The actual order, however, is H-13-A, TWK-D, TWK-C, TWK-L, TWK-B. When soils at equal plasticity but different liquid limits are compared, the one with the higher liquid limit should have the higher dry strength. Consequently, clays with a plasticity index of 15 should have, in increasing order of dry strengths: TWK-D, H-13-A, TWK-L, TWK-C, TWK-B. TWK-L has the lowest dry strength, but the dry strength of the synthetic mixtures and the halloysite could not be differentiated. 


\section{CHAPTER VI \\ DISCUSSION AND CONCLUSION}

\section{DISCUSSION}

The results of the unconfined compression analysis indicate that the shear strength of halloysite is higher than that of kaolinite. If the difference is real, then it is contrary to what was anticipated at the onset of this project since the fully hydrated and dehydrated halloysites are expected to have very low compressive strengths (Grim, 1962). The possibilities are that the original hypothesis was inaccurate, or one of the tested minerals posessed peculiar properties resulting in unforseen behavior. In exploring the possibility that the hypothesis was erroneous, it should be kept in mind that halloysites have low compacted optimum dry densities and that clays compacted to a denser optimum state generally will attain a higher shear strength. Any model which is used to prove that dehydrated halloysites have higher shear strengths than kaolinites should address these problems. Compaction influences the particle orientation and spacings. The higher optimum dry densities of kaolinites could be either the result of a more oriented particle arrangement or the consequence of 
reduced interparticle sacings. In the case of compacted clays, particle space reduction results in the increase of contact pressure which results in the increase of shear strength. Therefore, to substantiate the lower shear strength of kaolinites, the particle orientation of compacted kaolins should be probed. It is conceivable that the rod-shaped particles of halloysite wili not compact to such an extent as the hexagonal plates of the kaolinite flakes (Lambe and Martin, 1955). Therefore, halloysite will form a less oriented, less dense, flocculated soil structure. Since more force is needed to slide one particle over another when the clay flakes are oriented in a random array instead of a more oriented parallel arrangement, the less dense, less oriented halloysite will have a higher shear strength. Comparing the average void ratio of $0.851 \pm 0.029$ for halloysite with the $0.823 \pm 0.004$ void ratio of kaolinite (Figure 22), halloysite might have a slightly looser, less oriented structure than kaolinite, thus yielding a slightly higher shear strength of $1.88 \pm 0.17 \mathrm{~kg} / \mathrm{cm}^{2}$ when compared to the $1.51 \pm 0.20 \mathrm{~kg} / \mathrm{cm}^{2}$ strength of kaolinite.

To investigate the possibility of the minerals exhibiting unusual physical or chemical properties would require further testings which are beyond the scope of this thesis. It is known that slightly acidic environments fa- 
vor the formation of kaolinite; therefore, low $\mathrm{pH}$ values are typical for kaolins. However, kaolinite of Twiggs County, Macon, Georgia, mined from the Birch Pit is unique because of its high $\mathrm{pH}$ value of 7 to 8 (Kerr and Kulp, 1949). Kaolinite with such a characteristic cannot be flocculated without chemical treatment and would yield dispersed soil structure with low shear strength. Since the $\mathrm{pH}$ of the clays was not determined and it is not known whether the kaolinite of this study originates from the Birch Pit or not, the interpretation of the low shear strength of kaolinite TWK-A as the result of the high $\mathrm{pH}$ of the clay remains only speculative. If the low shear strength of kaolinite TWK-A is unusual for kaolinite, then the shear strength of $1.74 \pm 0.009 \mathrm{~kg} / \mathrm{cm}^{2}$ for OMSI-4 is too low.

The possibility that minerals of the same mineralogical type but of different origins may vary in their chemical and physical properties should also be considered. Therefore, choosing a hydrothermal halloysite and a sedimentary kaolinite for the study now appears not to have been the best choice, but it was the only one that could be arranged.

\author{
CONCLUSION
}

Contrary to what was expected, the unconfined com- 
pression analysis on compacted clays indicate that halloysite \#13 from Utah has a higher shear strength than the Twiggs kaolinite. The shear strength of this halloysite is attributed to a flocculated type soil structure where the acting electrical forces are more attractive than those of kaolinite. The contribution of halloysite to the shear strength of kaolinite in a synthetic mixture is in direct proportion to the percentage of the halloysite. The shear strength of the soil clays correlate well with those of the pure minerals or synthetic mixtures. No relationship could be established between the shear strength and plasticity of the clays.

The use of mineral composition as the shear strength indicator of kaolins is not recomended; the statistical "t" test failed to indicate that the shear strengths of the synthetic mixtures differed significantly from each other at the $90 \%$ level, although the test revealed that the shear strength of halloysite is different from that of kaolinite.

The soil structure seems to play and important role in the shear strength development of clays. Soil structure is not a permanent feature; it may alter under the influence of changing environment. Therefore, the investigation of the nature of the soil-water system, the effects of pollutants and organic waste materials on the environment might yield beneficial information for the soils engineer. 


\section{LITERATURE CITED}

Alietti, Andrea, 1966, Identification of disordered kaolinites: Clay Miner., v. 6, p. 229-231.

Askenasy, P.E., Dixon, J.B., and McKee, T.R., 1973, Spheroidal halloysite in a Guatemalan soil: Soil Sci. Soc. Am. Proc., v. 37, p. 799-803.

Atterberg, A., 1911, On the investigation of the physical properties of soil and on the plasticity of clays: Int. Mitt. Bodenkd., v. $1, \mathrm{p} .10-43$.

Bates, T.F., Hildebrand, F.A., and Swineford, A., 1950, Morphology and structure of edellite and halloysite: Am. Miner., v. 35, p. 463-484.

Bishop, A.W., 1961, The measurement of pore pressure with the triaxial test: Proceedings, Conf. on Pore Pressure and Suction in Soils, p. 38-46.

Bolt, C.H., 1955, Analysis of the validity of the GouyChapman theory of the electric double layer: Journ. Colloid Sci. v. 10, p. 206-218.

Bowles, J.E., 1970, Engineering Properties of Soils and Their Measurements: New York, McGraw-Hill Book Co., $187 \mathrm{p}$.

Brindley, G.W., 1951, The crystal structure of some chamosite minerals: Miner. Mag., v. 29, p. 502-525.

Brindley, G.W., 1961, Kaolin, serpentine, and kindred minerals, in Brown, G., ed., The X-ray Identification and Crystal Structure of Clay Minerals, chapter 2: London, Miner. Soc., p. 51-131.

Brindley, G.W., and Goodyear, J., 1948, X-ray studies of halloysite and meta-halloysite, II. The transition of halloysite to meat-halloysite in relation to relative humidity: Miner. Mag., v. 28, p. 203-215.

Brindley, G.W., and Robison, K., 1.946, The structure of kaolinite: Miner. Mag., v. 27, p. 242-253. 
Casagrande, Arthur, 1932, Research on the Atterberg limits of soils: Public Roads, v. 13, n. 8, p. 121-136.

Casagrande, Arthur, 1948, Classification and identification of soils: Trans. Am. Soc. Civil Eng., v. 113, p. 901992.

Chukrov, F.V. and zvyagin, B.B., 1966, Halloysite, a crystallochemically and mineralogically distinct species: Int. Clay Conf. Proc. (Jerusalem), v. 1, p. 11-25.

Dames and Moore Consultants, 1975, Subsurface investigation and earth deformation installation, landslide adjacent to Reservoirs No. 3 and No. 4, Portland, Oregon: Report 2110-037-04 for the City of Portland, 4lp.

Davis, J.C., 1973, Statistics and Data Analysis in Geology: New York, John Wiley and Sons, Inc., 550p.

Dumbleton, M.J. and West, G., 1966, Some factors affecting the relation between the clay mineral in soils and their plasticity: Clay Miner., v. 6, p. 179-193.

Enlows, H.E., 1970, Cleaning clay samples prior to X-ray analysis: unpublished report, Ore. State Univ. Dept. of Geology, $4 p$.

Evans, R.C., 1964, An Introduction tc Crystal Chemistry: Cambridge, University Press, 4lop.

Gast, R.G., 1977, Surface and colloid chemistry, in Dixon, J.B. and Weed, S.B., eds., Minerals in Soil Environments, chapter 2: Madison Wisc., Soil Sci. Soc. Am., p. 27-73.

Glossop, R. and Skempton, A.W., 1945, Particle size in silts and sands: Journ. Inst. Civil Eng., London, paper 5492, p. 81-105.

Grim, R.E., 1953, Clay Mineralogy: New York, McGraw-Hill Book Co., $384 \mathrm{p}$.

Grim, R.E., 1962, Applied Clay Mineralogy: New York, McGraw-Hill Book Co., 422p.

Gruner, J.W., 1932, The crystal structure of kaolinite: zeit. Krist., v. 83, p. 75-88. 
Hendricks, S.B. and Jefferson, M.E., 1938, Structure of kaolin and tak-prophyllite hydrates and their bearing on water sorption of clays: Am. Miner., v. 23, p. 863-879.

Hope, E.W. and Kittrick, J.A., 1964, Surface tension and the morphology of halloysite: Am. Miner., v. 49, p. 859-866.

Ingles, O.C., 1968, Soil chemistry relevant to engineering behavior of soils, in Lee, I.K., ed., Soil Mechanics, Selected Topics, chapter 1: London, Butterworths, p. $1-34$.

Jackson, M.L. and Abdel-Kader, F.H., 1978, Kaolinite intercalation procedure for all sizes and types with X-ray diffraction spacing distinctive from other phyllosilicates: Clays, Clay Miner., v. 26, p. 81-87.

Keller, W.D. and Haenni, R.P., 1978, Effects of microsized mixtures of kaolin minerals on properties of kaolinites: Clays, Clay Miner., v. 26, p. 384-394.

Kenney, T.C., 1967, The influence of mineral composition on the residual strength of natural soils: Proceedings, Geotech. Conf., v. 1, p. 123-129.

Kerr, P.F. and Kulp, J.L., 1949, Reference clay localities, United States in Reference Clay Minerals, American Petroleum Institute Research Project 49, preliminary Report No. 2: New York, Columbia Univ., 13lp.

Kruyt, H.R., 1952, Colloid Science, I, Irreversible Systems: New York, Elsevier Publishing Co., 195p.

Kunze, G.W. and Bradley, W.F., 1964, Occurrence of a tabular halloysite in a Texas soil: Clays, Clay Miner., v. 12, p. 523-527.

Lambe, T.W., 1951, Soil Testing for Engineers: New York, John Wiley and Sons, Inc., 165p.

Lambe, T.W., 1958a, The structure of compacted clay: Journ. Soil Mech. and Found. Div., Proc. Am. Soc. Civil Eng., v. 84, SM2, proc. paper $1654,34 \mathrm{p}$.

Lambe, T.W., 1958b, The engineering behavior of compacted clays: Journ. of the Soil Mech. and Found. Div., Proc. Am. Soc. Civil Eng., v. 84, SM2, proc. paper $1655,35 p$. 
Lambe, T.W. and Martin, R.T., 1955, Composition and engineering properties of soils, III: Proc. U.S. Highway Research Board, v. 34, p. 566-582.

Lambe, T.W. and Whitman, R.V., 1979, Soil Mechanics, SI Version: New York, John Wiley and Sons, 553p.

Lee. S.Y., Jackson, M.L. and Brown, J.L., 1975, Micaceous occlusions in kaolinite observed by ultramicrotomy and high resolution electron microscopy: Clays, Clay Miner., v. 23, p. 125-129.

McRae, J.L. and Turnbull, W.J., 1963, Effective stress theory of soil compaction: Discuss. Journ. Soil Mech. and Found. Div., Proc. Am. Soc. Civil Eng., v. 89, p. 101-108.

Newnham, R.E., 1961, A refinement on the dickite structure and some remarks on polymorphism in kaclin minerals: Miner. Mag., v. 32, p. 638-704.

Olson, R.E., 1963, Effective stress theory of soil compaction: Journ. Soil Mech. and Found. Div., Proc. Am. Soc. Civil Eng., v. 89, p. 27-45.

Pauling, L.C., 1930, The structure of the chlorites: Proc. Natl. Acad. Sci. U.S., v. 16, p. 578-582.

Pauling, L.C., 1967, The Chemical Bond; A Brief Introduction to Modern Structural Chemistry: Ithaca, N.Y. Cornell Univ. Press., 267p.

Schofield, R.K. and Samson, H.R., 1953, The deflocculation of kaolinite suspensions and the accompanying changeover from positive to negative chloride adsorption: Clay Miner. Bull., v. 2, p. 45-5l.

Schofield, R.K. and Samson, H.R., 1954, Flocculation of kaolinite due to the attraction of oppositely charged crystal faces: Discuss. Faraday Soc., v. 18, p. 135145 .

Shannon and Wilson Inc., Coinsultants, 1969, Final Report, OMSI-ZOo Landslide Investigation, Portland, Oregon: Report to Oregon State Highway Dept., Salem, Ore. and Bureau of Parks, Portland, Ore., Job no. 0-406, 34p.

Skempton, A.W., 1953, The colloidal activity of clays: Proc. 3rd. Int. Conf. Soil Mech. and Found. Eng., v. 1, p. 57-61. 
de Souza Santos, P., de Souza Santos, H., and Brindley, G.W., 1966, Mineralogical studies of kaolinite-halloysite clays: Part IV. A platy mineral with structure swelling and shrinkage characteristics: Am. Miner., v. 51, p. 1640-1648.

Stern, 0., 1924, zur theorie der elecktrolytischen doppelschict: Z. Electrochem., v. 30, p. 508-516.

Sudo, T., and Takahashi, H., 1956, Shape of halloysite particles in Japanese clays: Clays, Clay Miner., $v$. 4 , p. 67-79.

Taylor, A.W., 1959, Physico-chemical properties of soils: ion exchange phenomena: Journ. Soil Mech. and Found. Div. Proc. Am. Soc. Civil Eng., v. 85, SM2, p. 19-29.

Tazaki, Kazu, 1978, Micromorphology of halloysite produced by weathering of plagioclase in volcanic ash, in Mortland, M.M. and Farmer, V.C., eds., Developments in Sedimentology 27: Proc. VI Int. Clay Conf. Oxford, p. 415-422.

Terzaghi, Karl, 1936, The shearing resistarce of saturated soil: Proc., Int. Conf. Scil Mech. and Found. Eng.s Harvard Univ., Cambridge, Mass., v. 1, p. 54-56.

Trimble, D.E., 1963, Geology of Portland, Oregon and Adjacent Areas: U.S. Geological Survey Bull. 1l19, 1l9p.

Wada, K., 1961, Lattice expansion of kaolin minerals by potassium acetate treatment: Am. Miner., v. 46, p. 7891 .

Warkentin, B.P. and Yong, R.N., 1962, Shear strength of montmorillonite and kaolinite related to inter-particle forces: Clays, Clay Miner., v. 9, p. 210-218.

Wieckowski, T. and Wiewiora, A., 1976, New approach to the problem of interlayer bonding in kaolinite: Clays, Clay Miner., v. 24, p. 219-223.

Wiewiora, A. and Brindley, G.W., 1969, Potassium acetate inter-calation in kaolinite and its removal; effect of material characteristics: Proc. Int. Clay Conf., Tokyo, v. 1, p. 723-733. 
APPENDIX A

TABLES 


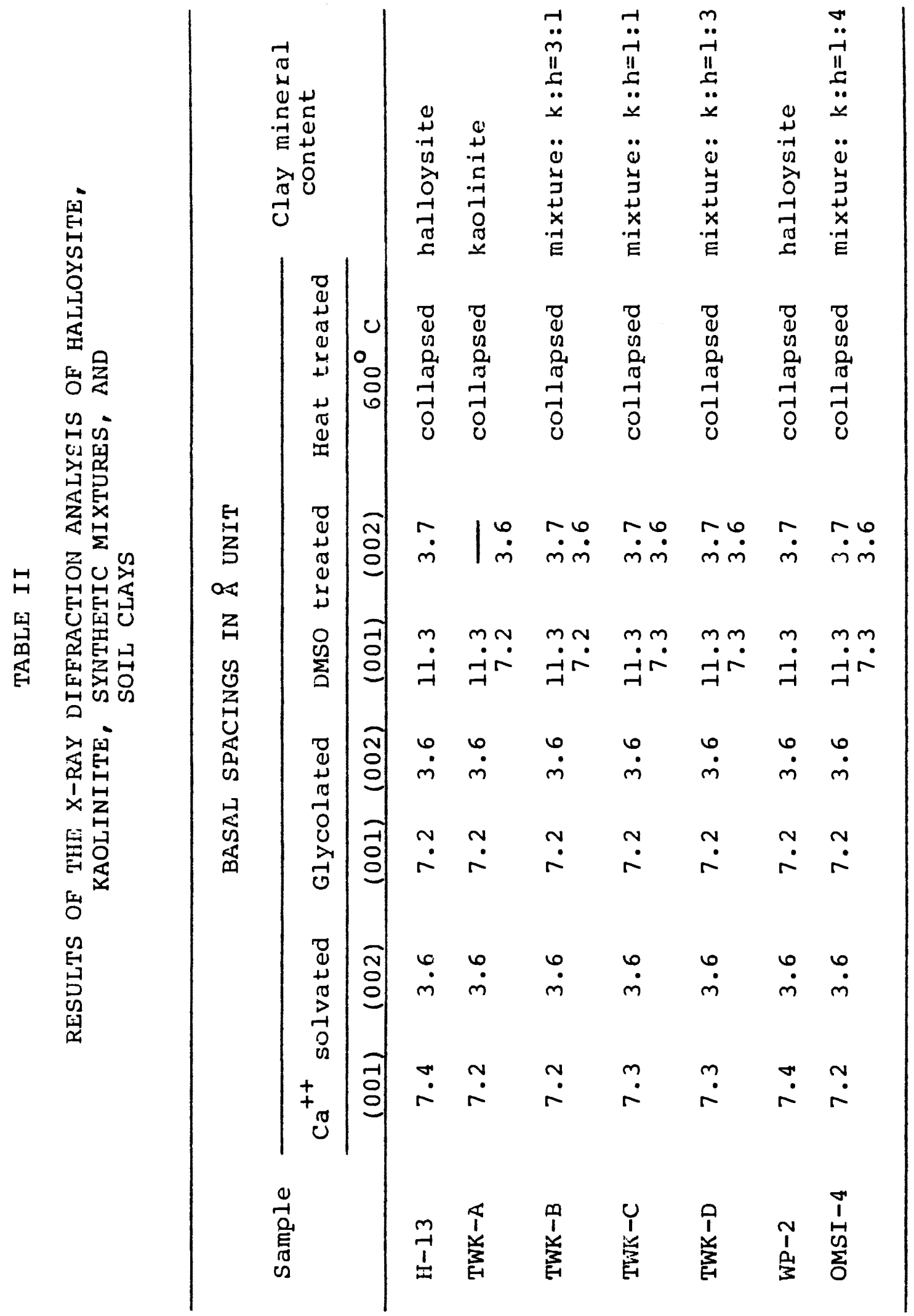




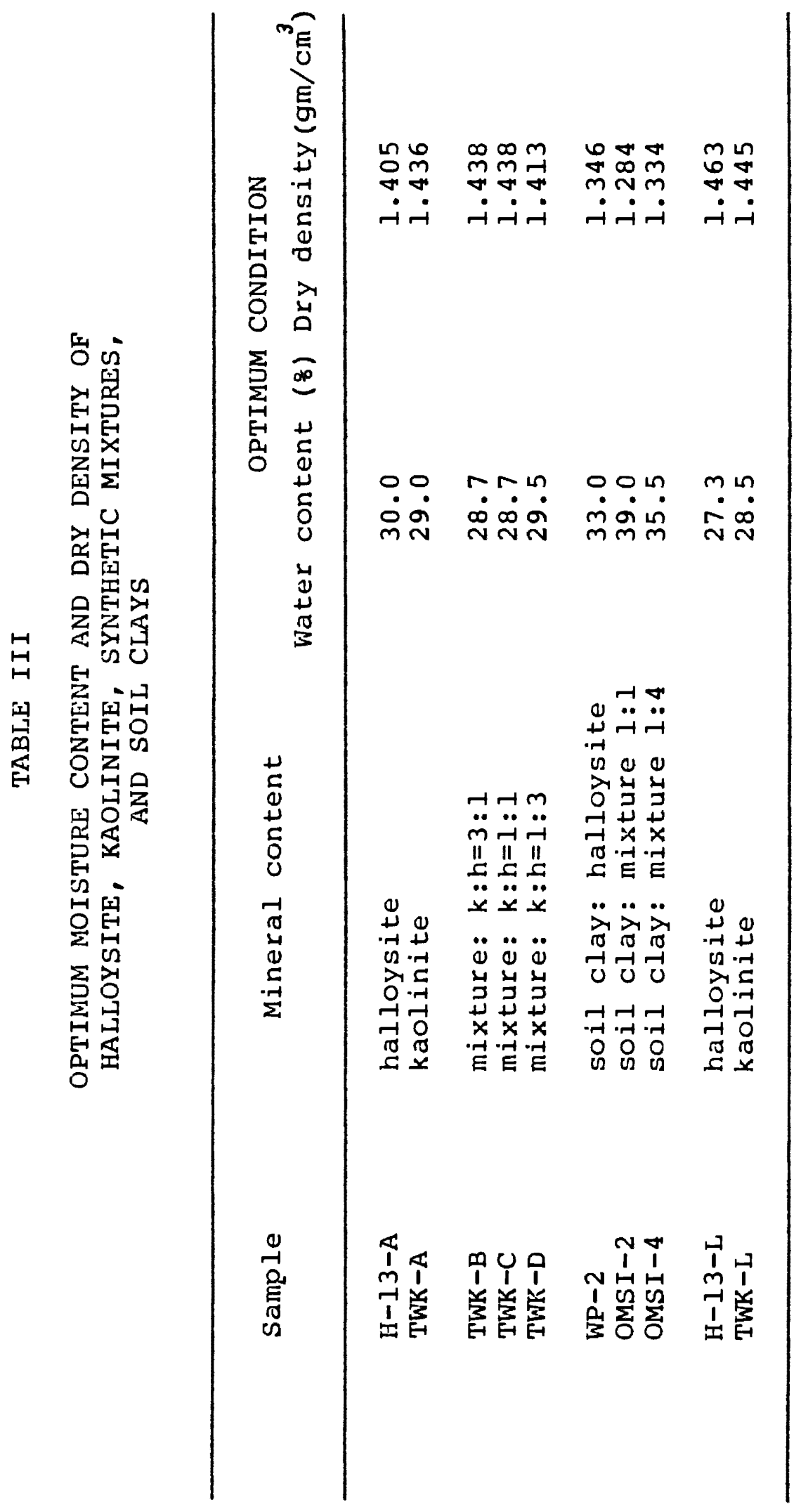




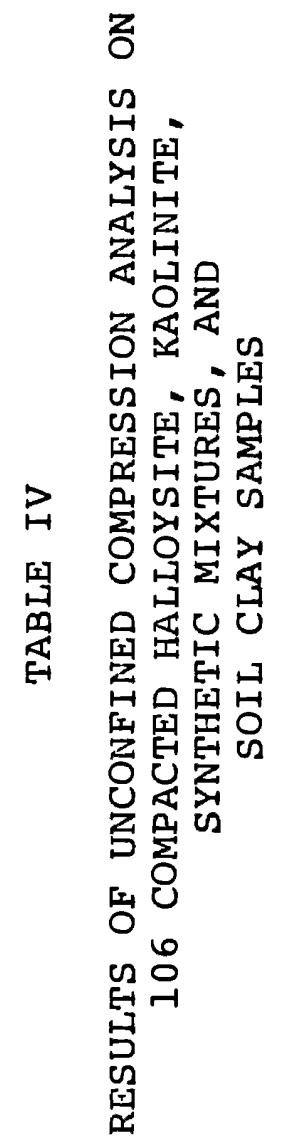

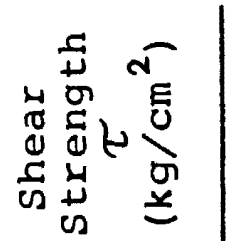

N n

Hम

ก

:.

00 H

N

Ho

i

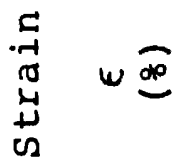

$\underset{\substack{0 \\ 0}}{0} \underset{\pi}{0}$

$\gg \pi$

ริ

$+$

$\cos$

光

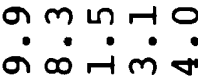

मr.

$m \rightarrow n \pi \sigma$

on a $\infty$ o
ت.

$a \infty N m$ ?

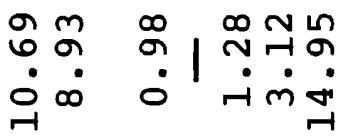

no $\quad 00 \infty \mathrm{mm}$ $m N \quad-6 N m m$ $\infty \infty 00 \infty \infty$ ம் $\dot{0} \dot{1} \dot{0} \dot{0}$ बa एं

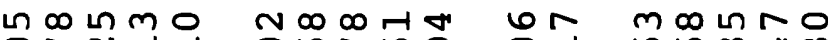

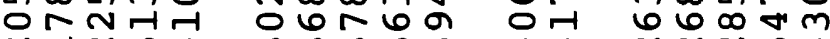

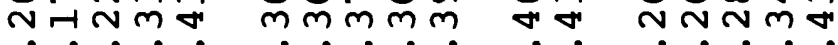

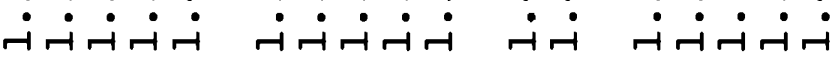

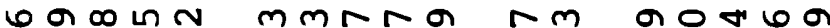

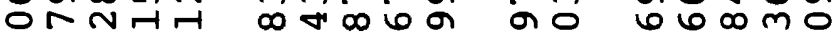
NHNM

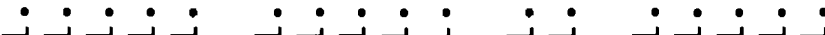
$>\stackrel{4}{0}$ O 내

口 9

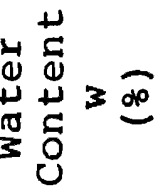
告
ก) ก ก ก ? a NNRO nmana $m m \sim N N$

in

N $\mathrm{N} N m \boldsymbol{n}$

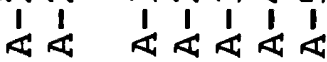
营 N $N N N m$ 


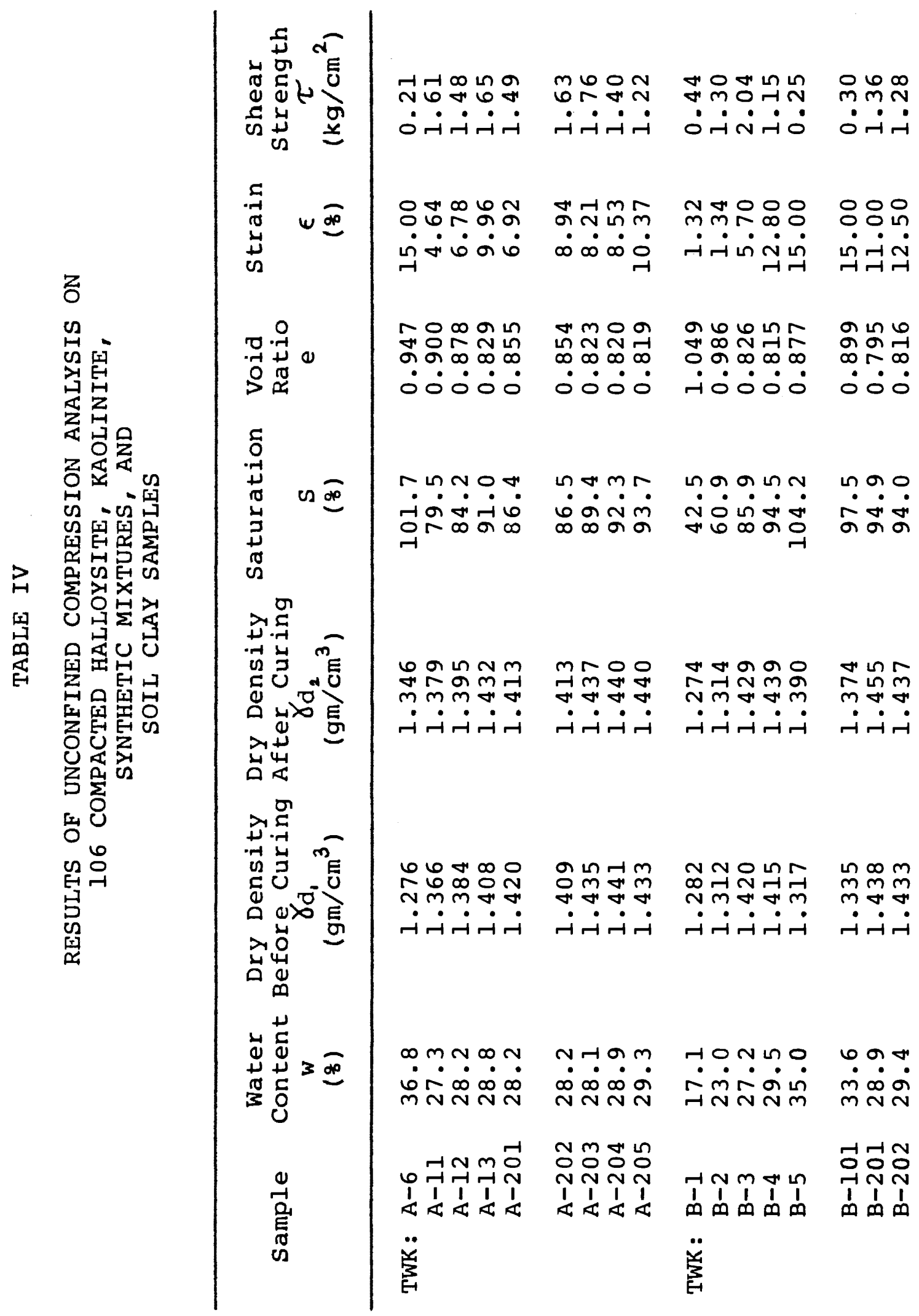




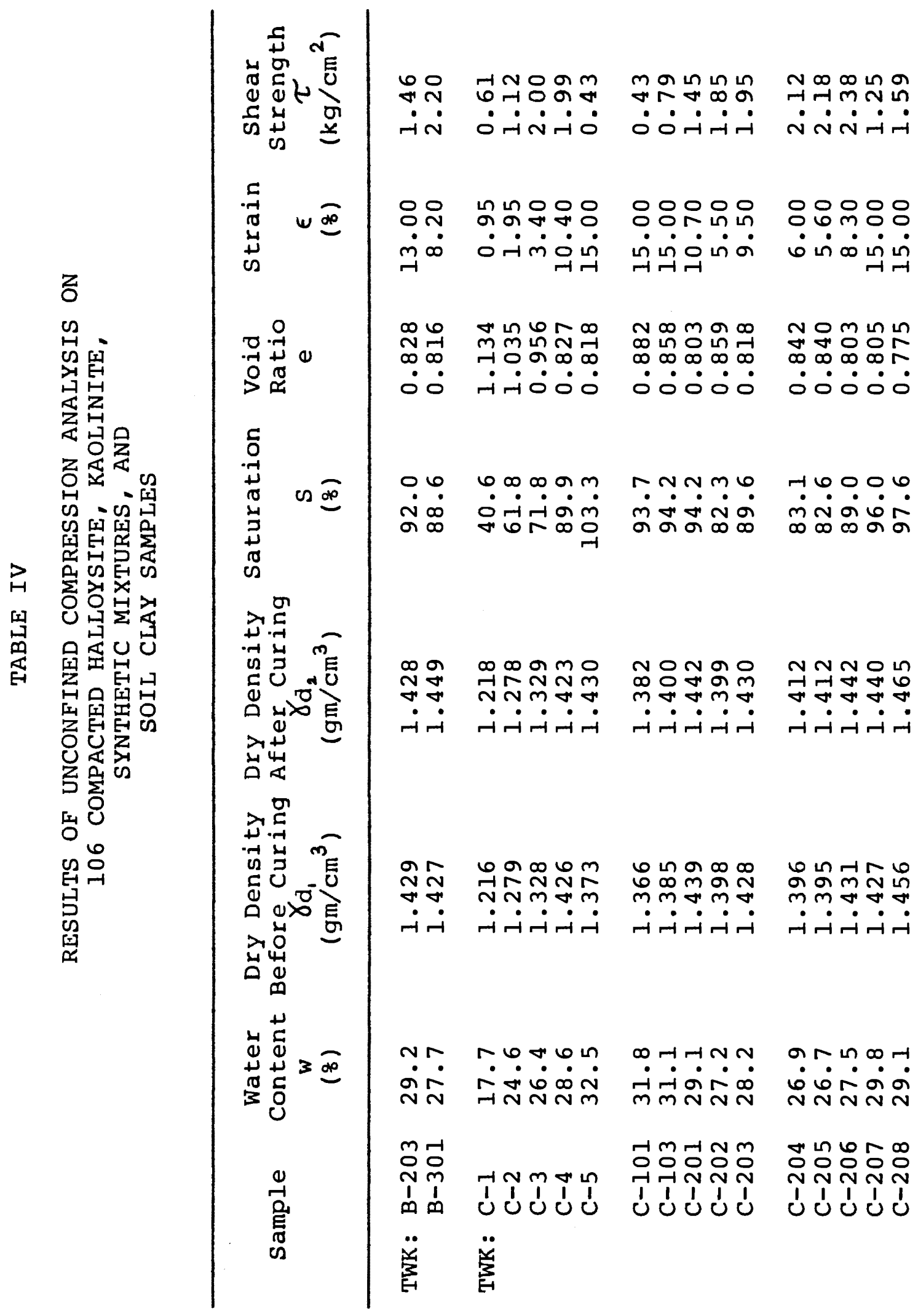




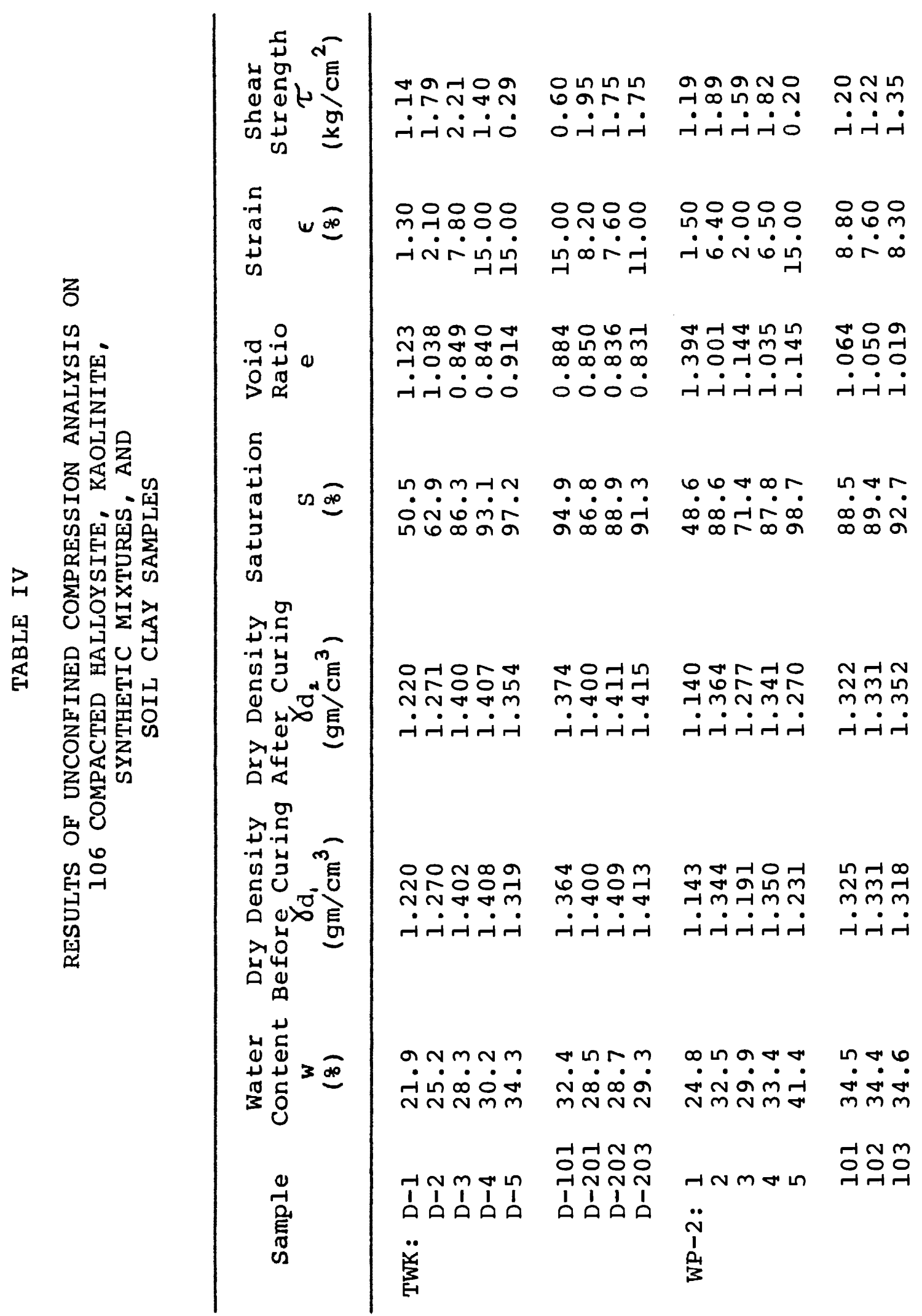




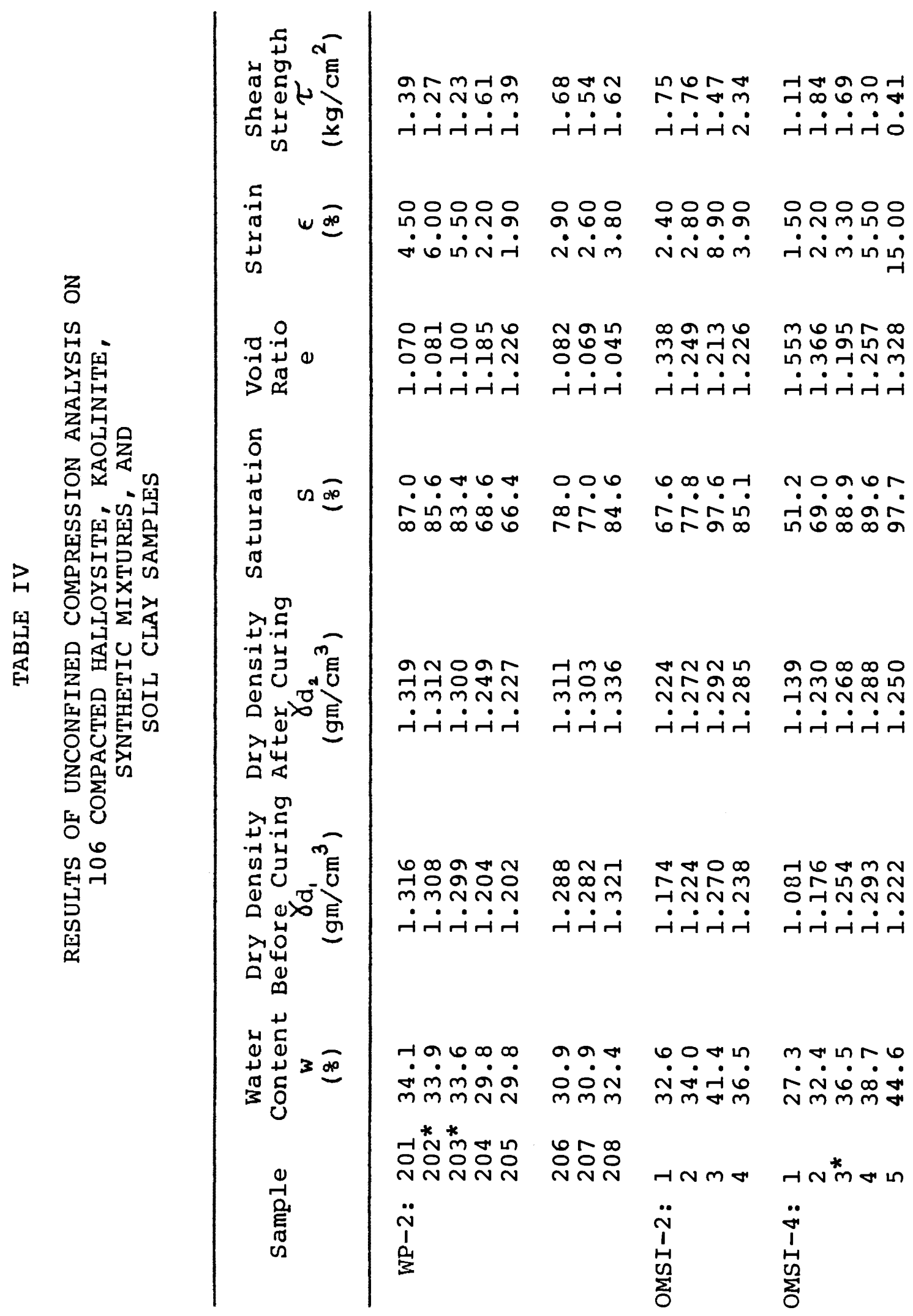




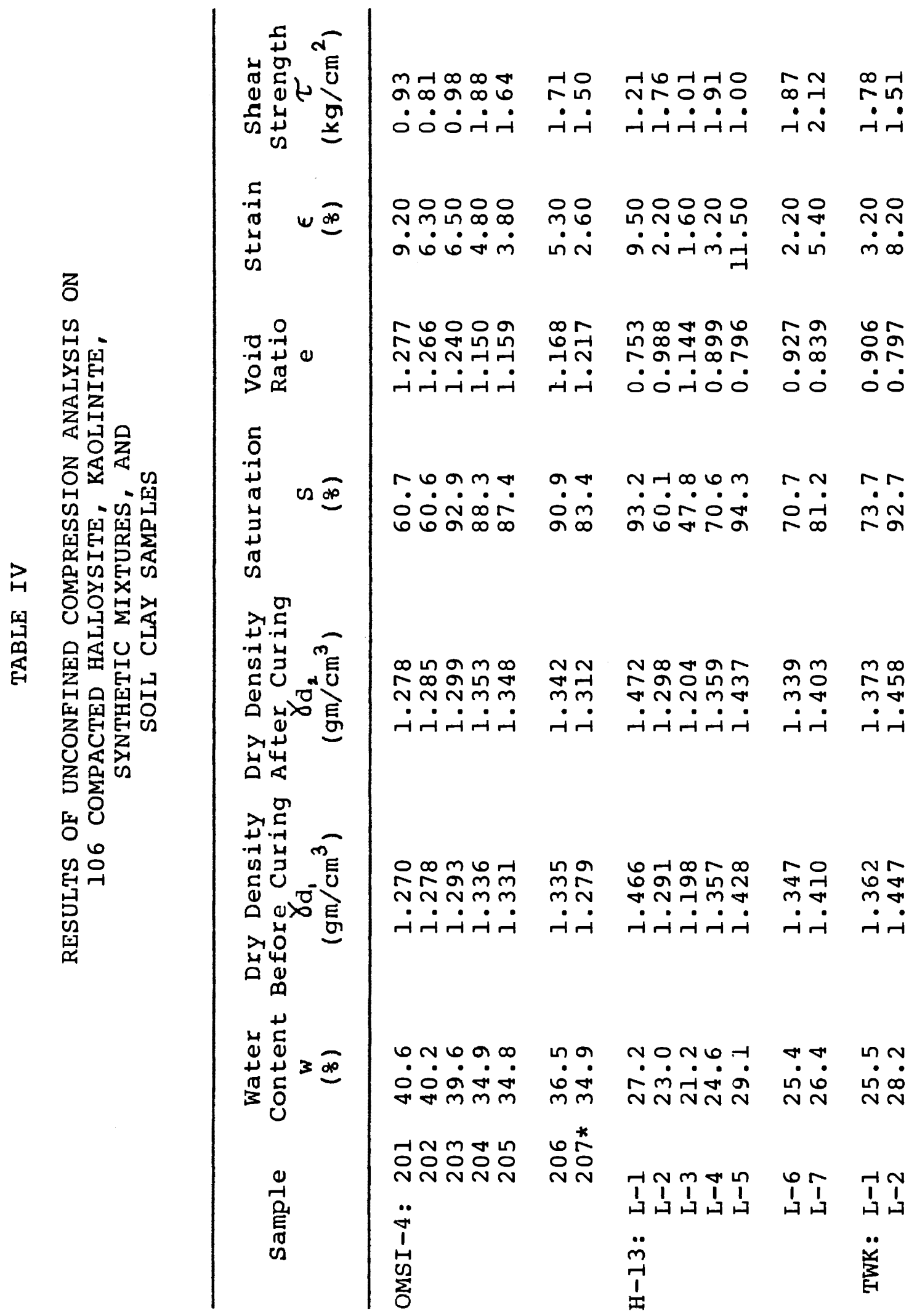




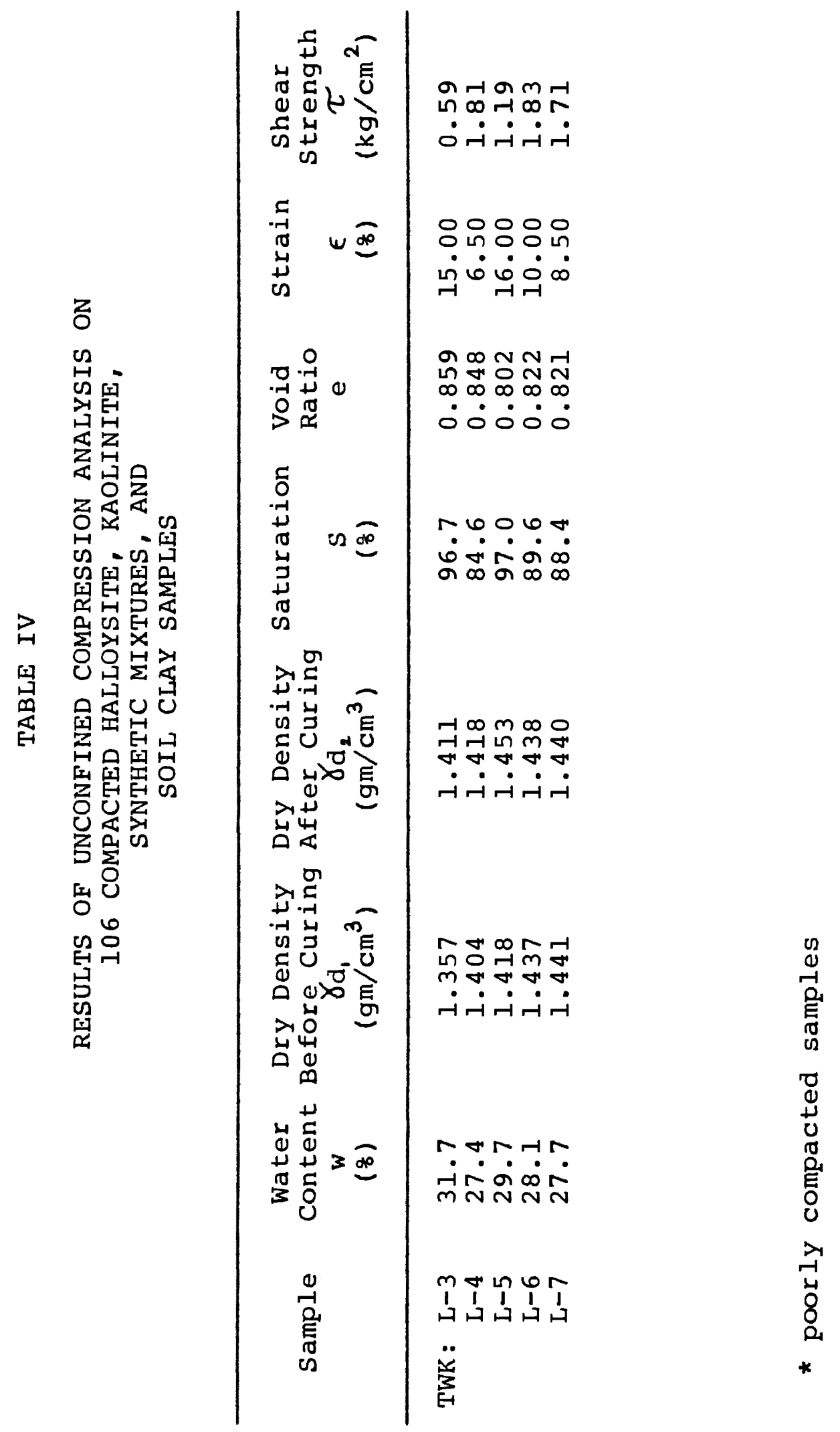




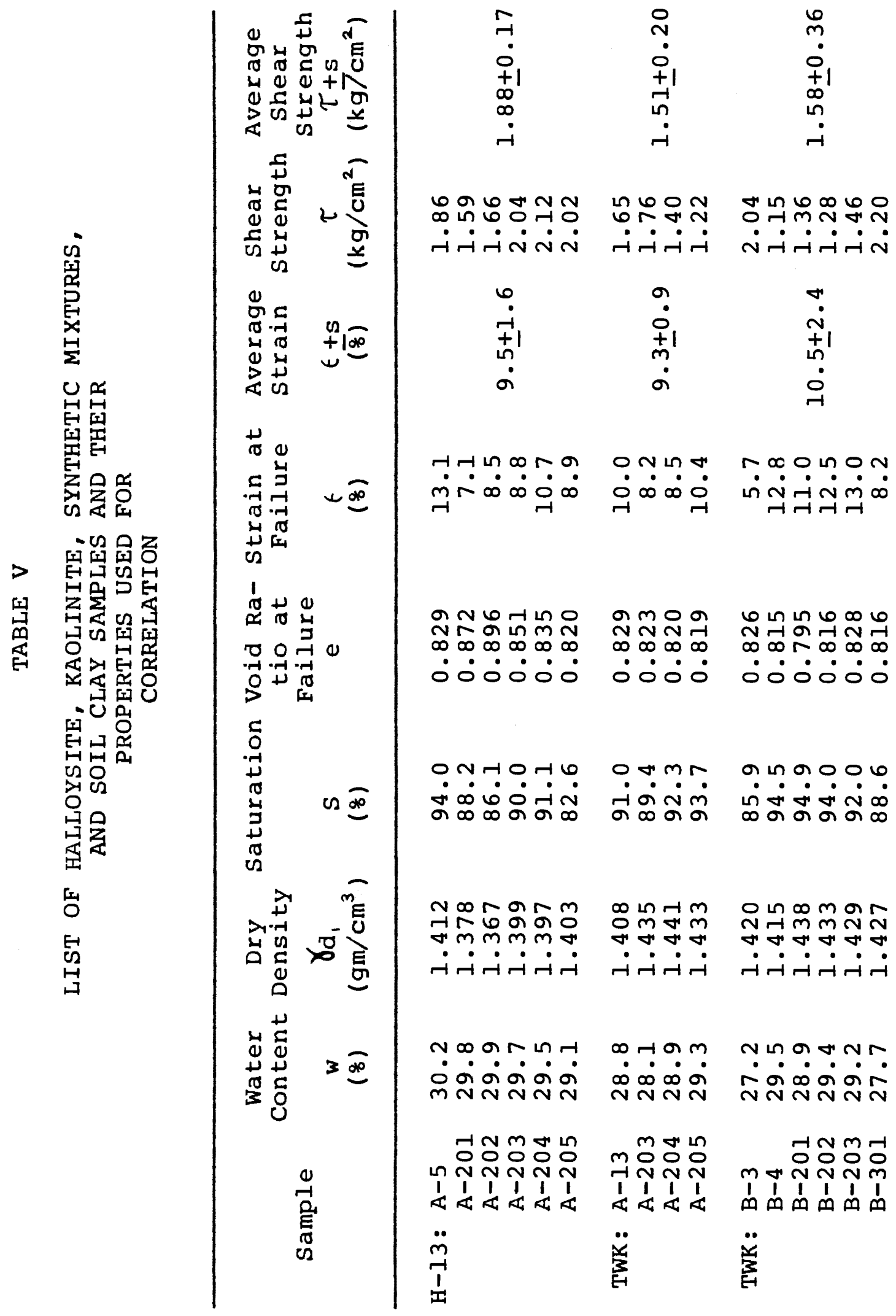



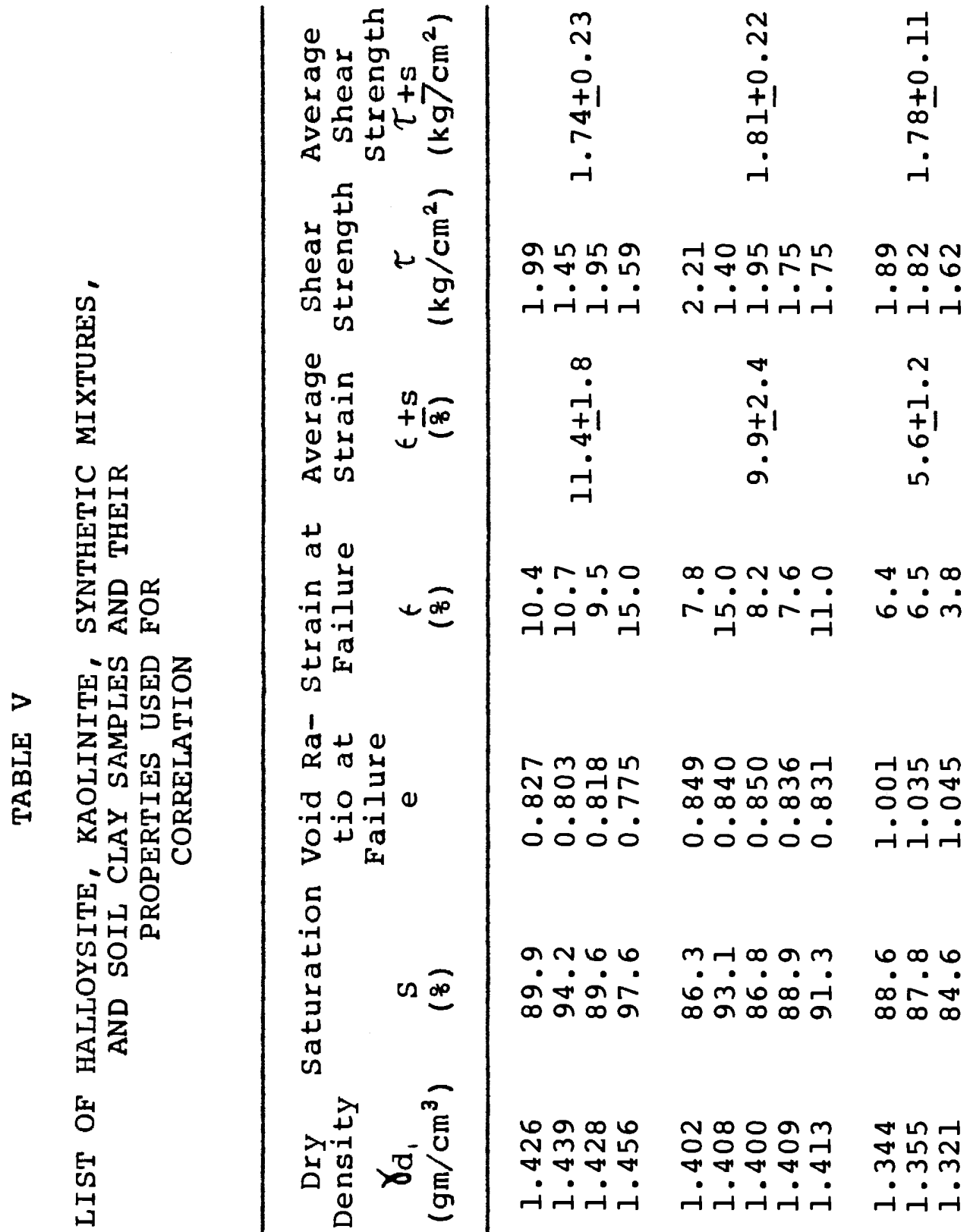

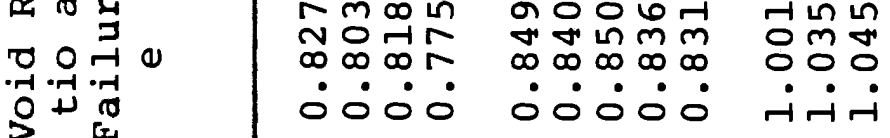

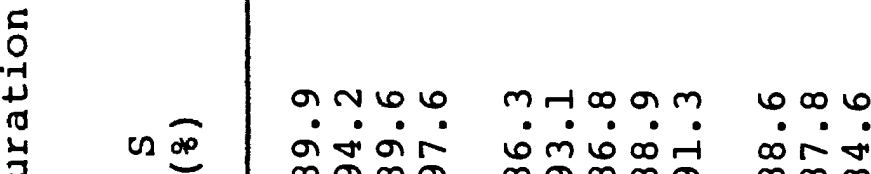

-

is

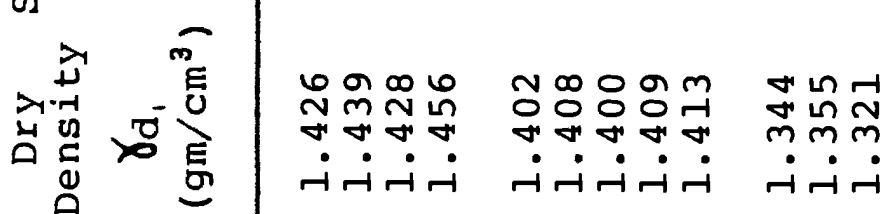

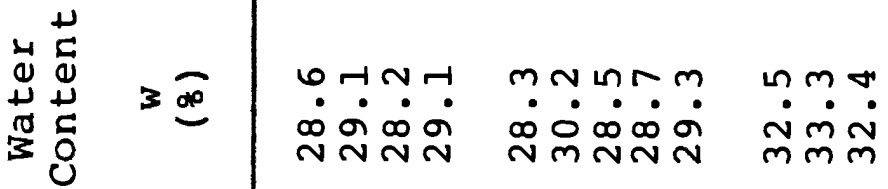

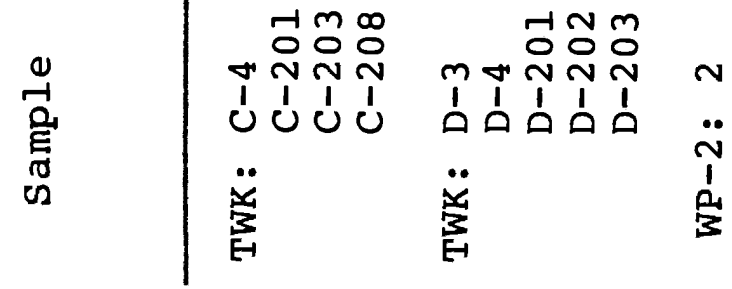




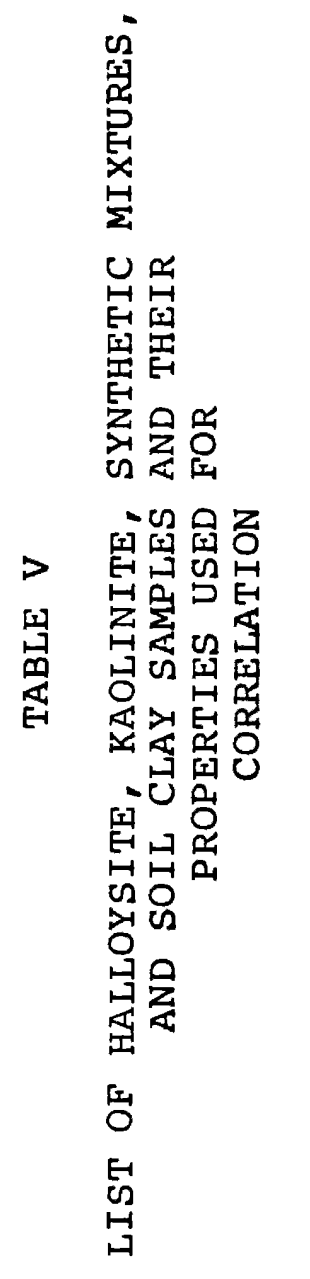

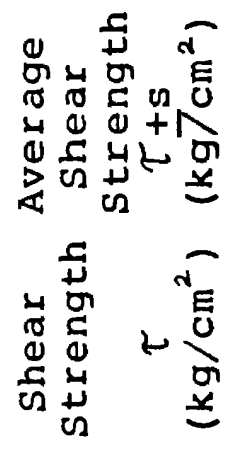

or

बั.

in $\pi+100$

0 म

ए त

$+\infty$

c

.

40

为

if II

$\frac{1}{0}+0$

क ه

○ 0 年 0

开

$8 \pi$

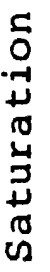

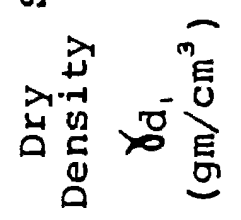

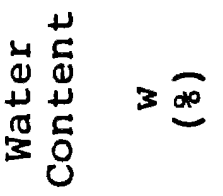

崩 $\begin{array}{ll}0 & N \\ 0 & 0 \\ 0 & 0 \\ +1 & +1 \\ \dot{1} & 0 \\ \dot{H} & +1\end{array}$

$\infty$ r



$\begin{array}{ll}0 & r \\ 0 & 0 \\ 0 & 0 \\ \dot{0} & 0\end{array}$

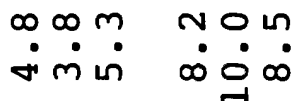

- $\infty \infty N+$

แก เก $6 N \mathrm{~N}$

नન

मिंम $\dot{0} 0$

m.

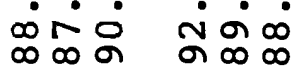

6 H

$m m m m \infty$

i- $\dot{1} \dot{i} \cdot$

मન मન

a $\infty$ แ

$\dot{\nabla} \dot{0} \dot{\infty} \dot{\infty}$

mmm NNN

カ่

NกN N

$\sum_{0}^{1}$ 
z

븐

C $\mathrm{E}$

[x है

e.

运资电

어될

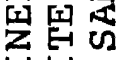

开

质 $>$

Z H

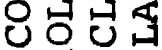

$\mapsto \quad$ Z

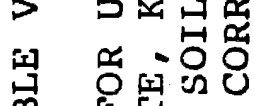

द्य है

Z出是

Оम

붕요

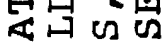

今日

四

$U$

되 타

员

U

Z

텁

U 0

U던

II

돈

A

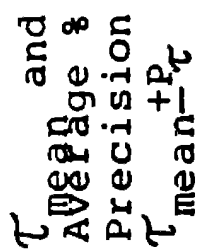

1)

$\vec{H}$

I

$\psi^{\stackrel{U}{E}}$

ब

ס क

हाँ है

ros 0 त

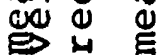

U匹

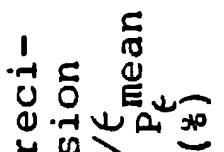

a 4

$\dot{u}$

ᄃ

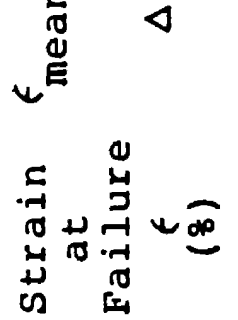

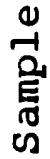

$a$
+1
$\infty$
$\infty$

$\underset{+1}{m}+\underset{n}{n}$

$m$
+1
$\infty$
$n$
$i$

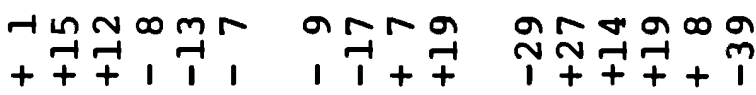

กลำ

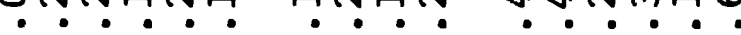

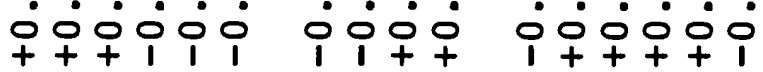

. m ᄂ

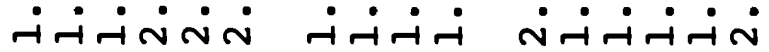

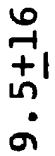

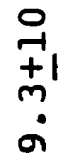

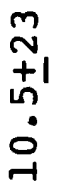

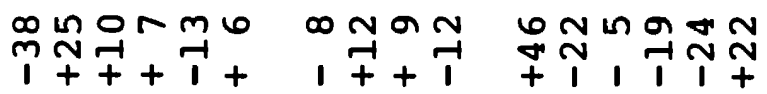
๑

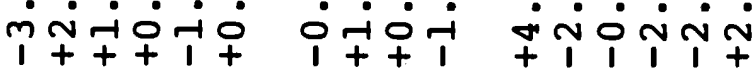

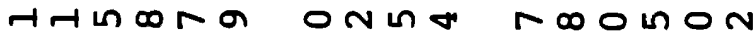

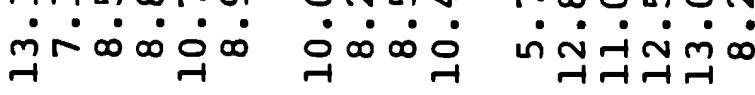

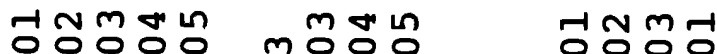
MNNNN $N N N N$ N $N$ N

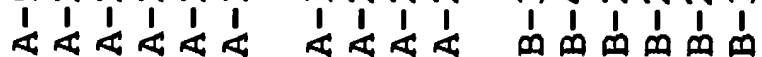
$\ddot{m}$

है 

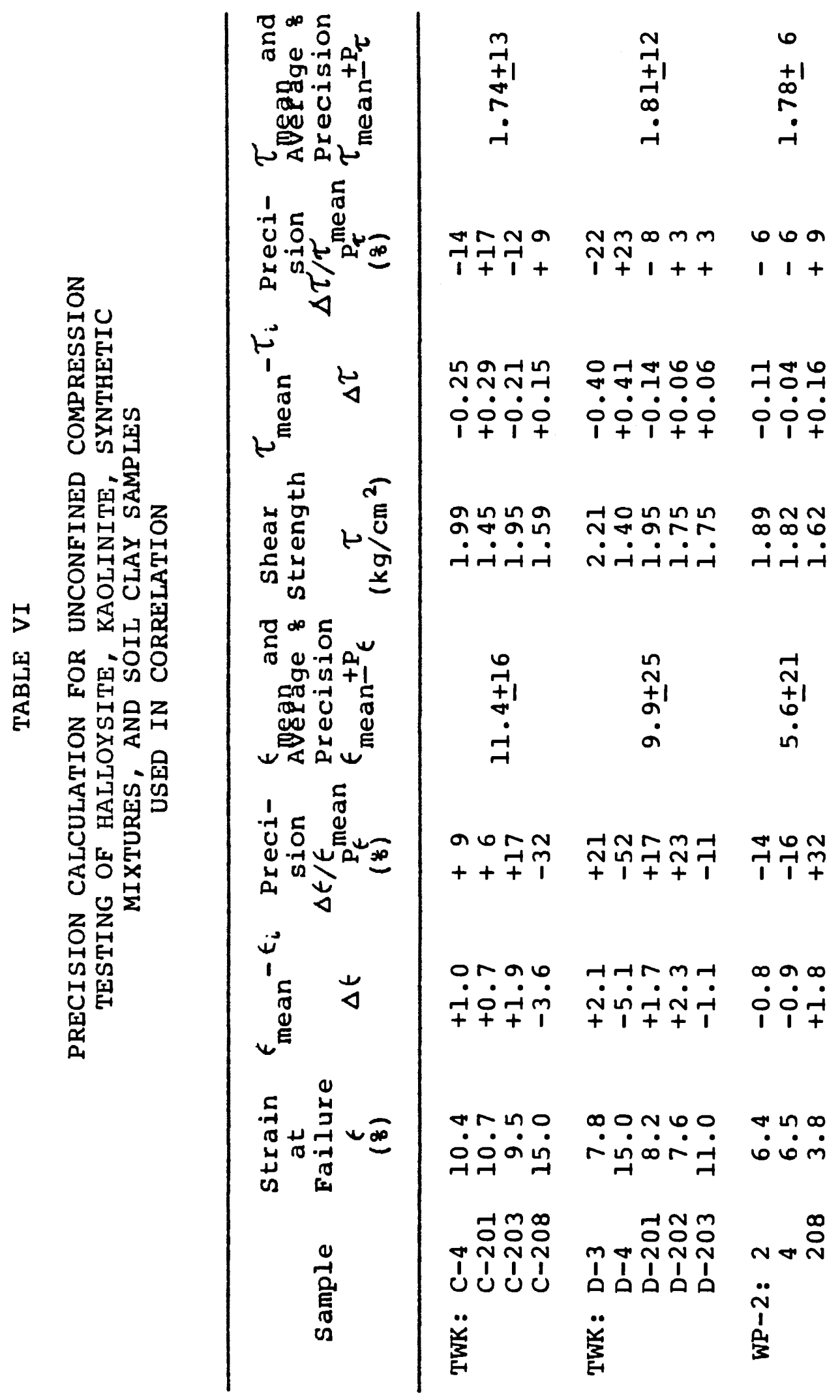

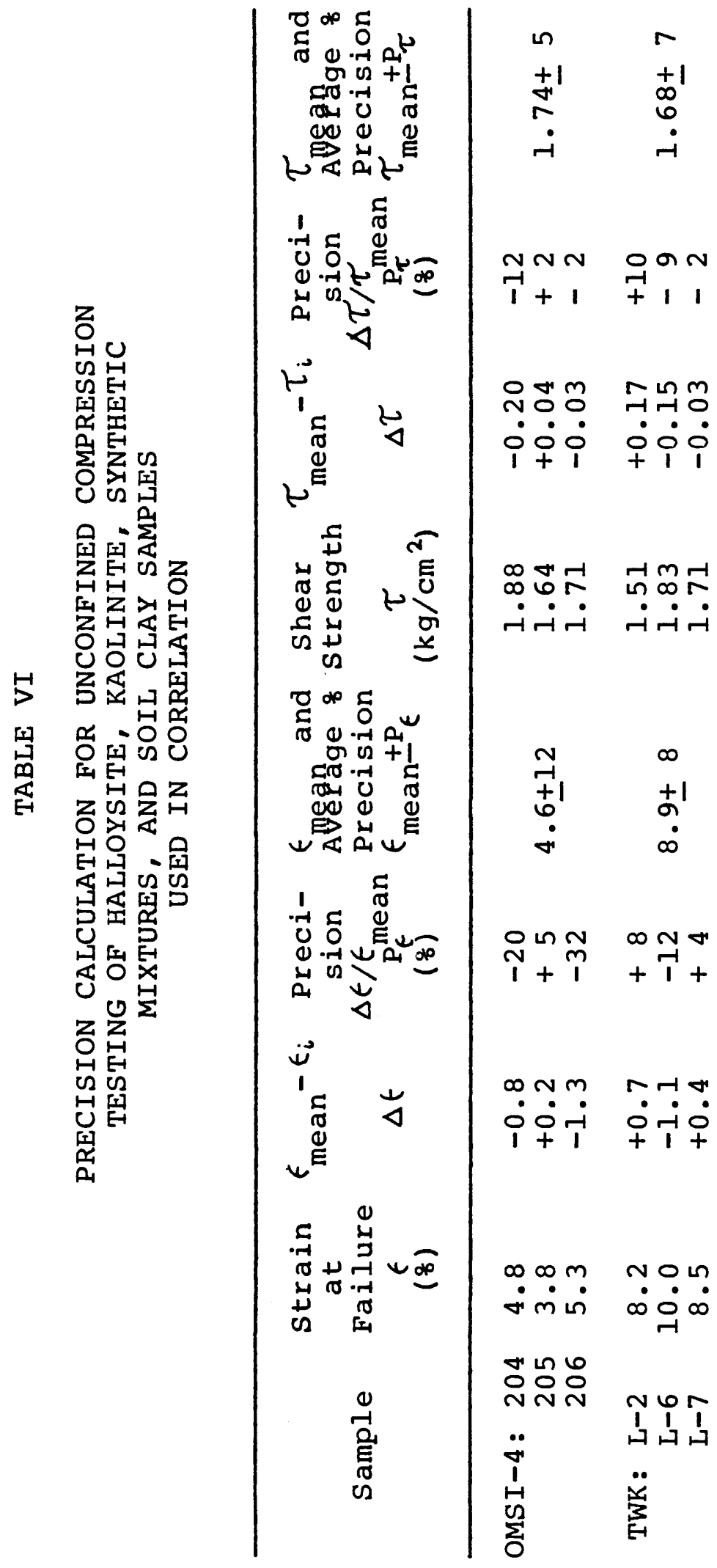


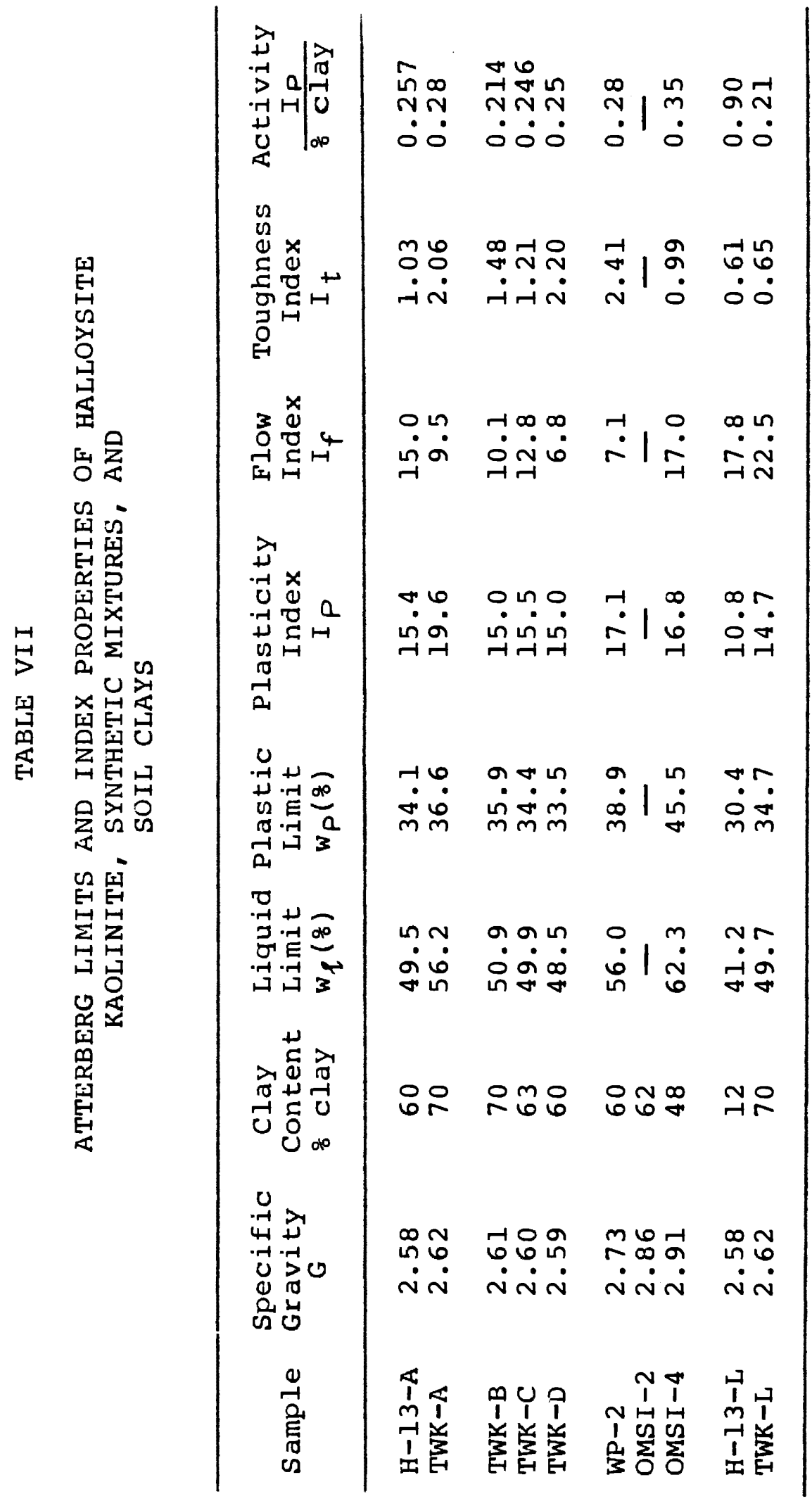




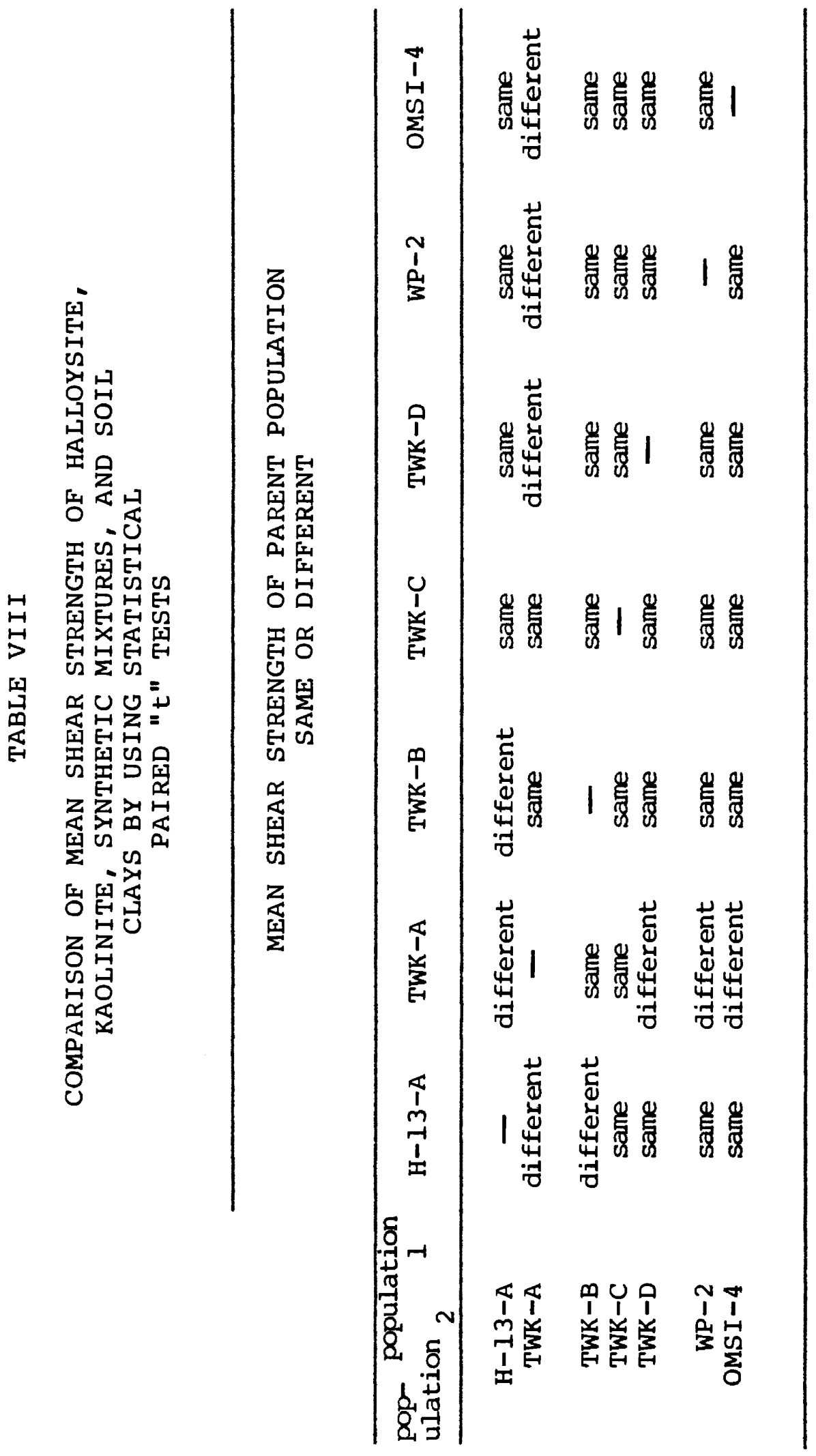


APPENDIX B

FIGURES 


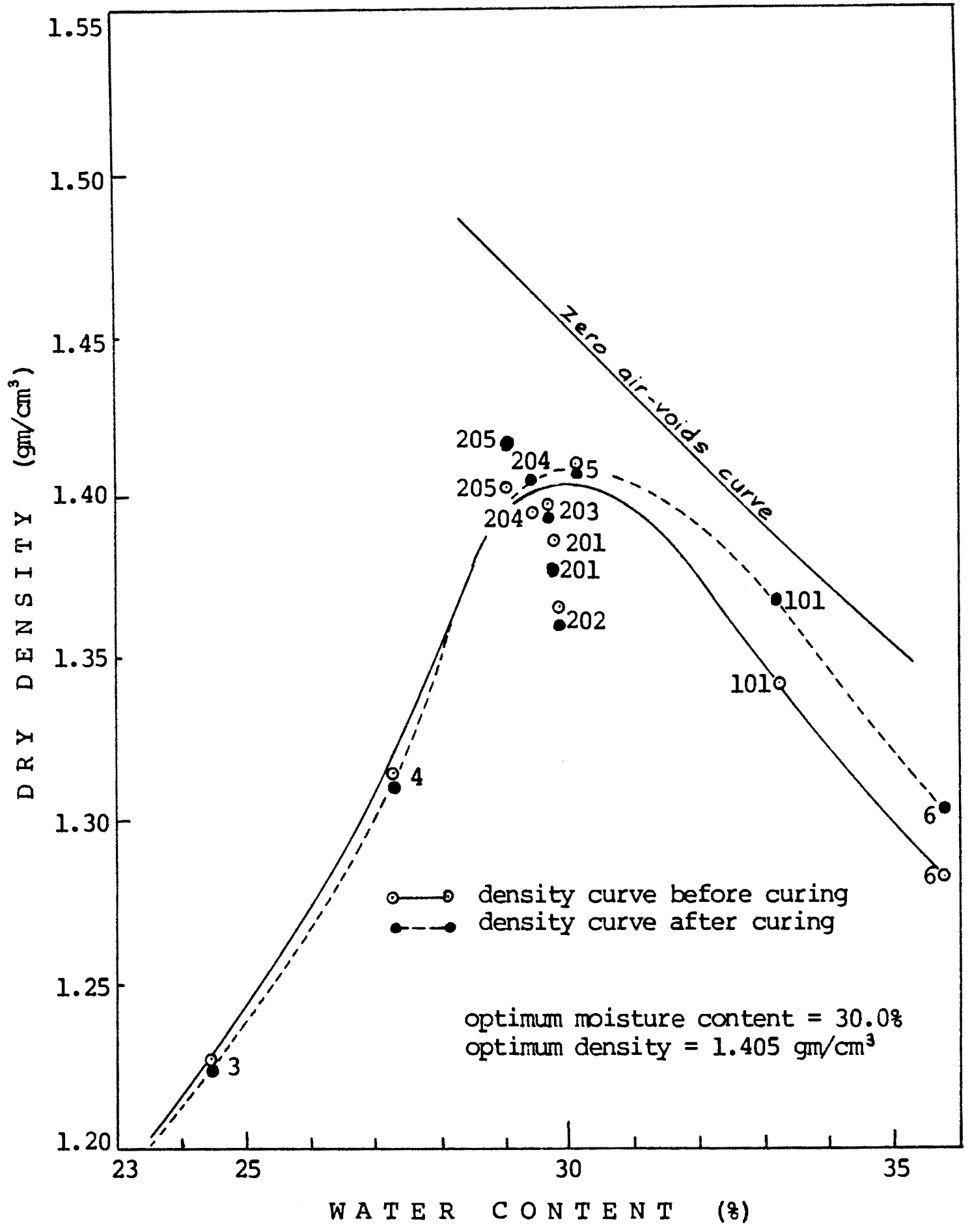

Figure 1A. Compaction curves of halloysite H-13-A. 


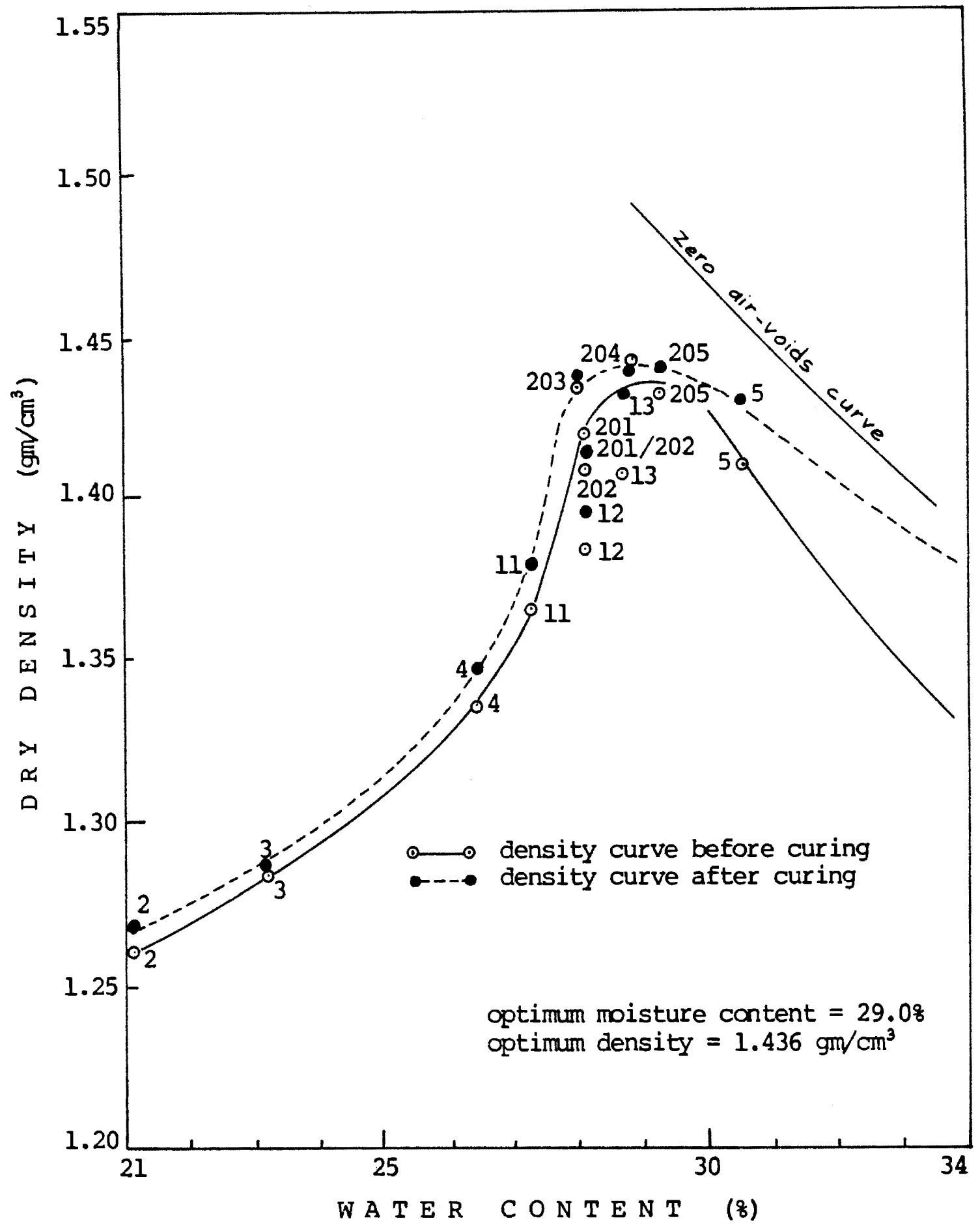

Figure 2A. Compaction curves of kaolinite TWK-A. 


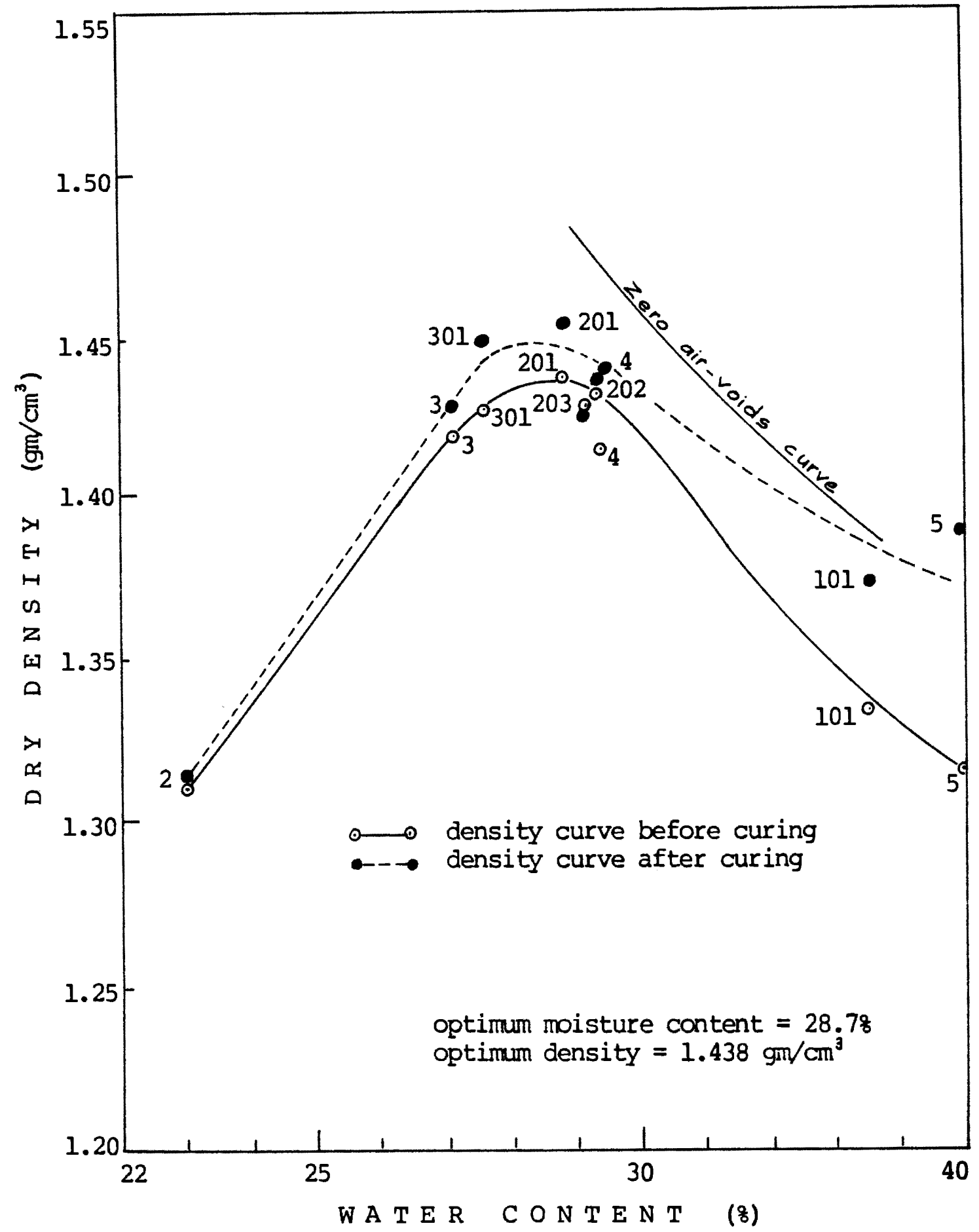

Figure 3A. Compaction curves of $3: 1(k: h)$ synthetic mixture TWK-B. 


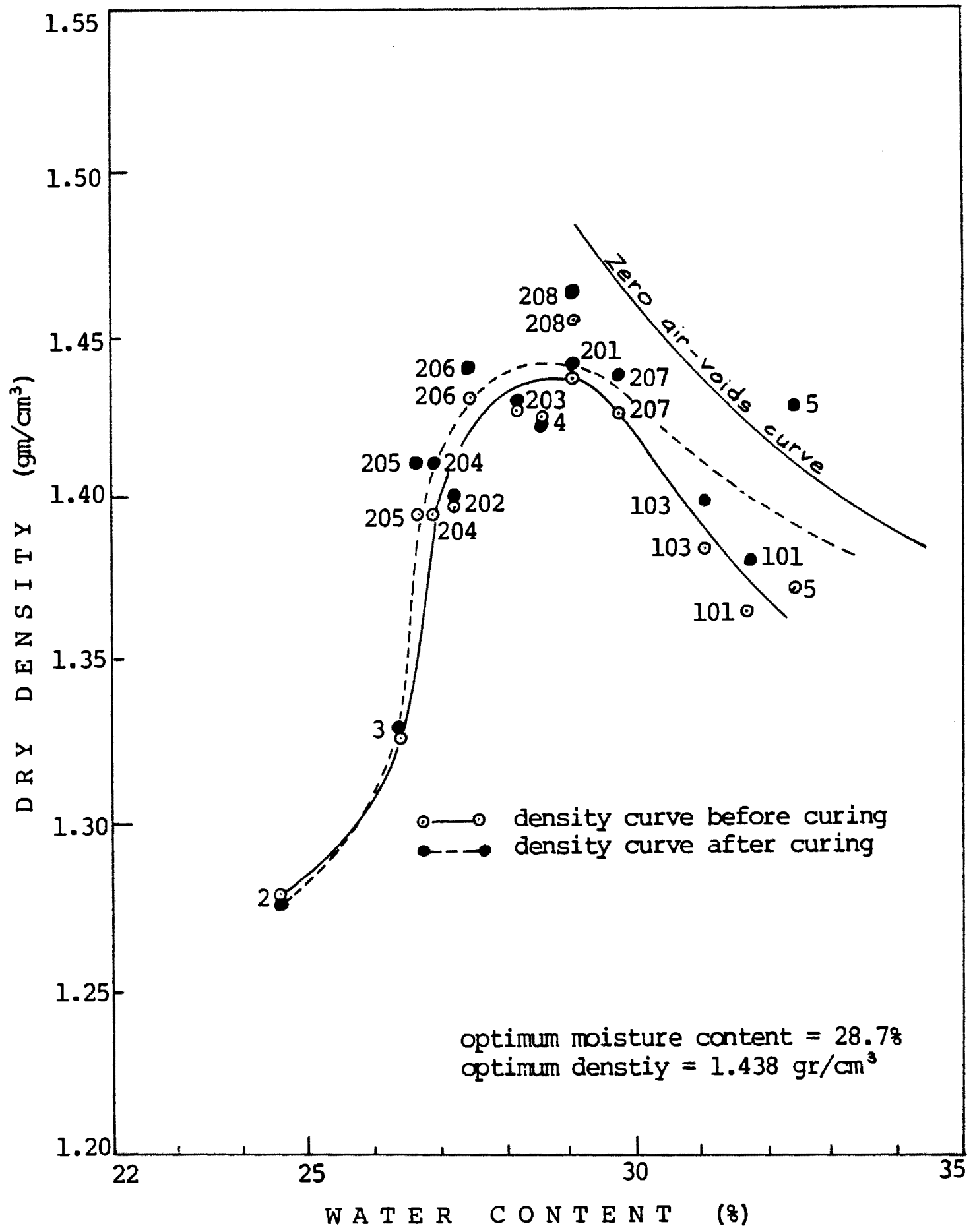

Figure 4A. Compaction curves of $1: 1$ (k:h) synthetic mixture TWK-C. 


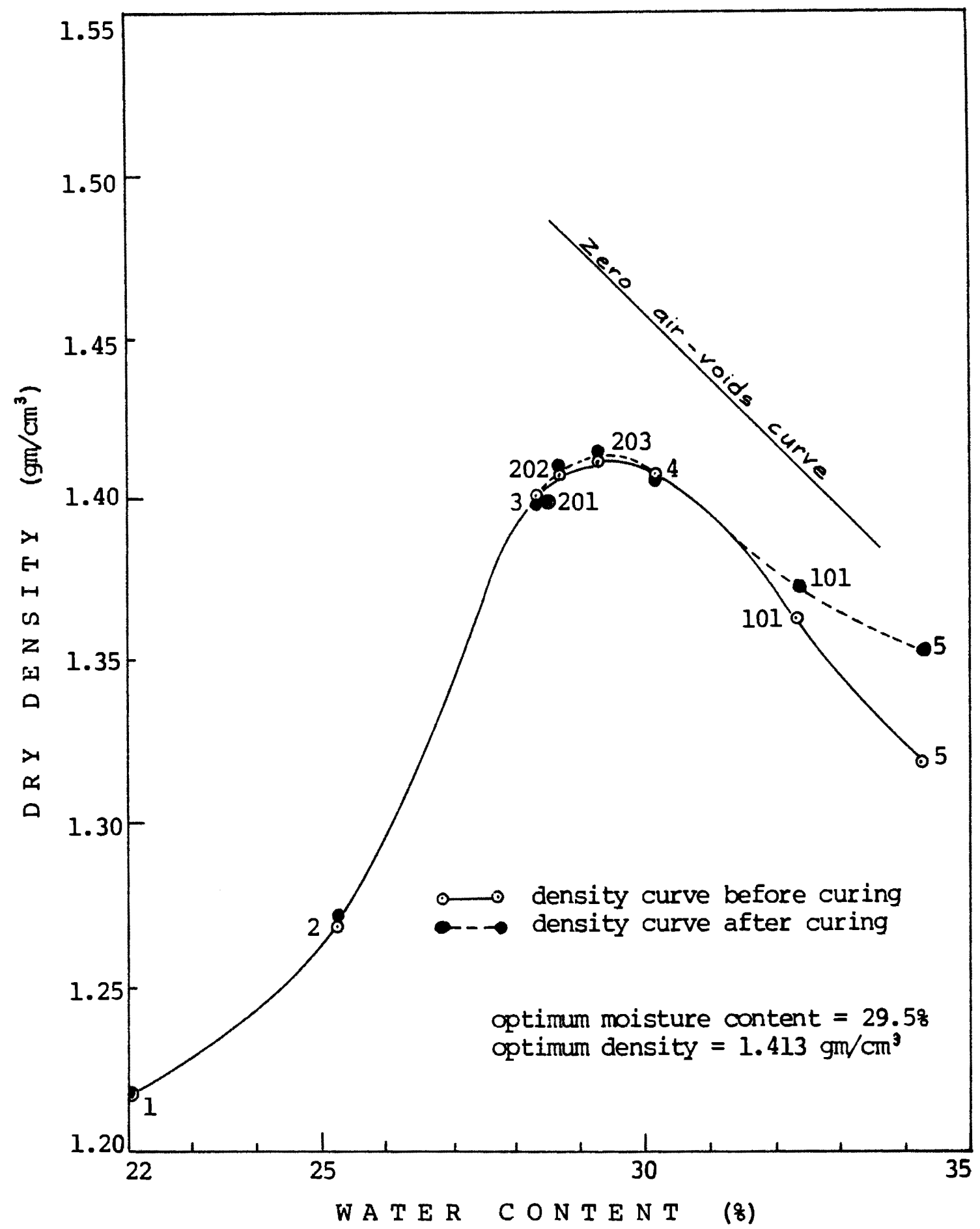

Figure 5A. Compaction curves of $1: 3(k: h)$ synthetic mixture TWK-D. 


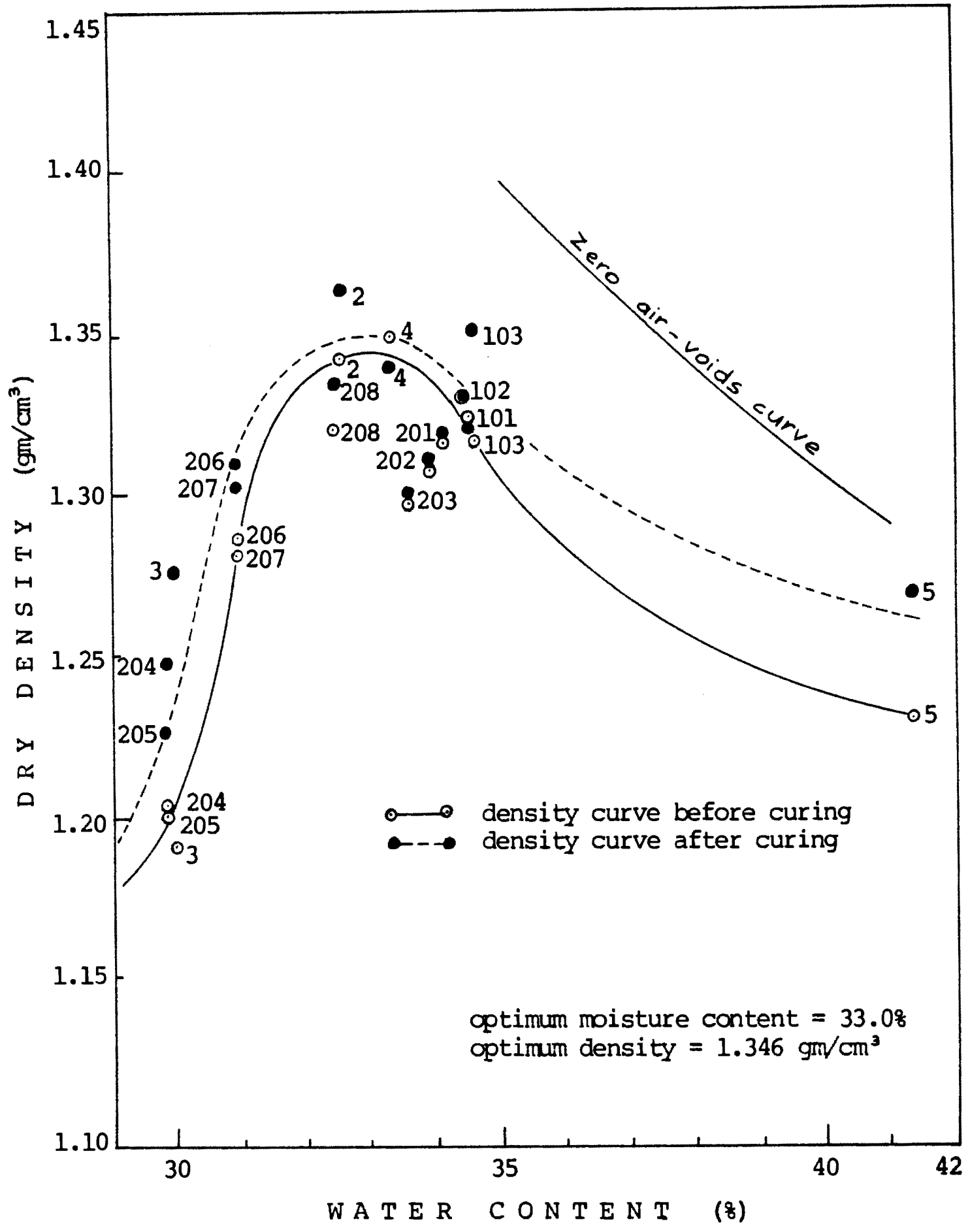

Figure 6A. Compaction curves of soil clay WP-2. 


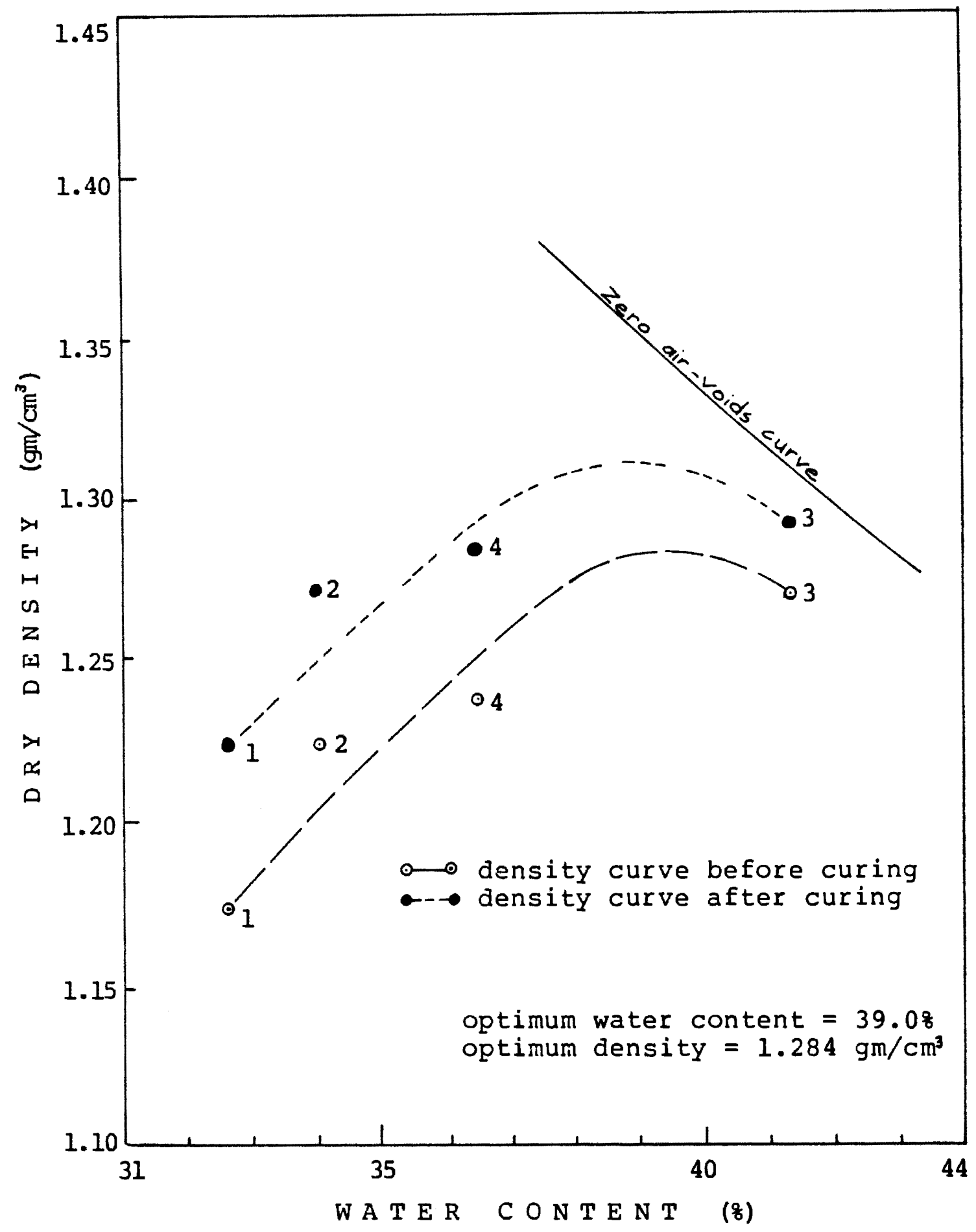

Figure 7A. Compaction curves of soil-clay OMSI-2. 


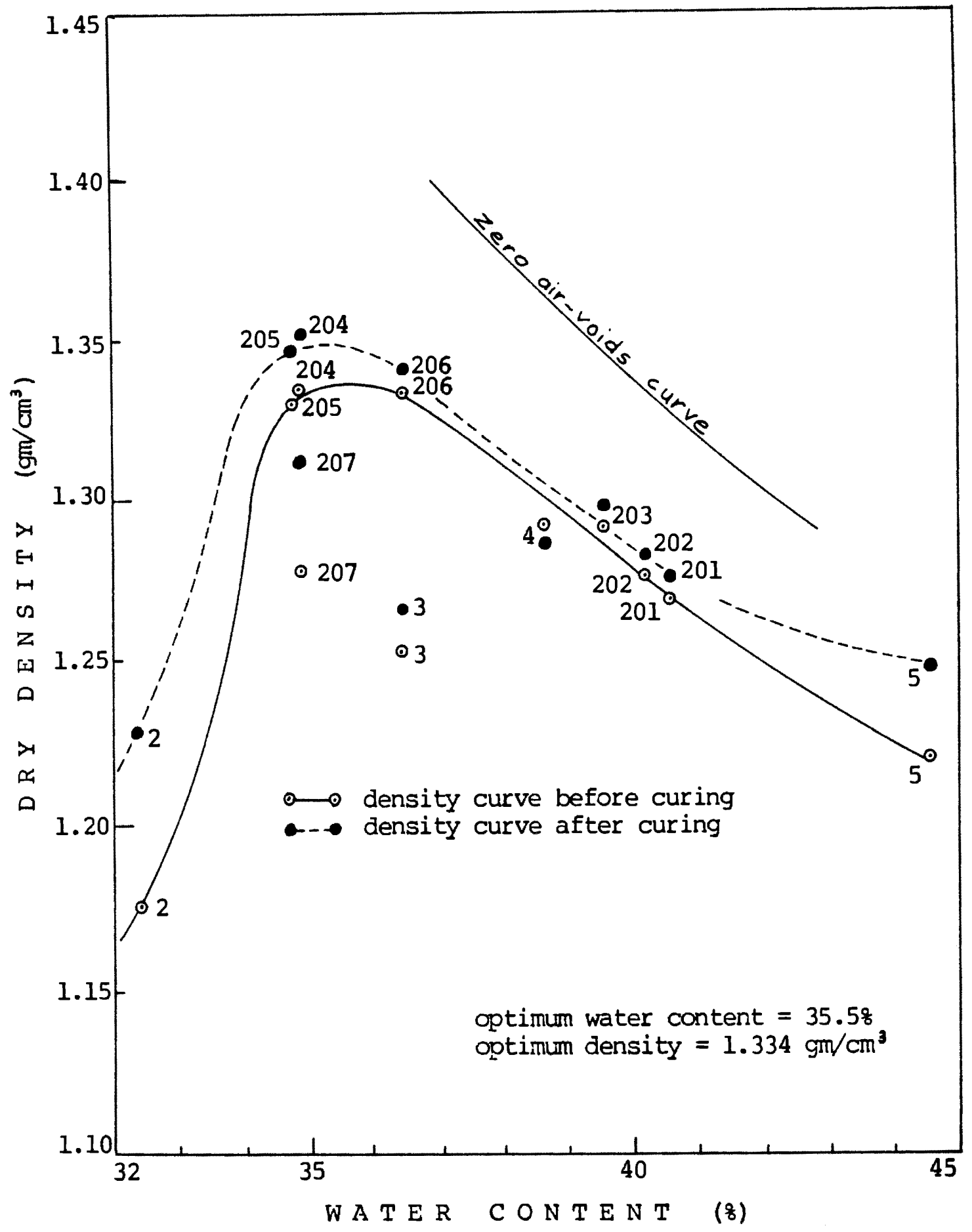

Figure 8A. Compaction curves of soil-clay OMSI-4. 


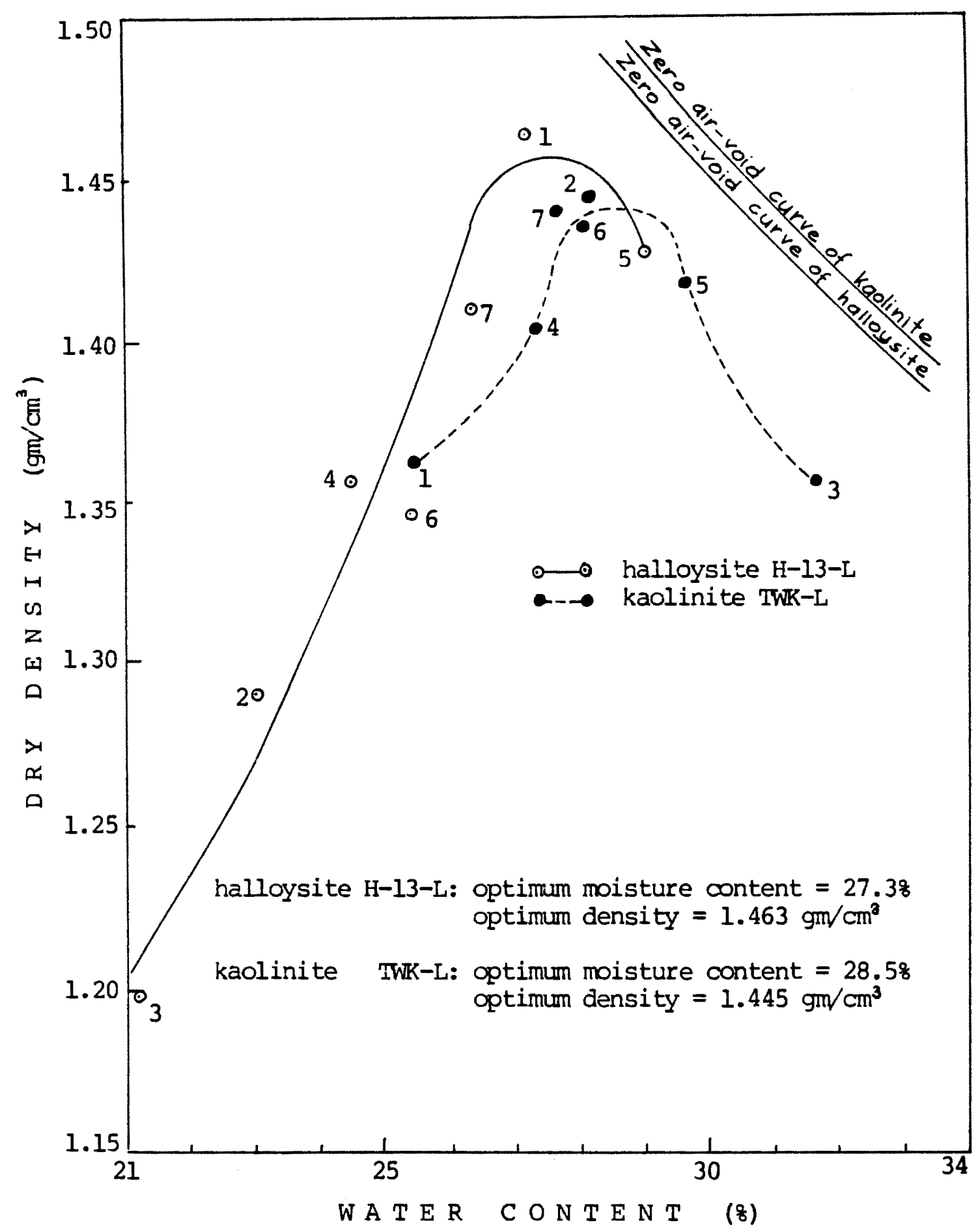

Figure 9A. Compaction curves of coarse grained halloysite and kaolinite. 


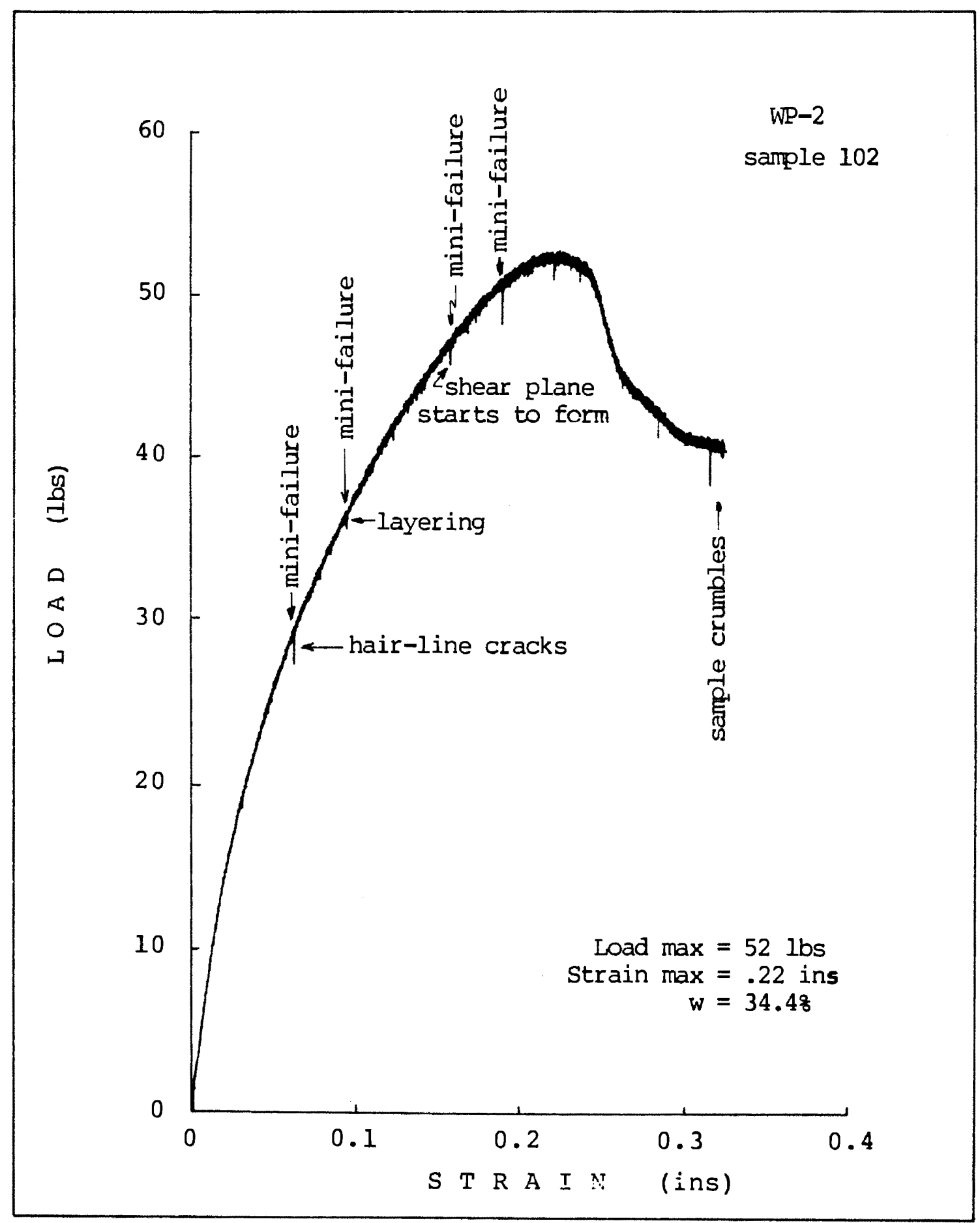

Figure 10A. Sample chart of load (lbs)-strain (ins) relationship using the 500 pound load cell during testing. 


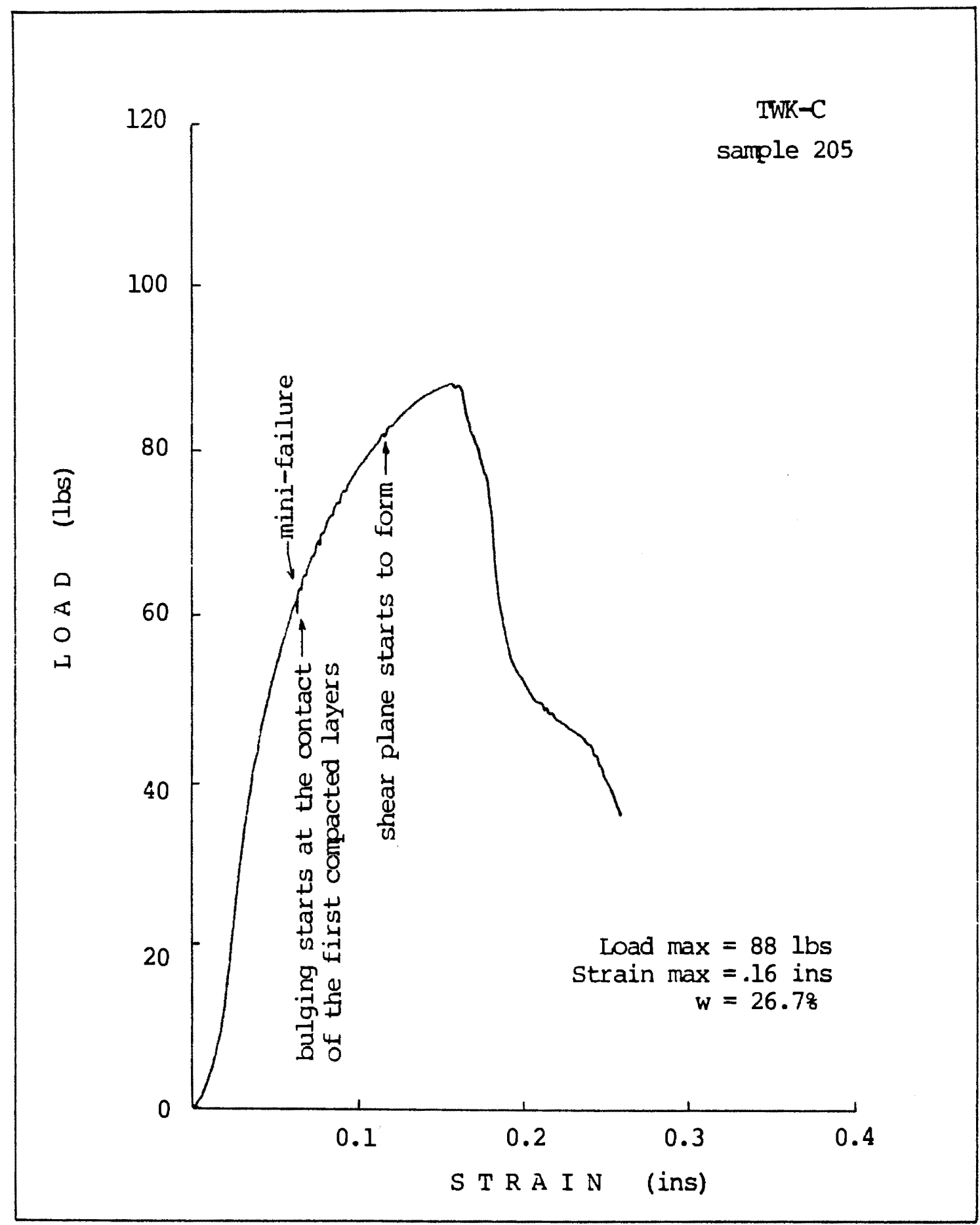

Figure 11A. Sample chart of load (lbs)-strain (ins) relationship using the 2000 pound load cell during testing. 


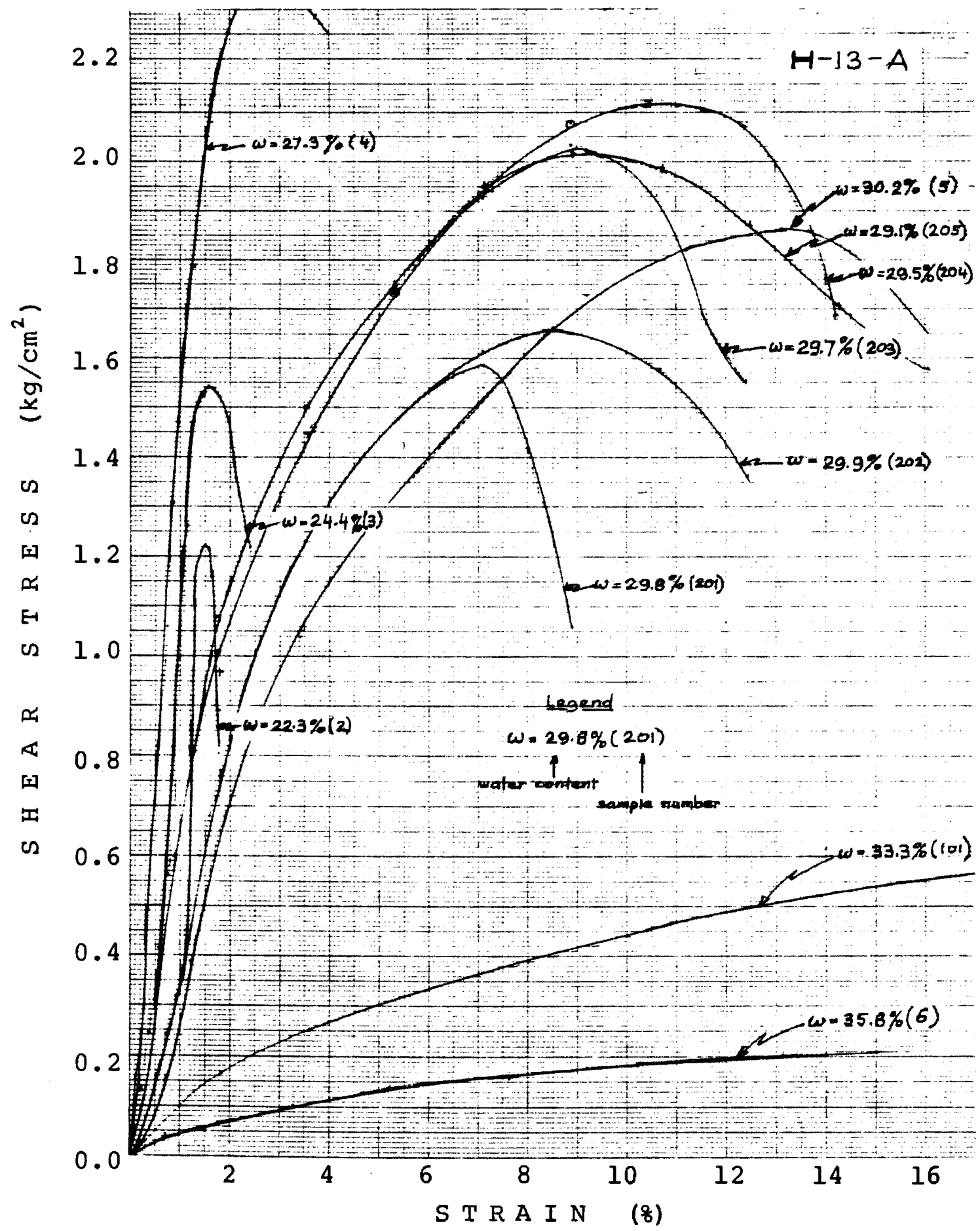

Figure 12A. Stress-strain relationship of halloysite H-13-A specimens. 


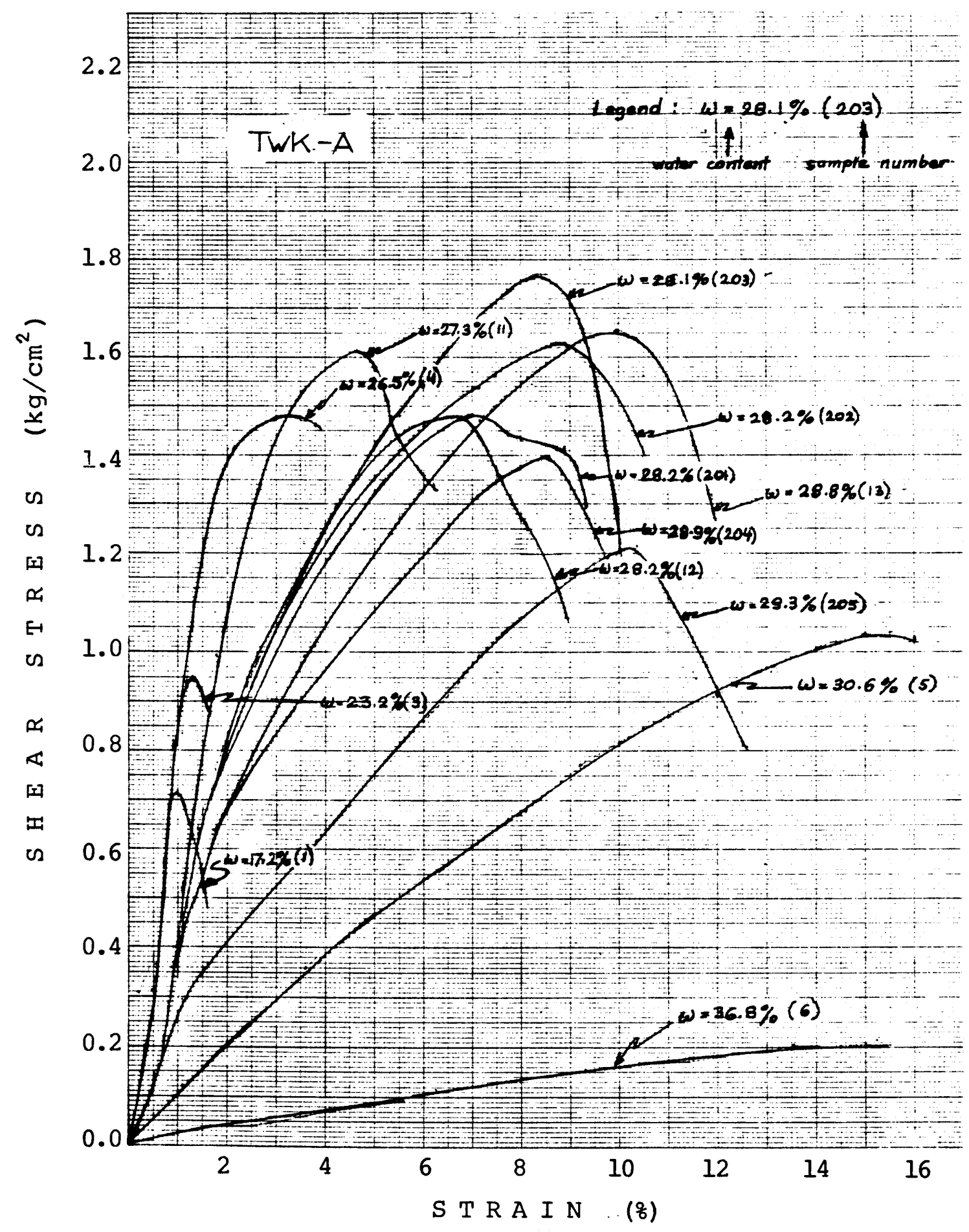

Figure 13A. Stress-strain relationship of kaolinite TWK-A specimens. 